enorden 



\section{Reforming environmentally harmful subsidies}

How to counteract distributional impacts

Annegrete Bruvoll, John Magne Skjelvik and Haakon Vennemo 
Reforming environmentally harmful subsidies

How to counteract distributional impacts

TemaNord 2011:551

ISBN 978-92-893-2253-9

(C) Nordic Council of Ministers, Copenhagen 2011

Print: Kailow Express ApS

Cover photo: ImageSelect

Copies: 170

Printed in Denmark

This publication has been published with financial support by the Nordic Council of Ministers. But the contents of this publication do not necessarily reflect the views, policies or recommendations of the Nordic Council of Ministers.

\section{www.norden.org/en/publications}

\section{Nordic co-operation}

Nordic co-operation is one of the world's most extensive forms of regional collaboration, involving Denmark, Finland, Iceland, Norway, Sweden, and Faroe Islands, Greenland, and Åland.

Nordic co-operation has firm traditions in politics, the economy, and culture. It plays an important role in European and international collaboration, and aims at creating a strong Nordic community in a strong Europe.

Nordic co-operation seeks to safeguard Nordic and regional interests and principles in the global community. Common Nordic values help the region solidify its position as one of the world's most innovative and competitive.

\section{Nordic Council of Ministers}

Ved Stranden 18

DK-1061 Copenhagen K

Phone (+45) 33960200 


\section{Content}

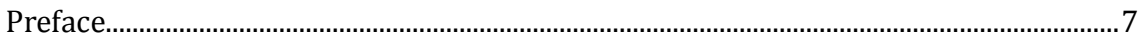

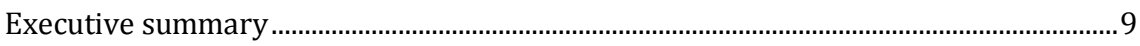

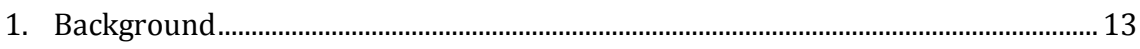

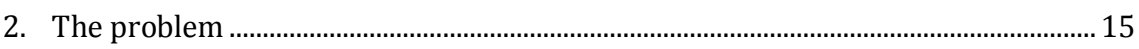

2.1 Examples of environmentally harmful subsidies............................................ 15

2.2 Possible benefits from removing environmentally harmful

subsidies ................................................................................................... 17

3. The Nordic countries....................................................................................... 21

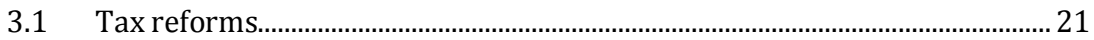

3.2 Remaining subsidies...................................................................................... 22

4. Definition of environmentally harmful subsidies...................................................... 25

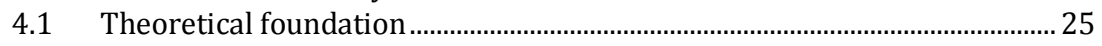

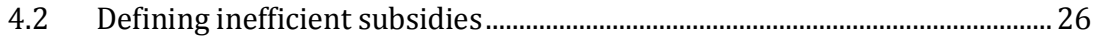

4.3 Partial market effects of environmentally harmful subsidies....................... 28

5. The accounting of environmentally harmful subsidies............................................. 31

5.1 Subsidies in general ............................................................................................ 31

5.2 Recommendations for accounting of environmentally harmful

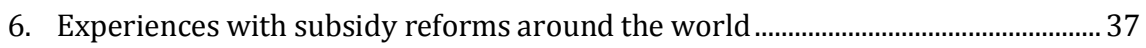

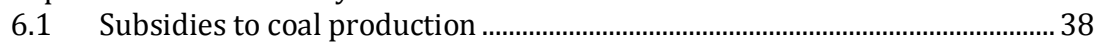

6.2 Nuclear power subsidies.................................................................................. 41

6.3 Exemptions from environmental taxes ........................................................ 41

6.4 Biofuel subsidies .................................................................................................. 42

6.5 Subsidies to fossil energy consumption in some low-income

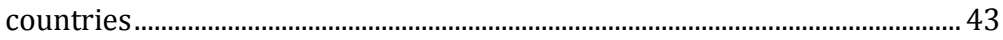

6.6 Subsidies to energy consumption in some high-income countries............... 46

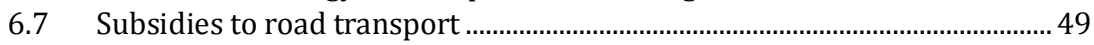

6.8 Aviation subsidies ....................................................................................... 51

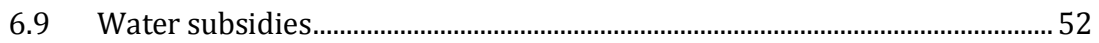

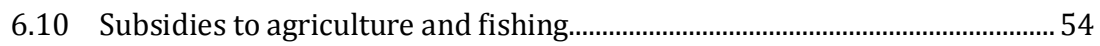

6.11 Summary: Lessons learned .................................................................... 57

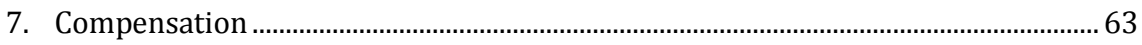

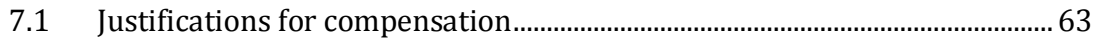

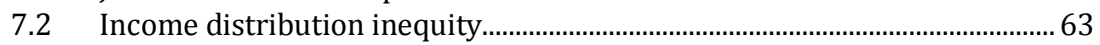

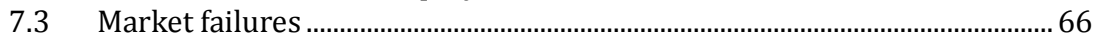

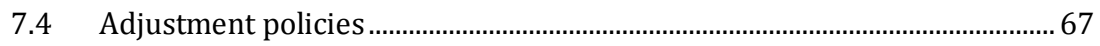

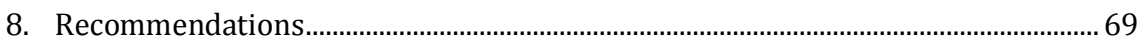

8.1 Identify the environmentally harmful subsidies.......................................... 70

8.2 Estimate the environmental and economic costs ............................................ 70

8.3 Evaluate the need for compensation .............................................................. 71

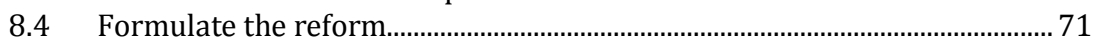

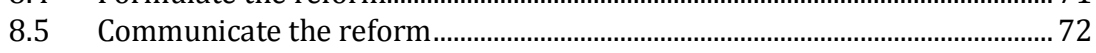

8.6 Correct for negative side effects............................................................ 74

8.7 Avoid new types of inefficient subsidies............................................................. 74

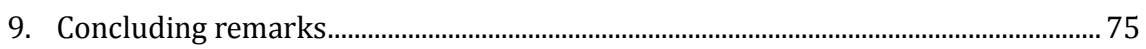

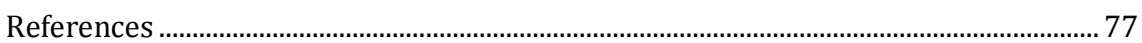


10. Appendix...

10.1 Appendix 1 - Theoretical foundation to taxes and subsidies....................... 81

10.2 Appendix 2 - Attempts to remove environmentally harmful subsidies ......... 90

10.3 Appendix 3 - Planned reforms ...................................................................119 


\section{Preface}

Removing and reforming environmentally harmful subsidies has been an important focus for discussion, and some action, for a number of years. In the present situation, with strong pressures for fiscal consolidation at the same time as climate and other environmental challenges remain high on the international agenda, the urgency for acting on this issue has increased greatly. Social considerations, concern over distributional effects of subsidy removal, are often raised as arguments against such action, and have been and remain a major obstacle to such reform in many countries, both developed and developing. Both the G20 commitment to reform of fossil-fuel subsidies, long-standing work on environmentally harmful subsidies by the Organisation for Economic Co-operation and Development (OECD), and work on such subsidies in the European Union (EU) demonstrate the high policy relevance of this issue.

The Nordic countries are known for using a strong component of economic, market-based instruments in their environmental policy mix, as well as for having a relatively egalitarian income distribution. How to combine such goals and policies is an important concern in all our countries, and distributional effects of both subsidy removal and of other economic instruments such as green taxes, have been much analysed and discussed. This report by Vista Analyse AS has been commissioned by the Nordic Council of Ministers to give an overview on environmental harmful subsidies, subsidy reforms and how to counteract distributional impacts.

The analysis has been carried out during the period October 2010May 2011. Main sources for the work have been the large number of reports from the environmentally harmful subsidy reform initiatives made by the G20 countries, the Global Subsidies Initiative, the EU and the OECD. Authors have been Annegrete Bruvoll, John Magne Skjelvik and Haakon Vennemo. 
The report discusses the theoretical principles for an efficient environmental and distribution policy and offers a comprehensive survey of experiences from policy reforms in different countries. The reform survey forms a background to recommendations for implementation of sustainable policy reforms, taking care of environmental, economic and distributional concerns. Experience from the Nordic countries is discussed, both to throw light on the problems with environmentally harmful subsidies in these countries, and to discuss what can be learned from this experience in a broader international context. Numerous examples from a wide range of developed and develop 7 ing countries extend the discussion. We foresee that this report gives useful Nordic input to other countries and other international fora to remove and reform environmentally harmful subsidies.

Copenhagen, July 2011

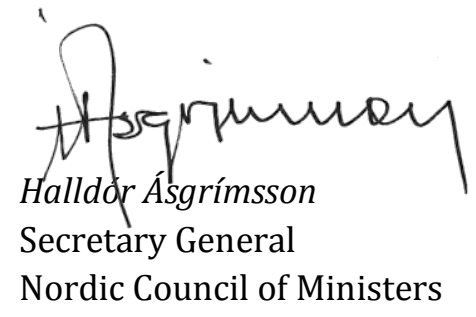




\section{Executive summary}

Environmentally harmful subsidies contribute to significant environmental costs and pose a heavy burden on public budgets around the world. According to IEA (2010), the phase-out of fossil fuel consumption subsidies would reduce global energy-related carbon emissions by about $6 \%$. The burden on public budgets is particularly high in developing countries. The total order of magnitude of fossil fuel subsidies is roughly estimated to almost 1\% of world GDP (IEA et al. 2010a).

Normally, subsidies are thought of as direct support over public budgets. But indirect support and polluters not paying the external emission costs are just other forms of environmentally harmful subsidies. Lack of environmental taxes, selective exemptions from governmental standards, preferential market access and price support represent different types of off-budget subsidies with principally the same effects as direct subsidies. Hence reducing the extent of environmentally harmful subsidies involves more than only removing the on-budget subsidies. Indirect subsidies and tax exemption should also be removed, and polluting activities should be fully taxed according to their external costs.

This report discusses the theoretical principles for an efficient environmental and redistribution policy, and offers a survey of experiences from policy reforms over a range of countries. The reform survey forms a background for recommendations of sustainable policy reforms, taking care of environmental, economic and distributional concerns. We particularly bring in the Nordic experiences, both to discuss the problems with environmentally harmful subsidies in these countries, and to discuss what can be learned from the experiences in a broader international context.

The review of environmentally harmful subsidies shows different experiences with respect to why subsidies are used and why attempts are made to remove them. The motives for using environmentally harmful subsidies differ between developing/emerging economies and high income economies like the Nordic countries. The most common justification for subsidies to energy consumption is to support low income groups. According to estimates, low income countries face the highest economic burdens from such subsidies. Estimates show subsidies reaching up to 15\% of GDP in some developing countries (Ellis 2010).

Developed countries face higher environmental awareness and higher willingness and economic possibility to prioritize the environment. The Nordic countries are among the richest in the world, and typical characteristics are strong public sectors. The "welfare state" secures minimum income and social service levels, while the counterpart is relatively high rates of taxation compared to other countries. High environ- 
mental standards and nature preservation seem to be a relatively stronger norm in these countries compared to developing/emerging countries and more densely populated areas around the world. Environmentally harmful emissions are usually subject to taxes or regulations, and subsidies of energy consumption are not widely used. Consequently, the Nordic countries have experienced significant reductions in most of the polluting emissions with local and regional environmental effects over the last decades. Though environmentally harmful subsidies seem to be more common in the form of support to industries, employment and regional development, the total environmental impact is probably relatively lower compared to most other countries.

The core of the problem related to environmentally harmful subsidies is that the support benefits significant groups. Removing the subsidies normally provokes opposition from pressure groups and political parties. To raise the necessary political support, it is important to produce high quality, reliable information about the benefits and costs, in order to communicate the net benefits to the society. Adversely, it has been shown that lack of transparent information has been a decisive obstacle to reforms. Predictability and broad political support increase the possibility of implementing sound reforms.

The subsidies must be defined along principal, theoretical lines. Given that the purpose of identifying environmentally harmful subsidies is to advise on policy change, subsidies correctly levied to adjust for market failure or in order to correct distributional impacts should not be included in the definition of a harmful subsidy, despite their possible environmental effects. On the other hand, tax exemptions and several non-budgetary support mechanisms should also be included in addition to the direct, budgetary environmentally harmful subsidies.

The environmental and economic costs and benefits should be evaluated to form a basis for which reforms to prioritize. The original purpose of the subsidies must be identified in order to evaluate whether compensatory measures are required to uphold the political goals.

Compensatory measures have proven to be of crucial importance in successful reforms of harmful subsidies around the world. Reducing harmful subsidies improves the public budgets and releases funding for direct compensation packages. To avoid new, inefficient subsidies, it is important to levy the compensation as close to the prioritized groups as possible.

There is a range of instruments and examples of compensation packages used to alleviate the impacts of removing subsidies, targeting the political goals more efficiently than subsidies to environmentally harmful activities. The Bolsa Familia program in Brazil, the Oportunidades program in Mexico, cash transfer programs in Indonesia and Ghana are all successful examples of comprehensive social protection packages efficiently targeting low income groups in combination with removal of environmentally harmful subsidies. Diversified income taxation is a 
textbook example of how to prioritise low income groups in high and low income countries. If regional compensation is justified, lump sum support could be given to general activities in the actual regions, for example as general support to the local municipalities or as investment in infrastructure.

It is also important to stress the need for avoiding new environmentally harmful subsidies. New subsidies should only be used to correct market failures and as direct support to politically prioritized groups out of distributional concerns. Subsidies implemented to alleviate the transition of the economy over a temporary time period after removing environmentally harmful subsidies should have a definite time frame. Particularly, it is important to look into new subsidies allegedly meant to target greenhouse gas emissions, if the subsidies stimulate other, environmentally harmful energy sources. Instead, emissions should be subject to direct taxes. 



\section{Background}

Subsidies are justified in theory to promote overall increase in social welfare. Typically, subsidies are used to adjust for market failures and income distribution. In practical policy around the world, the use of subsidies does not follow economic theory. Many subsidies are inefficiently targeted at environmentally harmful activities rather than at the particular income groups needing support, and in some cases the effects counter the intention of subsidies. Typical examples are the subsidization of environmentally damaging energy production and consumption. Fuel subsidies are frequently used to support low income groups, and subsidies to coal extraction are given to support competitiveness in industries and employment. Exemptions from environmental taxes for industries out of competitiveness concerns are also common.

While the optimal policy would be to tax the environmental damages, subsidies to polluting activities contribute to increase rather than abate the emissions. The practise is particularly common in low-income countries. This contributes to preserve old, energy intensive technologies and to slow down the transition to a less carbon intensive global economy. The economic support would be more effective if given directly to the targeted income groups. In addition to damaging the environment, the subsidies load public budgets and disturb relative competitiveness.

An important part of sustainable policy is to remove or adjust environmentally harmful subsidies. Many subsidy reforms have been carried through over time, and many are planned. The general picture is that still significant maladjustments remain, and that countries aiming for reform meet strong opposition from losing parties. According to IEA et al. (2010a), the total order of magnitude of fossil fuel subsidies is roughly estimated to $1 \%$ of world GDP. Removing these subsidies is estimated to reduce energy-related carbon emissions by about 6\% (IEA 2010).

Over the last decade, several parallel initiatives have been taken to increase awareness about the costs related to environmentally harmful subsidies, and to form policies for reforms. The initiatives cover overlapping groups of countries.

The OECD has conducted several reviews of harmful policies and potential policy reforms (see e.g. OECD 1998, 2005, 2006a, 2007, 2010; Mourougane 2010; Ekins and Salmons 2009).

In 2009, G20 leaders committed to rationalize and phase out over the medium term inefficient fossil fuel subsidies that encourage wasteful consumption. This initiative was followed up by the Asia-Pacific Economic Cooperation (APEC) leaders in 2009. These commitments were made in recognition that inefficient fossil-fuel subsidies distort markets, impede 
investment in clean energy sources and undermine efforts to deal with climate change. On request of the G20, the IEA, OECD, World Bank and OPEC produced joint reports on the scope of energy subsidies and suggestions for the implementation of their phase-out (IEA, OECD, The World Bank 2010; IEA, OPEC, OECD, The World Bank 2010; G20 2010).

The studies performed by IEEP (IEEP et al. 2007; Valsecchi et al. 2009 ) in the project Environmentally harmful subsidies: Identification and assessment are developed for the European Commission.

The IISD's Global Subsidies Initiative (GSI) core funders include the governments of Denmark, the Netherlands, New Zealand, Norway, United Kingdom and Sweden. This initiative was launched in 2005 to put a spotlight on subsidies and how they undermine efforts to put the world economy on a path toward sustainable development. The GSI's current period runs through 2011 and focuses on fossil fuels subsidies (Victor 2009; Braithwaite et al. 2010; Ellis 2010; Jones and Steenblik 2010; Koplow et al. 2010; Laan 2010; Laan et al 2010; Lang et al. 2010; Sawyer and Stiebert 2010). 


\section{The problem}

\subsection{Examples of environmentally harmful subsidies}

As we will get back to in chapter 4 and 5 , the extent of total environmentally harmful subsidies are difficult to estimate, both due to definition and statistical problems. Different estimates may include different subsidy bases. The estimates in this chapter are not necessarily in line with the theoretical definition in chapter 4.2, and they do not aim to cover the total sources of environmentally harmful subsidies. Rather, they indicate the size of such subsidies around the world covered by existing studies and as defined by the refereed sources. The methods for the calculations are under evaluation (cf. chapter 5). In particular, taking exemptions from or lack of externality pricing of e.g. coal into account could significantly increase the estimates.

The main picture from subsidies included in these studies is that:

- Environmentally harmful subsidies are most prevalent in developing countries

- Consumer subsidies are more common than producer subsidies

Most of the estimates cover the extent of subsidies to fossil fuels. The estimates by IEA et al. (2010a) and Lang et al. (2010) are based on the price-gap approach ${ }^{1}$, hence not including the lack of externality pricing (cf. chapter 4.2). According to these sources, worldwide fossil fuel consumption subsidies amounted to $\$ 312$ billion in 2009 , see figure 2.1 , the cast majority of them in non-OECD countries. Less work has been done to quantify the producer subsidies. According to IEA et al. (2010a), they add by at least another $\$ 100$ billion. Together, these subsidies add to $0.7 \%$ of world GDP ( $\$ 58,000$ billion in 2009; The World Bank). ${ }^{2}$

\footnotetext{
${ }^{1}$ This compares final consumer price with reference prices, which correspond to the full cost of supply, or the international market price adjusted for the costs of transportation and distribution.

${ }^{2}$ http://siteresources.worldbank.org/DATASTATISTICS/Resources/GDP.pdf
} 


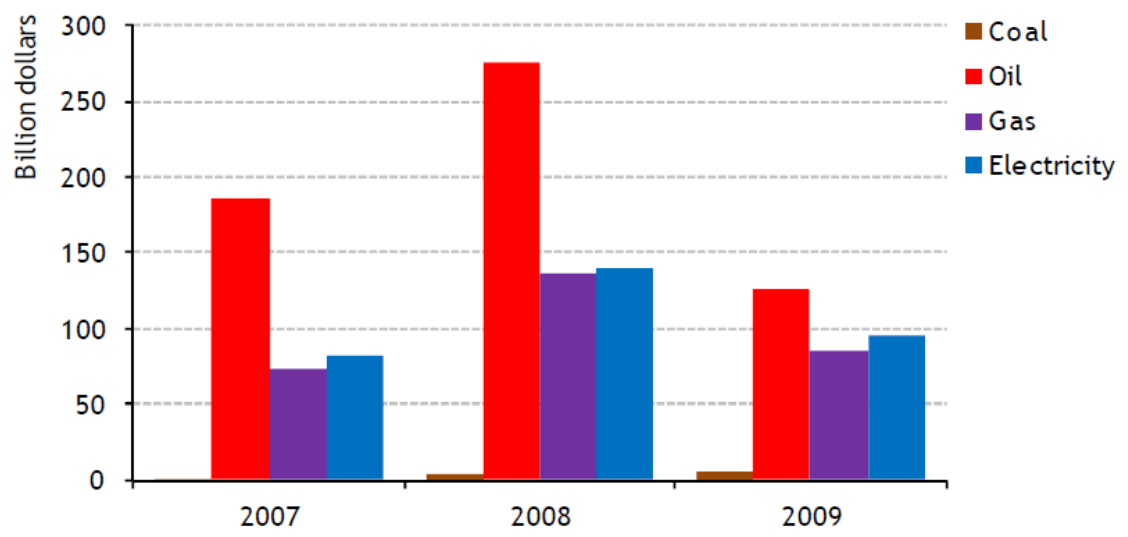

Figure 2.1. Economic value of fossil-fuel consumption subsidies by type. Source: IEA (2010).

Among 20 non-OECD countries, IEA found that oil products were the most heavily subsidized of fossil fuels at $\$ 152$ billion in 2007 (Ellis 2010, Morgan 2007), equivalent to $2.5 \%$ of total GDP in the 20 countries. ${ }^{3}$ This estimate includes subsidies to industrial and residential fuels, kerosene and liquefied petroleum gas (LPG), as well as transport fuels. Natural gas subsidies were estimated at $\$ 70$ billion in 2006 , while consumer subsidies for coal were smaller and considered to be around $\$ 10$ billion (Morgan, 2007). In many countries, particularly developing countries with low GDP per capita, consumption-related fossil-fuel subsidies have exceeded 2\% of GDP for many years (examples are Turkmenistan with 15.2\% of GDP in 2008; Ecuador, 8.7\%; Egypt, 8.4\% (Ellis 2010)). Expenditures relating to the subsidization of fossil fuels may override public health and education budgets.

Gasoline taxation is one frequent example of fossil-fuel subsidies. Wagner (2008) takes the US price level as the international minimum benchmark for a non-subsidised road transport policy. The fuel prices of the United States are average cost-covering retail prices incl. industry margin, VAT and road funds. Wagner (2008), see also Victor (2009), illustrate the retail gasoline prices across the world countries.

In the most subsidized countries, the retail price of gasoline is below the price for crude oil in the world market (30 US cents/litre), and the subsidies make fuel nearly free. The population in these countries is so large that the total subsidies add to significant amounts. Iran has the second lowest prices on earth of 0.1 US\$per litre, and their fuel subsidy totals roughly $1 / 7$ of the total of all world energy subsidies (Victor 2009). The most subsidizing countries are essentially the fuel suppliers.

The countries with the highest prices (up to 2 US\$/litre) apply massive taxes to energy products created to raise funds, dominated by western European countries. All Nordic countries, with the exception of Ice-

3 http://www.xist.org/charts/ec_gdp1.aspx 
land, belong to this group. In the middle are countries that often have a mix of both patterns. They tax some fuels while subsidizing others.

The pattern for diesel subsidies may differ, as diesel is generally applied to a wider array of purposes than transportation, and diesel users are often particularly well-organized freight haulers (Victor 2009).

Also, it is important to be aware of new, emerging environmentally harmful subsidies distorting the market, such as subsidies to low-carbon energy and renewable energy. Policy support for low-carbon energy has increased significantly over the past decade. Examples are subsidies to biofuels and diesel and nuclear power, see e.g. examples in chapter 6 and Appendix 2. The IEA estimates that worldwide government support to renewable electricity and biofuels amounted to $\$ 57$ billion in 2009, up from $\$ 41$ billion in 2007 (IEA et al. 2010a). These estimates do not include subsidies for renewable heat technologies or other emerging lowcarbon energy technologies such as CCS. The arguments have been to constrain growth in greenhouse gas emissions, to diversify the supply mix, prompted by varying oil prices and to reduce unemployment followed by the economic crises (IEA et al. 2010a). Also, subsidies to renewable energy are becoming more common and the amount seems to be increasing.

The problem with such subsidies is that all energy sources imply environmental costs. Low-carbon biofuels and diesel still emit $\mathrm{CO}_{2}$ and local pollutants, wind-power and hydro power require land use and have aesthetical costs. It the subsidies are not related to positive externalities, see chapter 4.2 , they classify as environmentally harmful subsidies. Rather than subsidizing the fossil fuels alternatives in order to combat climate change, carbon emissions should be efficiently managed by carbon prices and/or emission trading systems (see also the discussion of correct pricing of energy related externalities in chapter 10.1, Appendix 1).

\subsection{Possible benefits from removing environmentally harmful subsidies}

The main benefits from subsidy reforms can be categorized into environmental benefits and economic effects, including reduced strain on government budgets and improved economic effectiveness.

\subsubsection{Environmental benefits}

Given the extensive support to energy consumption and production, removing the inefficient subsidies would dramatically affect the energy markets. Subsidies on certain energy production or consumption undermine the competitiveness of alternative energy sources and efficient energy technologies. Exemptions from environmental taxes can lock in 
polluting technologies and hinder low cost pollution reductions. In particular, subsidies directed to reduce specific variable costs can have lockin effects. This may hinder the development and deployment of environmentally friendly technologies and have negative environmental effects in the longer term. The longer a subsidy is granted, the more it will impact on the lock-in effect and therefore on the environment.

Removal of subsidies would imply structural adjustment and improved efficiency in productivity and consumption. For example, lower subsidies to coal, gasoline and biofuels increase energy prices in general, reduce consumption and promote more efficient utilization of energy and substitution to non-subsidized energy sources. Since the subsidies are foremost targeted at fossil fuels, the emissions of greenhouse gases would be reduced. This represents a win-win situation, as it represents a cost efficient option of reducing GHG emissions.

Different studies show different benefit estimates, dependent upon which countries are included, time period and subsidies. In a review of the literature on fossil-fuel subsidies, Ellis (2010) looks into six major multi-country, multi-fuel studies undertaken since the early 1990s, covering in both OECD and non-OECD countries. All six studies found that fossil-fuel subsidy reform would result lower $\mathrm{CO}_{2}$ emissions, in a range of $1.1 \%$ in 2010 to $18 \%$ in 2050.

Burniaux et al. (2009) base their study on 20 non-OECD countries. They conclude that world GHG emissions would be reduced by $10 \%$ by 2050 if consumer subsidies for fossil fuels and electricity in these countries were phased out.

IEA (2010) estimates that a universal phase-out of all fossil-fuel consumption subsidies by 2020 would cut global primary energy demand by $5 \%$ and $\mathrm{CO}_{2}$ emissions by $6 \%$ compared with a base-line in which subsidies remain unchanged, see figure 2.2.

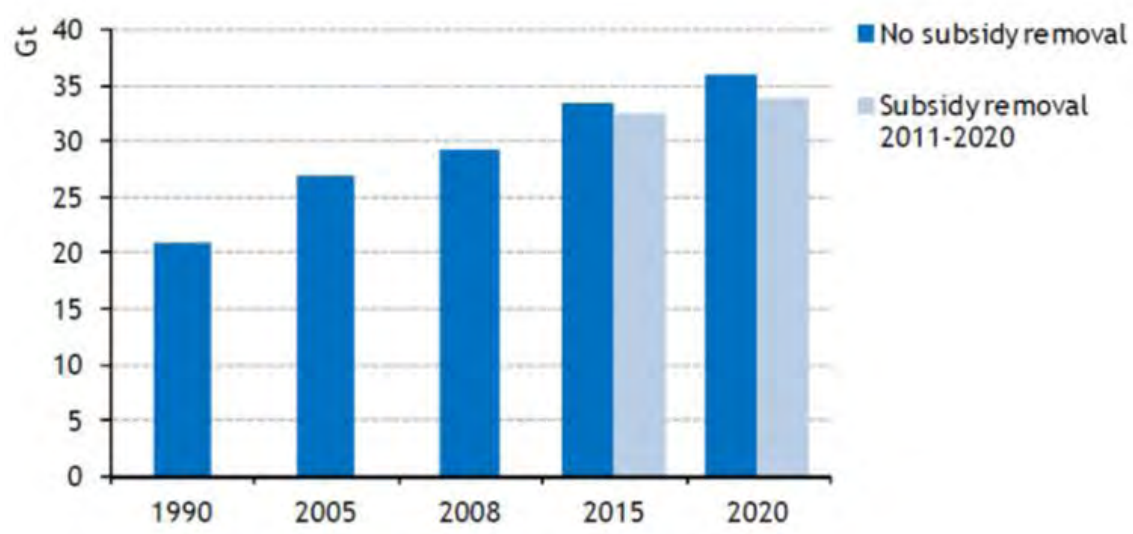

Figure 2.2. Impact of fossil-fuel consumption subsidy phase-out on global energy-related $\mathrm{CO}_{2}$ emissions. Source: IEA (2010). 


\subsubsection{Improved budget balances}

Further, removing subsidies would remove a costly drain on the government budgets. The subsidies are most often motivated in equity issues, such as to support low income groups or particular districts/industries. In most cases, removals of subsidies demand alternative subsidies to meet the same political goals, leaving the net budget gain less than the initial cut in harmful subsidies.

As mentioned above, the subsidies levied to fossil fuel consumption and production were estimated to $0.7 \%$ of world GDP in 2009. The burden is heavier for the low income countries. Among 20 non-OECD countries, the oil products subsidies were equivalent to $2.5 \%$ of GDP, and examples are found with rates up to $15 \%$ for some countries.

IEA et al. (2010b) review a number of empirical studies of the impact of removal of energy subsidies to the poor income groups, based on computable general equilibrium models (CGE) (Oktaviani et al. 2007; Manzoor et al. 2009; Abouleinein and Kheir-El-Din 2009; ESMAP 2004). These studies generally show that the low income groups lose when removing the subsidies. However, as noted by the IEA, the CGE models do not account for the impact of the redistribution of public revenue. The general textbook theory tells us that subsidies are better targeted if used directly by cash transfers. An efficient redistribution of the budget targeted directly at the affected income groups, would more effectively benefit the poor.

\subsubsection{Economic benefits}

Inefficient subsidies generally disturb the allocation of resources. Hence, removal of environmentally harmful subsidies will per definition increase overall welfare.

Ellis (2010) looks into six major multi-country, multi-fuel studies undertaken since the early 1990s. All six studies found that fossil-fuel subsidy reform would result in aggregate increases in GDP in both OECD and non-OECD countries in the range of 0.1 to $0.7 \%$ per year to 2050 .

Other studies analysing the direct effects on GDP show a first order decrease in overall production. It is important to note that these studies do not capture the benefits from reducing the subsidies, and the as they focus on the direct consequences for GDP. In addition, there are feedback mechanisms from the environment to economic efficiency in terms of health effects, reduced depreciation, and direct welfare effects in terms of consumption of nature/environment services. To estimate the total benefits from a more efficient policy, effects from redistributing the reduced budget costs to subsidies and revenues from increased taxes should also be accounted for.

Keeping this in mind, the literature shows that the direct effects on GDP are usually negative. Abouleinein and Kheir-El-Din (2009) study the impact of phasing out fuel subsidies in Egypt. They find that the elimina- 
tion of energy subsidies, without any offsetting policy actions, would reduce average annual GDP growth by 1.4 percentage points over the reference period and depress the welfare levels of households at all levels of the income distribution. Manzoor et al. (2009) estimate that removing subsidies to the energy sector in Iran results in shrinking of output, the reduction in urban and rural welfare respectively by 13 and $12 \%$, and also predict hyperinflation. ESMAP (2004) finds that the effects on the macroeconomic level of the removal of electricity subsidies in Mexico are small, with GDP, exports, imports, and employment all experiencing small declines. Welfare decrease for all income classes, but the poor are affected most because electricity subsidies are more important in proportionate terms for their incomes. Oktaviani et al. (2007) find that removing the fuel subsidies in Indonesia reduce household incomes and increase domestic prices, and hence impair macroeconomic performance of the economy. Overall incidence of poverty increase from 9 to $13 \%$ of the population, with rural areas worst affected. The authors conclude that the government should offset the impact of subsidy removal with measures to compensate households. Compensation, and general recycling of the increased public revenue, will stimulate the economic growth beyond these findings. 


\section{The Nordic countries}

According to the abovementioned estimates, support to fossil energy consumption and environmentally harmful subsidies in general are most widespread in developing countries. A lower need to alleviate poverty in rich countries may be the most important reason for this difference. Also, higher awareness and economic possibility to prioritize both high income and a good environment imply more weight on sound environmental policies in rich countries. This is well-know from the so-called Environmental Kuznets Curve literature, studying the causes for the inverted U-curve between income and emissions (Stern 2004; Bruvoll et al. 2003).

Sachs (2006) reviews the economic and political performance of the Nordic countries compared to the English-speaking OECD countries and the continental western EU countries. He finds that the Nordic countries have relatively high rates of taxation compared to the other countries, and generally perform better when it comes to economic growth, income per person and incentives to work. He largely attributes this to the acceptance for industrial change, active labor market policies, public sector commitments to higher education, retraining and R\&D etc.

The high income levels might have spurred the relatively early attempts at imposing environmental regulations in the 1960s and 1970s in the Nordic countries, along with several other western countries that also started focusing on the environment at that time. The Nordic countries were likely not as polluted as many other industrialized countries, since they had relatively few industrial hot spots and relatively sparse population. Thus, high environmental standards have been a stronger norm in these countries compared to poorer and more densely populated areas around the world. In general, the environmentally harmful emissions are subject to taxes or direct regulations, and the use of subsidies to energy consumption is sparse compared to many other countries.

\subsection{Tax reforms}

All Nordic countries have implemented environmental tax reform packages the last decades. Environmental taxation, i.e. reduction of implicit subsidies, has been accompanied with compensatory measures, including lower conventional taxes, typically labor taxes (see ECON 1997a; Larsen 2002, TemaNord 2006a).

Denmark introduced a tax on fossil fuels in 1977. Originally, it was intended to decrease the energy consumption in order to reduce the bal- 
ance of payments deficit and to some extent stimulate the use of natural gas. The tax scheme was expanded over time to include coal and natural gas as well. A tax freeze was imposed in 2001 but the tax has recently increased somewhat (TemaNord 2009). Other taxes, mainly on labor have been reduced over the years.

During the early 1990s a number of economic instruments were introduced for environmental and energy policy purposes in Finland, and since then the emphasis on taxation has gradually shifted from taxation of labor to taxation of polluting activities (TemaNord 2009). The most important environmental taxes are today taxes on fossil fuel and electricity use, with the $\mathrm{CO}_{2}$ tax as the most dominant. Taxes on different kinds of waste and the registration tax on cars are also imposed.

In 2010 a carbon tax was introduced on all fossil fuels used in Iceland, and the tax system of vehicles was changed to entirely depend upon $\mathrm{CO}_{2}$ emissions.

In Norway, economic instruments notably through taxes on $\mathrm{CO}_{2}$ emissions and electricity have been used since early 1990s. Taxes on labor and capital gains were reduced through a tax reform in 1992, and various excise duties and the value added tax have been increased to broaden the tax base. Another form for compensation followed the increase in the taxes on electricity and heating oils in 2001, with an increase the basic tax allowances.

In Sweden a green tax shift has taken place since the 1990s, higher environmental taxes have been shifted against increased personal allowances and lower social security contributions. The government has increased the $\mathrm{CO}_{2}$ tax, the electricity tax, the diesel tax, the waste tax, the tax on gravel, the pesticide tax, the road vehicle tax and petrol tax, and introduced an electricity tax for industry (TemaNord 2009).

\subsection{Remaining subsidies}

Still, although the problem compared to many other countries are small, the Nordic countries still have many remaining producer related EHS, both as direct subsidies over public budgets to primary sectors and energy production, and as foregone revenues in terms of exemptions from optimal taxation for certain industries.

Environmentally harmful subsidies financed over public budgets are analysed in SWECO (2008). In Norway, these are typically related to support to transport, agriculture, forestry, transport and regional development. Several forms of transport support are given both to airports, roads and sea transport, which stimulate emissions to air and sea. Support to primary industries also stimulate emissions, and contribute to reduce biological diversification.

Further, subsidies are given to stimulate energy production and saving. In Norway, 1.1 bill NOK was allocated to production of wind power 
in 2009, and significant subsidies are given to biofuels and heating projects. All of these energy sources imply environmental costs. If not directed at positive externalities, the subsidies are covered by the definition of environmentally harmful subsidies (cf. chapter 4). Rather than subsidizing the fossil fuels alternatives, carbon emissions should be efficiently managed by carbon prices and/or emission trading systems (see also the discussion of correct pricing of energy related externalities in Appendix 1).

Support is directed to certain industries out of competitiveness and employment concerns. Direct budget support is politically controversial and can also be practically difficult due to international competitiveness legislation (cf. EU). Instead, tax differentiation and exemptions are common. The Norwegian carbon taxes serve as example. These are highly differentiated, with certain industries facing low rates to protect labour and stimulate regional development. The subsidy element consists of the avoided tax payment in the industries with exemptions or lower rates than some agreed benchmark (cf chapter 5.1). Bruvoll and Dalen (2008) estimated the implicit subsidies to 2,8 bill. NOK in 2006, see figure 3.1.4 The main subsidized sectors are the process industries, metal and chemical production, and fishing. Some of these polluters have later been included in the emission trading system, but with free allowances.

Similar implicit subsidies are present in the other Nordic countries, with lower taxes for industries and electricity generation.

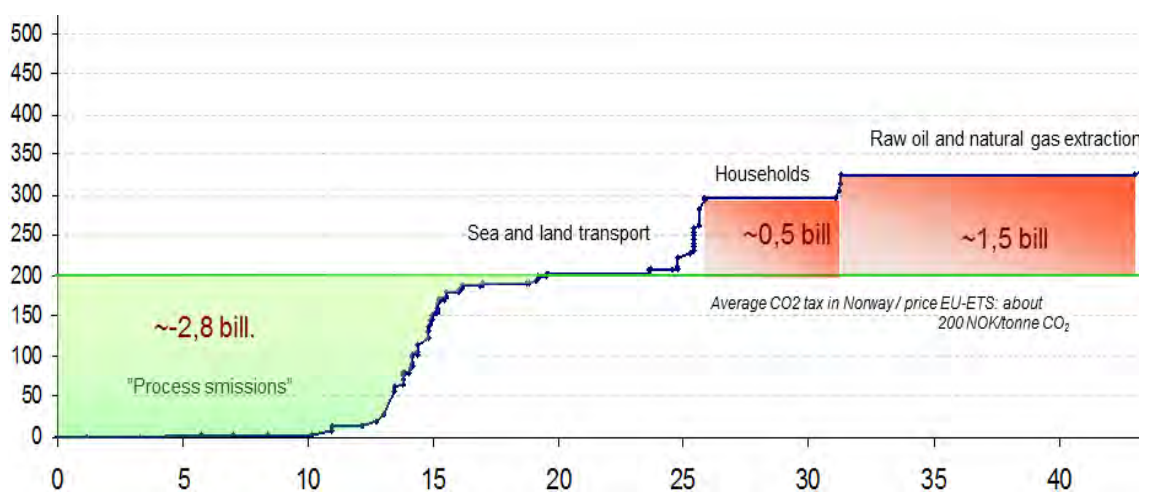

Figure 3.1. Implicit subsidies (and taxes) due to CO2 tax exemptions (and overpricing) in Norway, NOK, 2006.

Source: Bruvoll and Dalen $(2008,2010)$.

Reduced VAT rates are also common (see also chapter 6.6). The general VAT rates are about 25\% in all the Nordic countries (Iceland 24,5\% and Finland 22\%), and all countries except Denmark use reduced rates of about $8-14 \%$. Several the VAT rates are reduced for potentially environmentally harmful goods and services, such as for food and drinks,

4 The EU ETS carbon price, which also corresponds to the average tax, is chosen benchmark. Households, the offshore sector and landfills pay more than the marginal cost, which corresponds to an uneven fiscal tax burden. 
and passenger transport. The VAT is totally exempted for households energy consumption in certain rural areas (northern parts of Norway) and for electricity cars. Electricity taxes are also lower for Norwegian industries and in the northern parts of Sweden and Norway.

Another type of subsidies carried out as tax exemptions, are subsidies related to work travels (see also chapter 6.7). In all the Nordic countries, commuter subsidies are formulated as reduced income taxes for workers travelling between their domicile and second residents related to their work. Deductions are also given to general work travels over a certain distance.

Indirect subsidies formulated as tax exemptions are harder to reveal and calculate than direct subsidies to fossil fuel consumption. More thorough investigation of these sources will contribute to a fuller picture of the environmentally harmful subsidies in high income countries. 


\section{Definition of environmentally harmful subsidies}

\subsection{Theoretical foundation}

To decide the appropriate actions to reduce the negative effects of environmentally harmful subsidies, it is necessary to clarify the definition within a theoretical framework.

In a Perfectly Competitive Market, ${ }^{5}$ all resources are efficiently utilized and so-called Pareto-optimality is achieved. Pareto-optimality means that no one can increase utility unless at the expense of others. In this ideal situation no subsidies are needed, except for re-distribution concerns. But in reality, market failures, such as external effects, market power, lack of information, lack of competition etc. are present in all economies. Subsidies are one of several means to correct for market failures. Subsidies then serve two purposes; to correct for market failures, and to redistribute wealth out of equity concerns, see summary in table 4.1.

Table 4.1. The main principles for taxes and subsidies.

\begin{tabular}{lll}
\hline & Market failures & Re-distribution \\
\hline Taxes & $\begin{array}{l}\text { Taxes to correct negative externalities, equal to } \\
\text { the marginal external effect }\end{array}$ & $\begin{array}{l}\text { Revenues to finance subsidies and } \\
\text { other public expenditure }\end{array}$ \\
Subsidies & $\begin{array}{l}\text { Subsidies to correct positive externalities, equal } \\
\text { to the marginal external effect }\end{array}$ & $\begin{array}{l}\text { Subcording to political preferences } \\
\text { action }\end{array}$ \\
\hline
\end{tabular}

The usual cause for using subsidies in the market failure context, is to correct for externalities. Externalities are costs and benefits not transmitted through prices and incurred by another party than those affected by the cost or benefit. Hence, the market prices do not reflect the full social costs or benefits of producing or consuming a product or service, and producers and consumers may either not bear all of the costs or not reap all of the benefits of the economic activity. A benefit is called a positive externality or an external benefit, while a cost is called a negative externality or an external cost.

In the presence of positive externalities, a third party often benefits from a good at no cost. In an economic perspective, too little of the good

\footnotetext{
5 The core assumptions behind a Perfectly Competitive Market are: many suppliers each with an insignificant share of the market, the market supplies homogeneous or standardised products, perfect information, free entry and exit of sellers in the market, and no externalities in production and consumption so that there is no divergence between private and social costs and benefits.
} 
is produced or consumed. Examples are education (one persons' knowledge level benefits the society beyond the private individual utility), network effects (the more actors using a network, the better for others using the same network), research and development (e.g. new technologies can be disseminated for use by other producers). Externality subsidies to the activity can be used to correct the market and increase the supply of the good, either as price and investment subsidies or as government provisions.

Environmental economics typically deals with negative externalities. Examples are pollution associated with transport, or energy production and consumption. Externality taxes are efficient corrections of negative externalities, with optimal taxes equal to the marginal cost of the externality. ${ }^{6}$

The other main reason for subsidies is re-distribution of wealth and the support of specific groups. Support to publicly provided goods, support of low income groups and externality subsidies are generally financed by fiscal taxes. According to theory, fiscal taxes should minimize market distortions. ${ }^{7}$ This is in contrast to externality taxes, for which one purpose is to influence market behaviour and to reduce the externalities.

\subsection{Defining inefficient subsidies}

In this work our reference point is the perfect situation where taxes and subsidies optimally correct external effects and non-optimal distribution. We term all other subsidies inefficient subsidies.

In theory an inefficient subsidy may be a subsidy on the correct item, but with incorrect dosage. In this case we may consider the incorrect part of the dosage to be inefficient. Or it may be a subsidy on an inferior item, i.e. a situation where a subsidy on another item would have achieved the same objective at a lower distortionary cost to the economy.

In practice the most obvious and first type of inefficient subsidies is subsidies to polluting activities over public budgets, with an unclear distributional purpose.

The second type of inefficient subsidies is the indirect support related to exemptions from optimal taxation. The second type also implies reduced public budgets relative to the reference point, since failure to correct for negative externalities implies lost revenues. Tax exemptions are hence equivalent to budgetary subsidies to polluting activities.

\footnotetext{
${ }^{6}$ Due to the fiscal element in externality taxes, total taxes on polluting goods should vary according to the externality rule and the elasticity of demand by taking into account the additivity theorem in Sandmo (2000) 7 Under simplifying assumptions, the fiscal tax rate on a good should then be inversely proportional to the corresponding own price elasticity of demand (Ramsey 1927). Further, taxes should be levied at the end use, as (differentiated) value added taxes (VAT), implying no taxes on intermediate goods and imports (Diamond and Mirrlees 1971).
} 
Finally, the third category covers other inefficient subsidies which are of more indirect nature. This may be regulatory support mechanisms, income and price support, preferential market access, exemptions from governmental standards and other forms of subsidies (see examples later in table 5.1), given that these subsidies do not correct for market failures or effectively re-distribute wealth.

Further, although it is matter of judgement we believe that when taking the reference point above, it is not meaningful to include efficient subsidies in the definition of environmentally harmful subsidies, even if efficient subsidies increase the environmental pressure. For example, subsides correcting for positive externalities, such as to research and education can increase emissions related to these activities. Subsidies correcting for market failures should not be reduced despite their environmental effects. Given such subsidies, the label harmful does not bring about the right connotations. Instead, if not already correctly regulated, the environmental costs should be corrected through appropriate regulation.

Principally the definition of environmentally harmful subsidies is equivalent to all inefficient subsidies. For practical purposes, we are only concerned with those inefficient subsidies that cause environmental damages of some significant extent.

We summarize the definition of environmentally harmful subsidies as follows:

- Environmentally harmful subsidies are inefficient subsidies causing (substantial) negative environmental effects

- Inefficient subsidies are subsidies other than those that efficiently correct for positive externalities or efficiently correct for distributional issues

- For practical purposes inefficient subsidies can be categorized in three main groups:

A. Subsidies to negative environmental externalities

B. Exemptions from taxation of negative environmental externalities

C. Other inefficient subsidies 


\subsection{Partial market effects of environmentally harmful subsidies}

To illustrate the principal differences between type A. and B. subsidies, we schematically discuss two examples.

\subsubsection{Exemptions from taxation of negative environmental externalities}

The first example illustrates a market with a polluting production technology, for example coal based electricity production, see figure 4.1. Total supply faces increasing marginal production costs, while the willingness-to-pay (i.e. demand for electricity) is downward sloping. In equilibrium, demand meets supply at $X$ and at the price $p$.

In addition to the costs faced by the producer, the production implies external costs (for example carbon emissions). Hence, the total marginal production costs are higher than the private costs. A lack of taxation implies an efficiency loss equal to the shaded triangle, i.e. the integral of the area where marginal social costs exceed marginal willingness to pay.

The optimal equilibrium would be $X^{*}, p^{*}$, while the actual solution is at a higher production, $X$, and lower price, $p$. The first-best policy would be to levy a tax equal to the marginal damage cost of production, hence raising the producer's cost and securing the optimal solution. Since the reference point for the first-best option is at $X^{*}, p^{*}$, an exemption of the externality tax is equivalent to an environmentally harmful subsidy, cf. situation B. above.

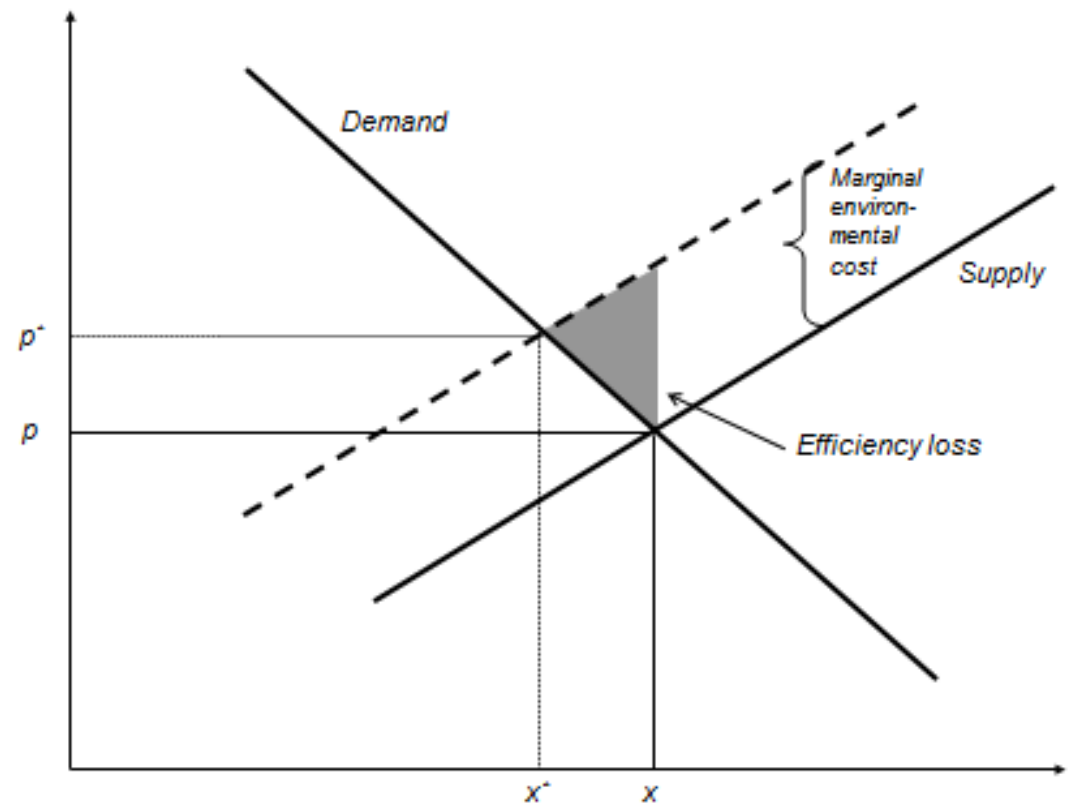

Figure 4.1. Lack of externality taxes. (Symbols: $X=q u a n t i t y, p=p r i c e, ~ *=o p t i m a l$ adjustment). 
Instead of environmental taxation, subsidies of alternatives to negative externalities often appear more politically acceptable. The relevant focus in this report is when the subsidies are given to negative externalities.

\subsubsection{Subsidies to negative environmental externalities}

Subsidies to negative externalities imply two additional market distortions. A common example is when rather than taxing carbon, subsidies are given to fossil fuels (see examples in chapter 6), see figure 4.2. We use producer subsidies as a case for illustration, but as shown in Appendix 1, the principal market effects are the same for consumer subsidies. We include a "clean" technology, $S^{g}$, in addition to the polluting technology, $S^{b}$, to illustrate the effects of such subsidies on non-polluting technologies. The supply curve $S^{*}$ represent the social cost curve, including both external costs and producers' costs. Hence the optimal solution, including both producers' costs and external costs, is in $X^{*}, p^{*}$.

We look at a situation where the external costs are not internalized, and the initial market solution is at $X_{0}, p_{0}$. So far, this situation implies a subsidy of type B. as explained above, with a corresponding efficiency loss equivalent to the dark shadowed area.

We then look at a situation where the government subsidizes the polluting technology by a subsidy rate $r$, cf. A. above. The supply then shift outwards $\left(S_{1}{ }^{b}\right)$ and total supply increases (from $S_{0}$ to $S_{1}$ ). The market equilibrium price decreases (from $p_{0}$ to $p_{1}$ ).

The subsidies imply lower energy prices, reduced production and incentives to invest in alternative energy $X^{g}$, and the polluting energy is stimulated. The efficiency loss expands due to an increasing difference between marginal social production cost, $S^{*}$, and marginal willingness to pay, $D$.

The winners are consumers (facing lower prices) and polluting producers (receiving higher prices $p_{1}+r$ ). The losing parties are the environment (as pollution increases), the clean technologies (as the market price decreases), and public budgets (direct subsidy expenditure and lack of tax income). 


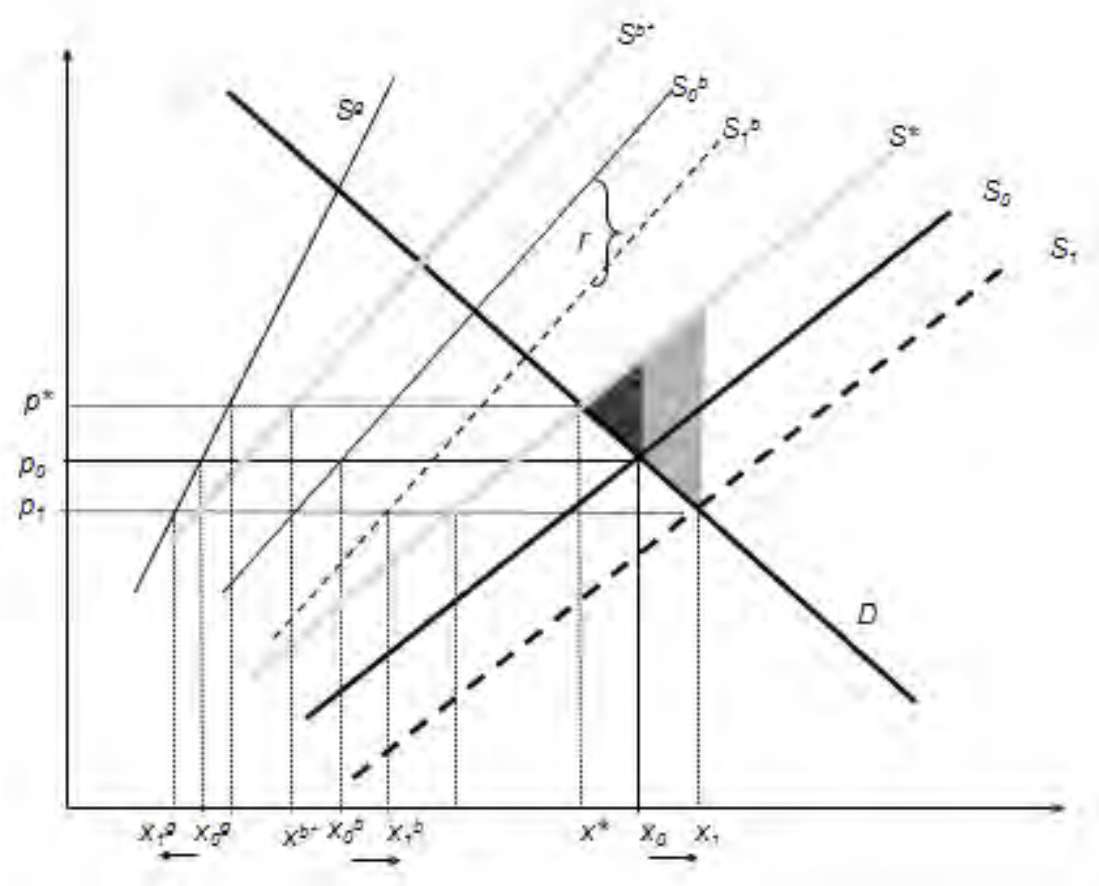

Figure 4.2. A subsidy to a negative externality. (symbols: $S=$ supply, $D=d e m a n d$, $g=$ non-polluting technology, $b=$ polluting technology, $x=q u a n t i t y, p=p r i c e$, $r=$ subsidy, $0=$ time before the subsidy, $1=$ time after subsidy, *=optimal adjustment).

This illustrates that removing environmentally harmful subsidies is not only a matter of removing direct subsidies, but a two-step procedure:

1. first to remove budget subsidies to polluting technologies (A)

2. second to include the technologies in externality tax regimes (B)

Examples are to reduce subsidies to coal production (1) and to introduce carbon taxes on the emissions from coal consumption (2). 


\section{The accounting of environmentally harmful subsidies}

The definition of environmentally harmful subsidies for accounting purposes proves challenging in practise. Several reports have approached the definition problem earlier, starting out with the definition of subsidies in general. First, it is challenging to define what instruments are really subsidies. Second, it is a challenge to define which subsidies are inefficient. Third, practicability concerns require a choice of which inefficient subsidies are relevant for studies of negative environmental effects.

\subsection{Subsidies in general}

In practise, there are numerous ways of creating subsidies. Subsidies may be formulated as direct lump sum transfers or feed-in tariffs, or as indirect support. The latter is particularly challenging, as the subsidies can take form as differences in domestic and world market prices resulting from trade restrictions, foregone resource rents in public projects due to low discount rates, publicly owned enterprises or prices lower than marginal costs due to e.g. lack of pricing negative externalities. Subsidies may target current production (e.g. production grants), future production (e.g. R\&D) or future obligations (e.g. government assistance to environmental trust funds). Some target specific activities and entail obligations for the recipient, such as producing energy by a particular method or requiring that certain facilities are modernised or shutdown (OECD 2005).

In IEEP et al. (2007), different definitions of subsidies for the purpose of accounting are reviewed, see table 5.1. The European system of accounts (ESA) definition aiming to satisfy national accounting represents one of the narrow definitions;

"Current unrequited payments from government to producers with the objective of influencing their levels of production, their prices or the remuneration of the factors of production."

The WTO agreement on subsidies, see table 5.1, is the only international definition that is both legally binding and agreed across sectors and countries (IEEP et al. 2007; WTO 2011). According to the agreement, a subsidy is deemed to exist if there is: 
- a financial contribution by a government or any public body8

- there is any form of income or price support, and

- a benefit is thereby conferred

All three of these elements must be satisfied in order for a subsidy to exist.

This definition is relatively comprehensive and serves as a starting point for many definitions used in practice. However, the definition is an instrument of international trade and law, and does not specify foregone revenues related to lack of environmental taxation.

The OECDs perspective is even broader by defining a subsidy as:

"a result of a government action that confers an advantage on consumers or producers, in order to supplement their income or lower their costs."

(OECD 2005).

This definition covers general support measures, such as tax rebates and exemptions, preferential market access, limited liabilities, and selective exemptions from government standards. It does however not include all types of lack of internalization of market failures, i.e. the full costs, unless lack of action is also defined as a type of "government action".

Pieters (1997) defines subsidies as "deviations from full costing", also including implicit income transfers resulting from lack of full cost pricing or non-internalisation of externalities, cf. the element B. in chapter 4.2. This is the most comprehensive definition, principally including deviation from optimal pricing and internalisation of external benefits and costs.

\footnotetext{
8 (i) a government practice involves a direct transfer of funds (e.g. grants, loans, and equity infusion), potential direct transfers of funds or liabilities (e.g. loan guarantees);

(ii) government revenue that is otherwise due is foregone or not collected (e.g. fiscal incentives such as tax credits);

(iii) a government provides goods or services other than general infrastructure, or purchases goods;

(iv) a government makes payments to a funding mechanism, or entrusts or directs a private body to carry out one or more of the type of functions illustrated in (i) to (iii) above which would normally be vested in the government and the practice, in no real sense, differs from practices normally followed by governments.
} 


\begin{tabular}{|c|c|c|c|c|}
\hline \multirow[t]{2}{*}{ Type of subsidy } & \multicolumn{4}{|c|}{ Definitions of a subsidy } \\
\hline & ESA & WTO & OECE & Pieters \\
\hline \multicolumn{5}{|l|}{ On-budget subsidies } \\
\hline Direct transfer of funds, e.g. grants & $\mathrm{x}$ & $x$ & $x$ & $x$ \\
\hline Potential direct transfers of funds, e.g. covering liabilities & & $x$ & $x$ & $x$ \\
\hline Government provides goods or services other than general infrastructure & & $x$ & $\mathrm{x}$ & $x$ \\
\hline Government directs other bodies to do any of the above & & $x$ & $x$ & $x$ \\
\hline \multicolumn{5}{|l|}{ Off-budget subsidies } \\
\hline Market price support & & $\mathrm{x}$ & $\mathrm{x}$ & $x$ \\
\hline Government revenues due are foregone or not collected, e.g. tax credits & & $x$ & $x$ & $x$ \\
\hline Tax exemptions and rebates & & $x$ & $x$ & $x$ \\
\hline Preferential market access & & $\mathrm{x}$ & $x$ & $x$ \\
\hline Accelerated depreciation allowances & & & $x$ & $x$ \\
\hline Regulatory support mechanisms, e.g. feedin tariffs, demand quotas & & & $\mathrm{x}$ & $x$ \\
\hline Selective exemptions from government standards & & & $x$ & $x$ \\
\hline Resource rent for foregone natural resources & & & $\mathrm{x}$ & $\mathrm{x}$ \\
\hline Implicit subsidies, e.g. resulting from the provision of infrastructure & & & & $x$ \\
\hline Implicit income transfers resulting from a lack of full cost pricing & & & & $x$ \\
\hline Implicit income transfers resulting from non-internalisation of externalities & & & & $x$ \\
\hline
\end{tabular}

Source: IEEP et al. (2007), Valsecci et al. (2009).

\subsubsection{Subsidies with negative environmental effects}

The definition of the narrower concept of environmentally harmful subsidies involves further challenges. Several definitions exist in the literature, which are not necessarily in line with our theoretical definition in chapter 4.2, as they may also include subsides efficiently correcting for market failures and equality issues.

For example, Valsecchi et al. (2009) adapt the following definition from OECD (2005):

"All other things being equal, the [environmentally harmful]subsidy increases the levels of output/use of a natural resource and therefore increases the level of waste, pollution and natural exploitation to those connected."

In their working definition of fossil fuel subsidies, the EU use the worldmarket prices as a benchmark, based on the approach of the IEA (G20 2010):

"A fossil-fuel subsidy is any government measure of program with the objective or direct consequence of reducing below world-market prices, including all costs of transport, refining and distribution, the effective cost for fossil fuels paid by final consumers, or of reducing the costs of increasing the revenues of fossil-fuel producing companies."

In the practical approximation to their calculations of environmentally harmful subsidies, the OECD has identified five main approaches (OECD 2005, IEEP et al. 2007): Programme aggregation; adding up the budgetary transfers of relevant government programmes, marginal social cost; measuring the difference between the price actually charged and the marginal social cost, resource rent; measuring the resource rent fore- 
gone for natural resources, producer/consumer support estimate; measuring the budgetary transfers and price gaps under relevant government programmes affecting production and consumption alike, and price-gap; measuring the difference between the world and domestic market prices of the product in question.

The Effective Rates of Assistance (ERA) method measures net government assistance to an industry by comparing the difference between the value-added by the assisted sector to the value-added generated by the same, but unassisted sector. It takes into account not only support directed at an industry but the amount of support indirectly received or the tax paid by the industry because the government has subsidized or taxes a supply industry (IEEP et al. 2007). The Norwegian ERA measurements (see e.g. Fæhn et al. 2001) cover indirect taxes and subsidies, budget support included, border protection and price regulations, such as discrimination of energy prices.

These reports offer useful guidelines for the definition of environmentally harmful subsidies in practise. Several of the initiatives mentioned in chapter 1 aim to improve these definition frameworks. The most recent one is the Global Subsidies Initiative GSI guide for measuring subsidies to fossil-fuel producers, including a list of potential direct transfers, government revenue foregone, government-provided or - purchased goods and services and income or price support (GSI 2010).

When comes to the size of the subsidies, the most obvious, direct budget support type subsidies are easy to measure in terms of economic transfers. The implicit subsidies related to a lack of internalization of environmental cost are more difficult to estimate because it is not obvious what prices are correct. The total effects of all forms of subsidies are principally the sum of the general equilibrium effects affecting not only the polluters, but also to sectors related to the polluting agents and interaction throughout the economy. Hence, general equilibrium models may be necessary to capture the total costs, cf. chapter 2.2.

\subsection{Recommendations for accounting of environmentally harmful subsidies}

Aside from pointing to the several studies of subsidy accounting framework above, it is beyond the scope of this project to further define the practical measurement. For more details, we point to the on-going works by e.g. GSI (2010). Based on the review of the earlier works, we see some important aspects to include in the further development of guidelines for accounting of environmentally harmful subsidies. These follow as consequences of using the perfect competitive market situation as a reference, and are important to the policy implications. 


\subsubsection{Exclude efficient subsidies}

Generally, the practical definitions from the sources referred to above disregard the potential theoretical justification of the subsidies creating the environmentally effects. Subsidies targeted to correct for market failures or efficiently directed to support politically prioritized groups, should not be included in the accounting of environmentally harmful subsidies, despite their potential negative environmental effects, cf. chapter 4.2.

\subsubsection{Include exemptions from externality taxation and other indirect subsidies}

While the main focus of environmentally harmful subsidies is on economic transfers, exemptions from externality taxation should also be included. In line with the definition in chapter 4.2, environmentally harmful subsidies include 1) subsidies to negative externalities, 2) exemptions from environmental taxation and 3) other indirect subsidies (see examples in table 5.1) when not correcting for market failures or effectively re-distributing wealth.

\subsubsection{Define the benchmark}

Finally, the differentiation and benchmark for externality and fiscal taxes create definition problems. For instance, tax rates on final energy use are often higher for small users (households) than for large users (energy intensive industry), cf. the Norwegian electricity taxes. The textbook defines the benchmark tax rate as a weighted average of the tax computed under the Ramsey inverse elasticity rule and the Pigouvian marginal social damage (Sandmo 1975, 2000). In practise, for the purpose of accounting the extent of environmentally harmful subsidies, estimates of the correct benchmark tax do usually not exist. Measuring the correct level of environmental taxes is challenging (cf. Bruvoll 2009a,b). The values of external costs are not observable in the market prices, and may rely on ethical views and vary across individuals and interest groups. An example is what social cost to the national and/or global climate should be ascribed a tonne of $\mathrm{CO}_{2}$ emissions. Usual approximations are the emission trading price, marginal willingness to pay, or estimates from cost studies.

The analyst then has to make to evaluate which benchmark to use. Importantly, the choice of benchmark defines the extent of the subsidy, and even whether a subsidy exists. If for example a high carbon tax rate of is taken as benchmark, energy intensive industries are subsidized, while if the low rate is taken as the correct estimate of external costs, there may be no subsidy at all. 



\section{Experiences with subsidy reforms around the world}

The estimates of environmentally harmful subsidies shown in chapter 2.1 indicate an extensive use of such measures around the world. However, over time many reforms have been made around both reducing public spending to environmentally harmful subsidies and reducing environmental tax exemptions/implementing new environmental taxes. This chapter reviews examples of such reforms. Some successful reforms are associated with compensation programs to avoid negative distributional effects. Other reforms have been less successful. In order to understand how to efficiently implement future reforms, valuable knowledge can be gained from earlier experiences.

The studies from the OECD, GSI, EU and G20 environmental subsidy reform studies mentioned in chapter 1 offer a range of examples. We consider these studies the most updated and comprehensive sources. Hence, we have based the review mainly on the literature from these initiatives; The G20 countries (G20 2010; IEA et al. 2010a; IEA et al. 2010b), the Global Subsidies Initiative (Laan et al. 2010), the EU (IEEP et al. 2007; Valsecci et al. 2009) and the OECD (Ekins and Salmons 2009; Hanesson 2006). For each example, the origin of the information is specified. The examples are described in further details in Appendix 2.

The examples show that once in place, subsidies are hard to remove even if the original motivation is no longer present. Over time, the cause for supporting low income groups may fade out, e.g. due to general increases in income, development of alternative labour demand, or demographic changes. For many of the subsidies, it is found that poor households benefit much less than the richer ones. This is an important argument for subsidy reforms. Another pressing aspect is increasing budget costs. Finally, increasing environmental costs and awareness are important driving factors behind subsidy reforms. In particular, many of the subsidies stimulate the use of fossil fuels and hence the emissions of greenhouse gases and local pollutants.

A fundamental reason to the preservation of environmentally harmful subsidies is the opposition from benefitting groups. Removing the subsidies normally provokes significant opposition from pressure groups and political parties. To raise the necessary political support, it is important to produce high quality, reliable information about the benefits and costs, and to communicate that the reform implies net benefits to the society. The typically successful reforms rely on compensatory measures and a 
broad political consensus. If overall consensus is not consolidated, we find examples that setbacks arise when governments change.

\subsection{Subsidies to coal production}

Coal production has been supported in many countries and over decades. The original rationale was based on the need to rationalise the coal industry in Europe, against increasing competition from less expensive imports, or less expensive alternatives (e.g. gas). In the EU, coal is heavily subsidized by governments, particularly in Germany's Ruhrgebiet region, northwest Spain, and Romania's Jiu Valley (World Nuclear Association 2011).

The major drivers of the reforms have been budgetary considerations, reduced perceived need to secure energy independence via coal mining. Coal subsidies inhibit changes in the industry, slow down the transition to renewable and low pollution energy sources, and remove the incentives to develop technologies that lower the pollution content of the fuels in questions.

Subsidies to coal extraction also increase $\mathrm{CO}_{2}$ emissions as they stimulate overproduction of coal and energy consumption. Coal is the most carbon-intensive of the fossil fuels, and it is the fastest-growing carbonemitting energy source. The share of coal related world $\mathrm{CO} 2$ emissions have been growing over time, see figure 6.1. The share was about 40 percent in 2007, and EIA expect the share to increase to 46 percent by 2035 (EIA 2010).

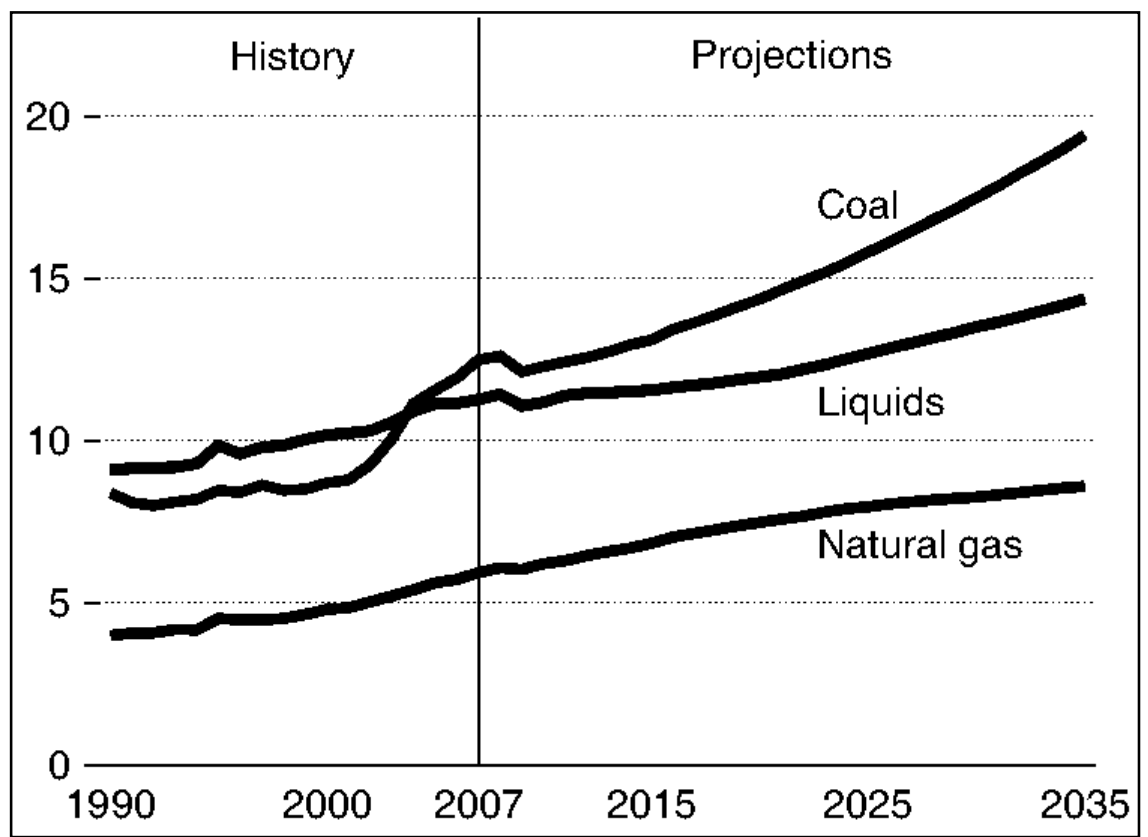

Figure 6.1. World energy-related carbon dioxide emissions by fuel type, billion metric tons.

Source: EIA (2010). 
Over time, several countries have reduced or removed coal subsidies. State aid for coal production was banned starting from the 1952 European Coal and Steel Community (ECSC), but several community legal instruments have allowed multiple exceptions. After 2002, direct state support to coal production was banned in the EU. In 2007, the eight of the EU Member states produced coal: Poland, Germany and Hungary, the UK, Spain, Czech Republic, Slovakia and Greece. France closed its last mine in 2004.

There have been proposals to phase out coal subsidies by 2022, reducing them by one quarter every three years, but some 100,000 jobs are involved. Total aid to the hard coal sector has been halved from €6.4 billion in 2003 to $€ 2.9$ billion in 2008 (World Nuclear Association 2011).

We review the development in coal subsidy policies and reforms in the five countries UK, France, Germany, Poland and Spain (sources: Europe Economics et al. 2006; IEA et al. 2010b; IEEP et al. 2007; Laan et al. 2010). The examples are referred in detail in Appendix 2, chapters 10.2.1-10.2.5.

\subsubsection{Subsidy removals}

Coal subsidy reforms have been attempted and carried through for half a century. In the $U K$, reforms were attempted throughout the 1960s and 1970s. Lack of commitment and political turnover rendered these efforts unsuccessful. The Thatcher government removed the subsidies, meeting significant protests, in the mid-1980s. Since the 1990s the UK has maintained a more or less competitive coal industry.

In France, the reduction of coal production gradually started in the early 1960s, and an agreement to close all remaining coal mines was reached in 1994. Between 1971 and 2000, the state spent around €35 billion on restructuring the coal sector. In 2007, subsidies to the coal sector were largely stopped.

In Germany, hard coal mining has been subsidized for almost half a century. In 2007, the average mining job was subsidized by $€ 75,000$ and coal mining subsidies amounted to almost $30 \%$ of the direct subsidies granted by the government in 2003. Subsidies were reduced by $50 \%$ from 1998 to 2008, and the aim is a complete phase-out by 2018.

Poland started the reform process in 1990. Restructuring provided for a strong emphasis on environmental protection, restructuring programmes, liquidation of consistently unprofitable mines and privatisation of those which turned a profit.

In Spain the dependency on the energy supply industry and contracts it had made with governments enabled its expansion when the rest of the European coal industry was in decline. In 2004, the average cost per tonne of Spanish coal was up to 9 times higher than the imported coal cost. The energy market was liberalised in 1998, with the introduction of a long-term restructuring plan including increased competition. 
Overall, the subsidy reforms have led to significant fall in coal extraction and employment within the coal sector.

\subsubsection{Compensatory measures}

In the $U K$, subsidies were given to stimulate competitiveness of the industry with a viable future and aid to the remaining industry to compete in the reformed electricity market. Support was given to create or safeguard jobs within socially and economically disadvantaged areas. The aid given to those entering unemployment was focused on creating alternative economic activities. This increased the support to the reform and maintain economic growth in otherwise disadvantaged areas. In France, extensive measures were used to promote alternative economic activity in the affected regions. Former miners were guaranteed employment until the age of 45 , when those with at least 25 years of service became eligible for a leave, during which they would receive $80 \%$ of their final working salary until retirement. In Poland, relatively generous severance packages were provided to miners leaving work, based on individual arrangements.

\subsubsection{Evaluation}

The key lessons are that the removal of coal subsidies has proven very challenging due to social consequences. The costs associated with these reforms still the main causes for coal subsidies around the world: employment costs, end fuel costs to consumers and security of supply. Generous compensation packages have proven important to facilitate reform, and gradual removal of subsidy has also helped to minimise damaging dislocation. Mining interests have proven effective at making political alliances. The scale of economic pressures resulting from the subsidies can eventually force reform. Climate policy and environmental pressure groups have become increasing pressing forces the last decades.

As an environmental reform, the restructuring of the $U K$ coal sector is deemed an example of success. It enabled the country to maintain a more or less competitive coal industry, but it was at the cost of extensive mine closures and significant social opposition. A key lesson from the UK experience is that coupling the reform with measures to stimulate economic development, and therefore create new job opportunities in areas where industrial activities are to be scaled down or closed, can increase support to the reform and foster economic growth in the longer run. Strong political will was a key factor.

The French reform required over 40 years to complete and billions of Euros to support the workforce. The continuing subsidies in Germany however, are often used by other countries as an argument to maintain subsidies to domestic coal industry. The subsidies are upheld by strong and organised particular interests connected with electoral power. 
Poland has still a very high extraction rate of hard coal combined with a complex system of export and restructuring subsidies. However, the reforms started out only two decades ago, which is a short time perspective when comparing with the reforms in the UK and Germany. Spain is another example where reforms have been carried out, but the coal sector is still dependent on subsidies, and significant subsidies still remain.

\subsection{Nuclear power subsidies}

Direct and indirect subsidies for nuclear power are given in the EU (Valsecci et al. 2009) as well as in the US (Koplow 2011). The direct subsidies in the EU cover funding for R\&D programs by the EU and several Member States, support for power plant decommissioning, debt writeoffs, provision of site security, and safety oversight. Indirect subsidies involve international treaties limiting full commercial and/or state liability, preferential tax treatment for decommissioning funds and decommissioning subsidies, and guaranteed supply contracts.

Negative effects are radiation and lower energy prices, reducing the incentives of technological development in new energy sources and energy efficiency. As an alternative to fossil energy, there is growing pressure to consider expansion of the industry.

There have been legal attempts to challenge the lack of a segregated decommissioning fund. These legal challenges failed in EU courts. Part of the political agreement in Germany related to the nuclear phase-out policy was to ensure that additional taxes would not be selectively imposed on the nuclear industry.

\subsection{Exemptions from environmental taxes}

Exemptions from environmental taxes are commonly used to support certain industries. The subsidy element consists of the avoided tax payment in the industries with exemptions or lower rates than some agreed benchmark (see chapter 5.1). The exemptions from the eco-taxes in Germany represent an example (see 10.2.6), where attempts have been made to reduce the subsidies. The logic behind the German eco-tax, implemented in 1999, was to internalize the externalities of energy use. The tax scheme contained partial exemptions for enterprises in the manufacturing sector and in agriculture and forestry. Arguments for exemptions have been concerns about competitiveness, the introduction of the emission trading system (ETS) and high energy prices.

The drivers for reducing the exemptions were both environmental and based on competition concerns. 


\subsubsection{Subsidy removals}

In 2003, the German eco-tax rates for businesses were increased from 20 to $60 \%$ of full rate. In 2006 however, new exemptions were introduced, including total exemptions of certain energy-intensive processes from energy taxation. In addition, the reduced eco-tax rates have applied to the entire energy tax rates for heating fuels, i.e. including the petroleum excise duty that already existed before 1999. For electricity and for natural gas and liquefied gas, this means a reduction of $40 \%$; and for heating oil $27 \%$. A key outcome of the reform, however, was the chance of moving towards harmonised energy taxation with a harmonised reduction of subsidies.

\subsubsection{Compensatory measures}

The reform was designed as revenue-neutral with simultaneous increase in energy taxes and lowered payroll taxes.

\subsubsection{Evaluation}

The eco-tax is a step in the right direction for reducing subsidies related non-internalised external costs. The exemptions however represent a continuation of the pre-tax lack of correct incentives. The main reason seems to be concerns about competitiveness in the world markets. Worldwide differences in energy taxation provided the rationale for granting eco-tax exemptions to domestic industries and contribute to the difficulties in reforming the eco-tax. This is a general problem across countries, as any industry can claim the same relative burden as long as any competing country exempts their industries from full externality taxation. The competitiveness problem points to the need for international cooperation in environmental taxation, not only for carbon emissions with global environmental effects, but for all kinds of pollution.

The set-back of the reform also shows that strong leadership on its own it is not a sufficient condition for the reform to endure. A broad coalition supporting the reform is preferable to avoid setbacks. In the German case, changing governments allowed for re-considerations of the eco-tax exemptions.

\subsection{Biofuel subsidies}

Subsidies to biofuels are becoming more frequent (cf. 10.2.7). The EU biofuels Directive requires the members to ensure that a minimum proportion of biofuels and other renewable fuels are placed on their markets. Also in the Nordic countries, biofuel subsidies are given. A variety of measures have been introduced, including preferential tax treatments. 
Production and consumption of biofuels do not imply any obvious positive externalities that justify general subsidies. The reasons most commonly given are to stimulate alternatives to fossil fuels and thereby reduce carbon emissions. Other arguments used are energy security and rural development by stimulating demand for certain farm products.

Concerning environmental effects, the first-best policy to mitigate emissions would be to place correct prices at the polluting energy sources, including biofuels, cf. the theoretical discussion in chapter 4 . Rather, biofuels production involves several negative environmental aspects, such as energy input, fertilizing, clearing of land and loss of biodiversity. Studies from the Nordic countries and literature surveys point to increasing, rather than decreasing, $\mathrm{CO}_{2}$ emissions from biofuel subsidies (Holtsmark 2010, Wibe 2010).

As pointed out by OECD (2007), biofuel subsidies have made little evident contribution to energy security in the OECD countries, in terms of mitigating price spikes and localized temporary energy shortages. Also, as a policy for transferring wealth to people living in rural areas, the efficiency in these subsidies is low, as the instruments are not directed at the target.

Attempts have been made to remove some of the subsidies. This has led to new, indirect subsidy systems, such as biofuel quotas in total energy and green certificates. Such inefficient subsidies can create new problems that are difficult to remove. As an example (see Valsecci et al. 2009), Germany has a relatively long history of political support for biofuels and is currently the world's leading producer of biodiesel and Europe's leading producer of ethanol. In 2006, the German government established a system of gradually increasing taxes on biofuels. The large budgetary implications of the tax exemption secured political support for these reforms, despite domestic industry opposition. However, in 2007 a quota system was introduced, which sought to reduce the impact of the introduction of taxes on biofuels. The system is another form of subsidy, as it sets a minimum requirement of the biofuel content in relation to energy content. In the future, bio methane from biogas will also be considered in the total and the petrol quotas.

\subsection{Subsidies to fossil energy consumption in some low-income countries}

According to the current estimates of environmentally harmful subsidies, consumption subsidies to fossil energy are most used. We review some experiences with consumer subsidies to fossil fuels by looking into the subsidy reforms in Mexico, Indonesia, Ghana, Senegal and Malaysia (sources: G20 2010; IEA et al. 2010a,b; Laan et al. 2010). The examples are referred in detail in Appendix 2, chapters 10.2.8-10.2.12.

Subsidizing energy has been a means of supporting the incomes of low income households. These subsidies amount to significant shares of 
GDP and impose heavy loads on governmental budgets. In 2008, 19\% of government expenditure in Indonesia was devoted to energyconsumption subsidies. Subsidies were reported to have cost the Malaysian government about $4 \%$ of GDP in 2008. In 2004, Ghana spent roughly $2.2 \%$ of its GDP subsidizing fuels and $1 \%$ on support to its national refinery company. In Mexico, subsidies for energy consumption have been equivalent to more than one and a half\% of GDP.

As according to theory, this is an inefficient instrument to support the poor. In Ghana, it was found that the rich received the greatest benefits from subsidies. In Indonesia, it is estimated that only roughly $15 \%$ of the total kerosene subsidy reached the poorest $30 \%$ of the population. Hence subsidy reforms represent great potential benefits in reducing poverty efficiently. Quantification studies of how and to what extent the poor in Ghana would be affected by deregulation were important for the reform support and for designing policies to reduce impacts of higher fuel prices on the poor.

Another cause for the subsidies has been to reduce externalities from other energy sources. This is a well-known problem in western countries today, as non-fossil fuels are increasingly subsidized. In Senegal, the LPG subsidies were originally introduced to reduce deforestation by substituting part of charcoal consumption with LPG. In the long run, these subsidies led to an unsustainable fiscal burden, disproportionate benefits for the relatively rich and fuel smuggling. In 2006, the cost of LPG subsidies amounted to $1.4 \%$ of GDP. It had also adverse distributional effects: the 40 poorest $\%$ of the population gained only $19 \%$ of the total improvement in welfare from the LPG subsidy, while the richest $40 \%$ gained $61 \%$. The IMF has estimated that if conditional cash transfers were to target the poorest $10 \%$ of the population, 58 cents of the expenses would reach people in the poorest quintile of the population compared with 22 cents from the excise tax exemption for kerosene and only 6 cents for the LPG gas subsidy (IMF 2008).

\subsubsection{Subsidy removals}

Mexico is currently reforming its excise arrangements for refined products and the subsidies are expected to be eliminated by late 2012, and retail prices of fossil fuels have gradually increased. It is expected that by continuing current policies under current market conditions, subsidies to gasoline, diesel and LPG will disappear in the medium term.

Indonesia started to gradually liberalize the fuel market in 2005. The subsidies for diesel and fuel oil are completely eliminated and the aim is to eliminate all energy subsidies by 2014. Government expenditure is almost halved from nearly $20 \%$ in 2008. 40 million households shifted their consumption from kerosene to LPG in the period through 2009.

Ghana has made several attempts to liberalize their fuel prices with stepwise rises in petroleum prices to better link domestic with interna- 
tional prices. The reform included a communications campaign and mechanisms that were intended to reduce political interference in fuel prices. In Senegal a phased reduction of subsidies to LPG started in 1998, but the plan was put on hold in 2002 due to increasing global LPG prices, exchange rate variations and inflation, resulting in continuing high subsidies.

Malaysia introduced a broad package of reforms to their energy subsidies in 2008, increasing the energy prices by $24-124 \%$.

\subsubsection{Compensatory measures}

In Mexico, the government has implemented a cash transfer intended to help low-income households cover their energy needs, see box 7.1. This is better targeted at the poor and is formulated to avoid incentives for environmentally harmful increases in energy consumption.

In Indonesia, the government undertook a cash transfer program to 16 million poor families, see box 7.1, the costs amounting to about $0.7 \%$ of GDP. In the continuation, the phasing out is implemented in a gradual manner in order to minimize the spill-over impact on the poor. Incentives are given to use cleaner and more efficient energy such as liquid gas, funding is given to develop the capacity to use renewable energy, income taxes are reduced, the rate of asset amortization is accelerated, import duty exclusions for industries using renewable energies are used, and fiscal disincentives, such as imposing sales tax and value added tax on fossil fuels, are performed. The distribution of subsidized fuel is contained to certain users, for example, by providing a subsidy for poor fisherman to buy fuel in fixed quantities. The price subsidies are transformed to a targeted subsidy through reinforcement of poverty alleviation programs.

In Ghana, the effect on the poor was cushioned by cross-subsidization fuels used typically for cooking and lighting, elimination of fees for staterun primary and secondary schools, support for public transport, extra funds into a health-care scheme for poor areas, increase in daily minimum wage and programs spread electrification to rural areas and purchase essential equipment for workers.

In Malaysia, the government offered cash rebates in the form of lower annual road taxes, windfall taxation on certain sectors and expansions of the social safety net.

\subsubsection{Evaluation}

These examples show that subsidies to energy consumption prove inefficient in targeting income distribution. With positive income elasticities, high income groups use most energy and benefit most of the subsidies. Rather, subsidies should target the distributional concerns as directly as possible. The Indonesian and Mexican experiences highlight the importance of ensuring a suitable compensation strategy for poor, and that this can reduce the impact on government expenditures. At the same 
time, stepped approaches have shown important, with some fuels being tackled later in the reform process. Still, strong political opposition continues to hold back the reform strategies. Also the Malaysian experience underlines the need for compensation packages to meet the negative distributional consequences.

Ghana is an example of the necessity of political foundation and stability. The price-setting regime proved to be only as robust as the political will behind it. The poor were hardest hit, and the reform was suspended during 2003, due to fear of social and political instability in the run-up to elections. After coming into position, the opposing party (NDC) fulfilled its promises from the election campaign and reversed the process by reducing fuel taxes. After that, fuel prices in Ghana were far below corresponding fuel prices in neighbouring countries, leading to a dramatic increase in fuel consumption and smuggling out of the country. Automatic linking of domestic and international prices, without subsequent cross-subsidization, helps preventing politicization of fuel prices. Successful communication and compensation strategies improved public acceptance of the price increases in Ghana, pointing to the necessity of ensuring political support. The protests associated with the 2003 reform were not repeated in 2005. Research to identify those most-likely to be negatively impacted by de-subsidization, information campaigns about the benefits of reform, cash transfers to the poor, and greater independence and transparency of fuel prices are positive factors for the success of subsidy reforms.

Also, energy subsidies to reduce the use of another energy source prove to create new environmental problems, such the LPG subsidies in Senegal used to reduce charcoal consumption. This may be a warning to Ghana, who cross-subsidizes fuels to alleviate the cost effects from reducing petroleum subsidies. Direct measures to reduce environmental damages should be used rather than subsidies to alternatives. E.g. disincentives for the use of charcoal and wood, rather than fuel subsidies, would more efficiently address the goal of reducing deforestation. However, the first-best option is not always possible. If for example no alternatives to the environmentally damaging energy sources are available, the elasticities with respect to demand are small, and it is likely that the only effect would be increased costs to the consumers.

\subsection{Subsidies to energy consumption in some high- income countries}

VAT reductions are a direct and unconditional subsidy to (energy) consumption, see the chapters 10.2.13-10.2.16 in Appendix 2. Several countries apply reduced VAT rates to energy products such as coal, heating oil, natural gas and electricity.

Generally, low VAT on energy has a primarily social objective to protect low-income households. The subsidies due to VAT reduced rates for 
EU households in the beginning of the 90 s are estimated to $€ 7.3$ billion (IEEP et al. 2007). As can be seen from the status in 2007, several more VAT reductions for energy products have existed in earlier decades, see table 6.1. A number of EU countries have abolished VAT reduction for energy products over time past, but still several remained in 2007.

In the Nordic countries, several the VAT rates are reduced for potentially environmentally harmful goods and services, such as for food and drinks, and passenger transport. In Norway, the VAT is totally exempted for energy consumption in Northern Norway and for electric cars.

Table 6.1. Reduced VAT rates for energy products in EU Member States, households, 2007.

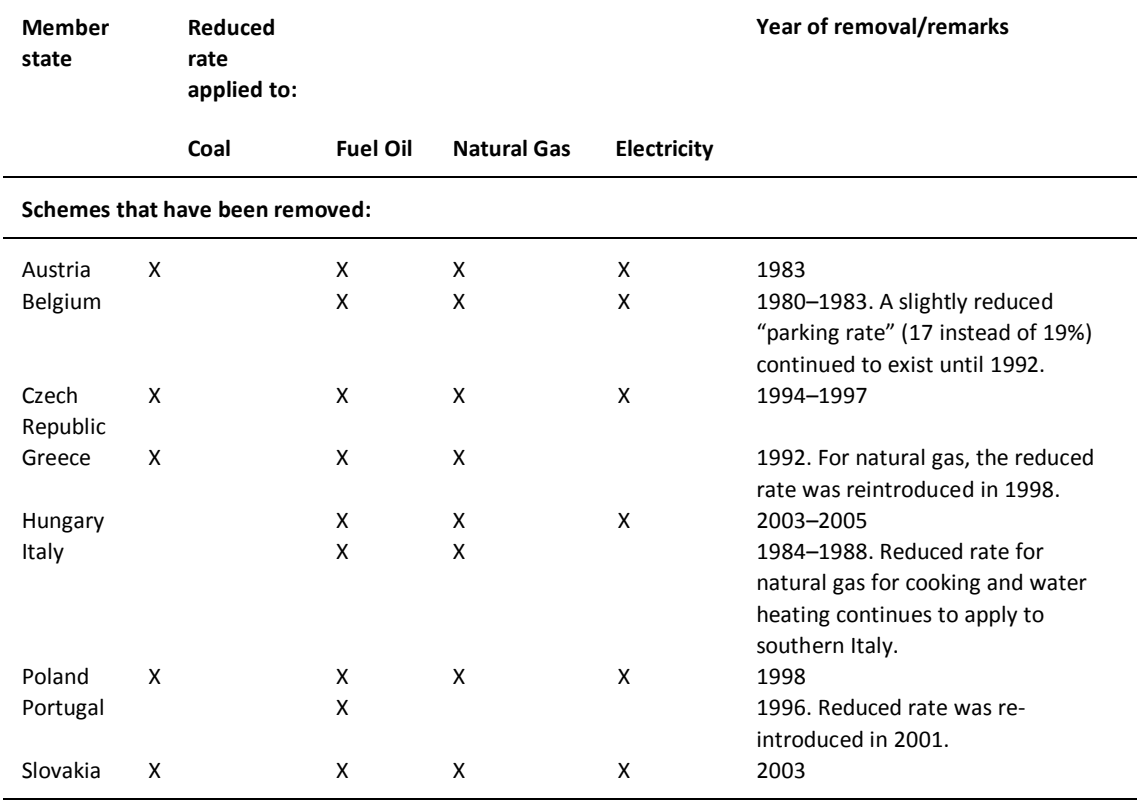

Schemes that continue to exist:

\begin{tabular}{|c|c|c|c|c|c|}
\hline Belgium & $x$ & & & & \\
\hline Cyprus & & & $x$ & & \\
\hline Estonia & $x$ & & & & \\
\hline France & & & $x$ & $x$ & Only on standing charge \\
\hline Greece & & & $x$ & $x$ & \\
\hline Ireland & $x$ & $x$ & $x$ & $x$ & "Parking rate" (13.5\%) \\
\hline Italy & $x$ & & $x$ & $x$ & $\begin{array}{l}\text { Natural gas: only for cooking and } \\
\text { water heating in southern Italy }\end{array}$ \\
\hline $\begin{array}{l}\text { Luxem- } \\
\text { bourg }\end{array}$ & $x$ & $x$ & $x$ & $x$ & $\begin{array}{l}\text { Coal and fuel oil: "parking rate" } \\
(12 \%)\end{array}$ \\
\hline Malta & & & & $x$ & \\
\hline Portugal & & $x$ & $x$ & $x$ & \\
\hline $\begin{array}{l}\text { United } \\
\text { Kingdom }\end{array}$ & $x$ & $x$ & $x$ & $x$ & \\
\hline
\end{tabular}

Source: IEEP et al. (2007).

Several reforms have been performed to reduce VAT subsidies and other subsidies to energy consumption. These examples are found IEA et al. (2010b), IEEP et al. (2007) and Valsecci et al. (2009).

In Poland, the VAT rate for energy products was less than one third of the basic national VAT rate in the early 1990s. Poor households in Poland benefited much less from energy subsidies than the richer ones. The main reason for the reform was budgetary, reinforced by external 
institutions such as the IMF and the World Bank. The $U K$ applies a reduced VAT rate on energy products, providing a subsidy to the final consumers of these products equal to a value of $10 \%$ of product price in 2009. This promotes greenhouse gas emissions, acidification and depletion of non-renewable energy resources.

Another type of subsidies comparable to VAT subsidies, was the price regulation of natural gas in the United States, where natural gas consumers - and producers - were subsidized by allowing producers to charge prices high enough to cover the costs, plus a "fair" profit. This price regulation by the large number of different natural gas producers created extreme administrative burdens. Prices were kept artificially low in 20 years, fuelling a large increase in consumption.

\section{Subsidy removals}

In Poland, starting in 1995, the reform gradually increased the VAT for energy products to bring it into line with the basic rate of VAT. The reform was successful and took place as scheduled.

In the $U K$, attempt at reforming the VAT subsidies in 1995 failed for political reasons. Sense of urgency seems to be lacking, as there are no signs of recent calls for reform.

In the US, deregulation started in 1978, and in 1993, all remaining regulations applying to the well-head price of natural gas were eliminated, allowing the market to completely determine the price of natural gas at the wellhead. The price deregulation spurred production and the replacement of inefficient technologies, encouraging a more rational use of natural gas.

\section{Compensatory measures}

In Poland, compensatory measures were taken for poor families and pensioners, including direct allowances and cheap credit to modernize heating sources. The amounts budgeted for direct compensation payments were generally modest and pertained only to $1 \%$ of all households.

\section{Evaluation}

This Polish case shows that increasing VAT rates can be achieved relatively expediently with a limited need for compensatory payments, even in a country where, at the time, household income was much lower than in most EU Member States. A favourable circumstance was that inflation in Poland was falling continuously from nearly $600 \%$ in 1990 to $7 \%$ in 1999, while real disposable household income was increasing rapidly. This left the share of expenditure on energy more or less unaltered. While this favourable circumstance that may not will repeated, it is an 
example of the potential of passing through reforms in periods with great structural changes.

The $U K$ represents a less successful attempt. Despite the share of energy costs in budget of households has decreased considerably, and other, less distortionary ways of providing support to the targeted households are available, still the political will to reform seems to be lacking. This may be representative for the VAT subsidies in other countries as well; the political costs are judged higher than the environmental benefits.

The process of deregulation in US took many years. The reform was helped by the rising petroleum prices in the mid-1970s, which increased consumers acceptance for the inevitability of higher gas. The reform is an example of how new domestic supplies become available in response to higher prices, which should be kept in mind regarding the present policies subsidizing new renewables.

\subsection{Subsidies to road transport}

The cases outlined in this chapter are discussed in IEEP et al. (2007) and Valsecci et al. (2009). The examples are referred in detail in Appendix 2, chapters 10.2.17-10.2.21.

There are considerable distributional issues related to transport taxes. In particular, heavy goods vehicles put significant stress on road infrastructure. These subsidies are typically indirect subsidies in the sense of lack of full pricing. Subsidies are also given to private work-related transport to commuters. Many EU Member States tax diesel fuel at lower rates than petrol, providing a subsidy for households and firms. Benefits of the subsidy accrue to owners of private diesel-fuelled vehicles, which tend to be wealthier than owners of petrol vehicles. The diesel subsidy disadvantages firms producing petrol and households owning petrol vehicles.

Another form of transport subsidies are support to company cars and commuter subsidies. These are typically used in rich countries, where the losing parts are typically not low-income groups. Company car taxation system encourages car use, with a declining tax rate applied drivers who drove the most. The marginal cost to the employee of driving a company car becomes often close to zero. The provision of company cars has in the EU become by far the most important category of fringe benefits. Commuter subsidies are formulated as deductions for travelling expenses from income taxes, also adding up to significant amounts of foregone eluded revenues. Tax breaks at threshold levels give strong incentives to reach the necessary miles to secure the tax benefits.

Rationales for the commuter subsidies have been to increase access to job markets for people living in rural areas. Another reason, in Germany, was to offset the impacts of Eco-tax reform. 
In their review of Nordic countries, Temanord (2008) argues that tax allowances for commuting between home and work place generally incites to longer transport and higher cost, resulting in more and bigger cars and more mileage. Given according to mileage, transport allowance encourages more scattered habitation and increases $\mathrm{CO}_{2}$-emission and other pollution. They argue that transport allowance should be given independent of the actual cost and only with small regard to distance.

Examples of countries that have this subsidy are Austria, Belgium, Denmark, Finland, Germany, Ireland, Norway, the Netherlands and Sweden.

\section{Subsidy removals}

EU countries have implemented charges to capture some of the costs related to shipping by road. Over the years 2001-2005, Austria, Germany and Switzerland implemented distance-based heavy goods vehicles charges to recover infrastructure costs.

Germany started the reform of its income tax deduction system to be independent of transport mode in 2000, also benefitting public transport users. The per-kilometre rate was increased and the subsidy was limited to travel exceeding 20 kilometres to work. In the Netherlands, the travel cost deduction since 2001 has been restricted to commuters travelling by public transport.

NGOs campaigned against the UK company car subsidies for many years, but were resisted by those benefiting from the system. In 2002, the system was fundamentally changed to be based on a combination of list price and $\mathrm{CO}_{2}$ emissions.

As a result of the subsidy reductions to shipping by road, revenues have increased and there have been a shift over to a user pays principle. Transport efficiency, in terms of haulage load per vehicle has increased and the number of loaded trips, has increased, the growth in road freight has decreased, and there has been a substitution over to rail transport. These changes have decreased associated emissions of $\mathrm{CO}_{2}$ and other pollutants in Germany.

The commuter subsidy reforms in Germany have cut the subsidy almost in half. It has however been criticised by allowing the subsidy only for trips over $21 \mathrm{~km}$ per day, resulting in stronger subsidies to those living far away.

\section{Evaluation}

A strong external pressure on environment and economy has been a key driver of road pricing. Also, budgetary difficulties can be a motivating force for tax or subsidy reform. Still, significant subsidies still remain. Road subsidies are generally spread across both industry interests and strong consumer groups, and reform was made difficult by the trade-off 
between environmental and social considerations. Hence, a strong evidence base has been a key requirement to secure public acceptance and cross-party consensus.

The company car subsidies in EU are also still widespread, and so far only minor environmentally motivated differentiation reforms are done. Key challenges are strong vested interests and lobbies and the lack of awareness of implied welfare loss. The reform in UK is an exception, and a case for example for other countries. A strong evidence base was necessary to convince doubters that change was needed. NGOs campaigned on this for many years, but only when several government departments and progressive companies had been persuaded was it possible to make real progress. Strong leadership and clarity of aims and transparency in implementation have also been important. These are also examples that a gradual approach to reform can be effective and more easily accepted.

\subsection{Aviation subsidies}

Source: IEEP et al. (2007) (see also 10.2.22).

Since the 1940s, the aviation industry worldwide has enjoyed several benefits. Financial support to the aviation industry includes fuel tax exemption, VAT exemptions on international tickets, and duty free sales on non-EU flights and on board. The main arguments for subsidy reforms are to remove relative market distortions to other means of transport and to internalise external environmental costs, $\mathrm{CO}_{2}$ emissions in particular. In the Kyoto protocol, national emission targets exclude international aviation, but will be included in the EU ETS from the start of 2012. The intention is for the EU ETS to serve as a model for other countries considering similar national or regional schemes, and to link these to the EU scheme over time, and to form the basis for wider, global action.

\section{Subsidy removals}

From the start of 2012, emissions from all domestic and international flights on EU airports will be covered by the EU Emissions Trading System. Norway and Iceland have also decided to include emissions from air transport in the system. The Netherlands has been the first EU country to introduce a kerosene tax on domestic flights, contributing to a reduction of the budget deficit.

\section{Evaluation}

Earlier attempts of removing the implicit subsidy to the aviation industry have shown that unilateral actions are difficult to carry through. Consensus at an international level is necessary to ensure coordination and harmonisation of national strategies. As aviation is an international in- 
dustry, competitiveness concerns are particularly acute. It will still be a challenge to reach an agreement at the global level in the long term.

\subsection{Water subsidies}

The environmental problems related to water subsidies are less relevant in the Nordic countries, while particularly pressing in countries with less precipitation relative to population density, see chapter 10.2.23-10.2.25.

Traditionally water subsidies, i.e. lack of full pricing for water services, have been used to increase productivity and enable people to settle in rural areas in many countries. Subsidies to irrigation prove significant in size, and water scarcity is a serious threat in many countries, especially in southern Europe. The subsidies have shown to induce overexploitation of water resources, and to burden public budgets as operation and maintenance costs are not covered, and hence have an equity dimension. Such subsidies can represent incentives for growing water-intensive crops in inappropriate regions, resulting in pollution and depletion of water bodies, water overuse and use of inefficient technologies.

According to OECD (2000), the household sector have moved away from decreasing-block and flat-fee pricing structures and toward uniform volumetric or increasing-block tariff systems. Most countries use two-part tariffs, i.e. with fixed and volumetric components, with the volumetric portion making the largest portion of the total water bill. Many countries use pricing systems based solely on volumetric pricing, with no fixed charge element at all, and even where fixed charges persist, there was evidence of shifts toward the reduction or even abolition of large minimum free allowances.

The examples below discuss water subsidy reforms in the Czech Republic, Australia and Spain, described in Ekins and Salmons (2009), IEEP et al. (2007) and Valsecci et al. (2009).

The pricing of water in the Czech Republic historically covered only a fraction of its cost. In Spain, water pricing is usually based on area size rather than on the actual volume of water used, and therefore does not provide incentives to farmers to improve water use efficiency. This has historically led to a relatively high level of consumption.

Australia offers another typical example, where, prior to the 1980s, the emphasis of was on engineering solutions and on increasing water supply to address shortages. The development of irrigation was explicitly intended to promote rural settlement. During the 1980s, increasing scarcity, rising supply costs and pressure on state budgets led to a number of initiatives, including experiments with pricing reform and tradable water entitlements. Main drivers were environmental and resource management considerations, and efficiency improvements in order to improve competitiveness. 


\section{Subsidy removals}

The introduction of price signal has been necessary to water users aware of the scarcity of the resources.

After 1990, water pricing in the Czech Republic moved from covering only a fraction of the cost to full cost recovery, and the cost had increased by 35 times in 2004. All houses have been provided with consumption metering, creating incentives to efficient use. The Australian reform in 1994 was also motivated full cost of resources, efficiency concerns and to eliminate cross-subsidies and make other subsidies transparent. Consumption-based charges were made for households and firms and cross-subsidies from industrial and commercial users to households were reduced or eliminated.

After the reform, the volume of water consumed in households was about 10\% below the EU average in the Czech Republic. Between 1990 and 1999 water withdrawals decreased by $88 \%$ in agriculture, by $47 \%$ in industry and by $34 \%$ in public water mains. In Australia, the reform led to a decline in both individual water consumption and the unit supply cost of water in urban areas.

In Spain, some attempts in some regions to remove subsidies have been made. In one region, a new water charging structure included both a fixed and variable charge linked to water use, with farmers paying significantly more than under the original area-based approach. These resulted in a $30 \%$ reduction in water consumption.

\section{Evaluation}

The water subsidy reform in the Czech Republic is considered a positive example, as water consumption was significantly reduced. The reform was helped by some particular circumstances, as the former Czechoslovakia witnessed a major political change during the early 1990s. The reform was hence part of the restructuring and shift to a market economy and a gradual recognition of environmental values. Another helping factor was a gradual increase in cost, in step with increasing incomes.

The reforms in Australia and Spain prove less successful. In Australia, the progress has been slow and uneven, and in Spain, attempts have successfully been made in some regions, but several regions still subsidize water consumption. A general problem seems to be that some of the factors that have proven important to the more successful reforms are not used. Both compensation mechanisms and political information and understanding of the benefits seem to have been lacking in these reforms. In Australia, the benefits - reduced environmental damage and improved economic efficiency of water allocation - were diffuse and poorly understood by the public, as were the costs of inaction, and there were lack of consensus on some of the basic scientific questions. Rather, most individual consumers were worse off under the reform than they had been previously. Also, water entitlements were perceived as ac- 
quired rights. Consequently, there was considerable resistance to any reductions in volumetric entitlements. The reform did not address the potential social impacts of the reforms or the need for any transitional support.

Hence, information and compensation measures to low income farmers may help passing water reforms through.

\subsection{Subsidies to agriculture and fishing}

Significant subsidies to primary industries have evolved over decades in both developed and developing countries. As\% of gross farm receipts, the support varied widely, see figure 6.2 , from $1 \%$ in New Zealand to $62 \%$ in Norway in the period 2006-2008, see chapter10.2.26-10.2.28.

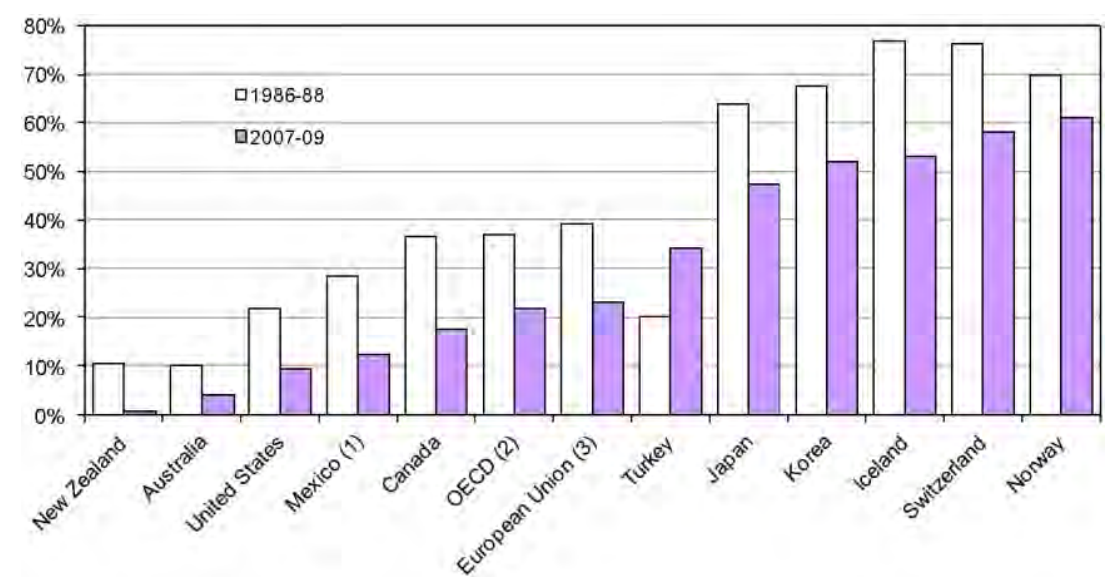

Figure 6.2. Producer Support Estimate by country, 1986-88 and 2006-08,\% of gross farm receipts.

Source: OECD (2009).

In EU, agricultural and fisheries subsidies form over $4 \%$ of the budget. The last decade, the EU's agricultural policy has undergone significant changes as subsidies have mostly been decoupled from production. As seen from table 6.2, the total support to agriculture as\% of GDP have been significantly reduced over the last decades. Note that this measure also reflects the growth in GDP, and the support still remains high in real numbers. 
Table 6.2. Total support estimate, percentage of GDP.

\begin{tabular}{lcc}
\hline & $\mathbf{1 9 8 6 - 8 8}$ & $\mathbf{2 0 0 7 - 0 9}$ \\
\hline Iceland & 5,0 & 1,2 \\
Norway & 3,5 & 1,0 \\
New Zealand & 1,6 & 0,2 \\
European Union & 2,6 & 0,9 \\
OECD & 2,3 & 0,9 \\
\hline
\end{tabular}

Source: OECD Producer and Consumer Support Estimates database,

http://www.oecd.org/document/59/0,3746,en_2649_33797_39551355_1_1_1_1,00.ht ml\#country.

The arguments for the subsidies are usually equity concerns, selfsupport and rural development. The agricultural sector stands for significant emissions to air, soil and water, including emission of greenhouse gases, erosion, deforestation and general over exploitation of resources. Subsidies to primary industries are considered to impose significant costs to developing countries by distorting trade, since foremost rich countries can afford to support their producers. It has been argued that subsidized agriculture is one of the greatest obstacles to economic growth in the developing world. Also, agricultural and fishery subsidies can lead to over exploitation of the resources and directly harm the environment.

In this section, we look into the farm subsidy reform in New Zealand and fishery subsidies in the EU and Norway. The sources to examples are Ekins and Salmons (2010) and Hannesson (2006).

New Zealand is reputed to have the most open agricultural markets in the world after radical reforms started in 1984. Before that, there had been a gradual acceleration in grants and subsidies, adding up to around 30 different forms of assistance. These subsidies caused severe distortions in the sector, with significant excess supply, inflated agricultural land prices and distorted production decisions. In the early 1980s, New Zealand was suffering severe economic problems and substantive economic reforms were needed to increase growth. The agriculture sector was a primary target.

$E U$ fisheries subsidies were first introduced in 1970 with the objective of supporting and encouraging increased fish production. As a result, the fishing industry became increasingly capital-intensive and technologically productive. The increased capacity of fishing fleets was a major factor in the depletion of fish stocks over the following decades. Overall poor performance is due to chronic overcapacity of which overfishing is considered both a cause and a consequence. In Norway, fishery subsidies were about $70 \%$ of value added in the industry in 1981, driven by the strong standing of the fishermen organization and the idea that fisheries were important to keep the fishing communities viable. 


\section{Subsidy removals}

Starting in 1984, Government assistance to the agricultural sector in New Zealand was virtually eliminated over a short time period. Minimum price schemes were abolished, tax concessions and free government services were withdrawn; land development loans, fertilizer and irrigation subsidies, subsidized credit, assistance for flood control, soil conservation and drainage schemes were phased out.

As a result the economic and environmental indicators for the agriculture sector have improved significantly. Phosphate leaching was reduced; the reduction in the national sheep flock yielded benefits for erosion control, water quality and methane emissions; and there was a substantial decline in the felling of native forest. While these benefits were partly offset by the impacts of increases in other agricultural activities, the overall environmental impact was positive.

The $E U$ fishery subsidies have shifted to balance between resources and fishing fleet capacity, strengthen the competitiveness of the sector, foster protection of the environment and natural resources and encourage the sustainable development in areas with activities in the fisheries sector. In particular, the most direct forms of capacity-enhancing subsidies have been phased out. After 1981, the Norwegian subsidies gradually came down, encouraging structural changes that have made a fundament for a self-sufficient industry.

\section{Evaluation}

The reform in New Zealand is considered a success, despite the lack of assistance and despite its relatively rapid implementation. The removal of subsidies was initially unpopular and culminated in the largest rural sector protest march in New Zealand's history in 1986, but still only $1 \%$ of the farmers left the industry and overall rural population rose slightly. As opposed to the recommendations related to reforms in poor countries, the success is partly ascribed to the speed of the reforms, and partly to the state of the government finances. Some assistance was provided in the form of debt rescheduling in 1986-87 and with farm debt restructuring, while the government wrote off some farm debt and encouraged private lenders to do the same. Expert help was provided to help farmers with the development of business plans and credit mediation.

Another important factor was the general consensus among the main political parties over the need for reform - both in agriculture and the wider economy. The reform was implemented to an agreed and transparent timetable - with farmers being given clear signals about the depth, breadth and pace of the reform, and was part of a wider economic reform programme that included measures which reduced factor input prices.

The reform of the fishery subsidies in $E U$ were motivated in both environmental and fiscal causes. New member states joining the EU in 
2004 were poorer than the existing EU15 and had high expectations of support for their fishery sectors. Economic pressures resulting from rising oil prices and falling revenues as a result of the decline in fish stocks resulted in heavy lobbying by the fishing industry to maintain subsidies. Still it is an example of the difficulty of reversing subsidies. The fishery subsidy regime had been in place for several decades, and when the financial periods ended, the presumption was that subsidies would be renewed rather than removed. This is a general problem with implementing subsidies with no clear time limit.

Also the Norwegian support was meant as extraordinary emergency after some years with falling productivity. In addition, the resource wealth in the form of offshore oil and gas deposits discovered in the late 1960s justified the support. Hence, it is an example how the survival of subsidies when the budget constraint is not pressing.

\subsection{Summary: Lessons learned}

This chapter summarizes the main important factors from the review above.

\section{Energy subsidies are inefficient redistribution instruments}

Environmentally harmful subsidies prove to be inefficient instruments to re-distribute wealth and to support regional development. This confirms theory. Several examples show that the rich receive the greatest benefits from the subsidies $(10.2 .9,10.2 .10)$. In Indonesia, only roughly $15 \%$ of the total kerosene subsidy reached the poorest $30 \%$ of the population. Hence subsidy reforms and redistribution of the revenues represent great potential benefits in reducing poverty. In Senegal (10.2.11), the 40 poorest $\%$ of the population gained only $19 \%$ of the total improvement in welfare from the LPG subsidy, while the richest $40 \%$ gained $61 \%$. The IMF has estimated that if conditional cash transfers were to target the poorest $10 \%$ of the population, 58 cents of each dollar spent would reach people in the poorest quintile of the population compared with only 22 cents from the excise tax exemption for kerosene and only 6 cents for the LPG gas subsidy (IMF 2008).

\section{Clear and relevant information is essential}

Good quality information and transparency prove crucial to secure sufficient understanding and public and political support to the reforms in many cases. Some parties will per definition lose, unless they are compensated. Resistance to the reforms is expectedly rather the rule than the exception. The benefits from improving efficiency in the total policy 
mixture must be communicated. As an important part of the information communication, both losing and benefiting parties must be identified.

For example, the two-step reform in Ghana (10.2.10) illustrates that the public acceptance was significantly higher in the second step, when communication was more emphasised. Quantification studies of how and to what extent the poor in Ghana would be affected by deregulation were important for the reform support. The experiences in Ghana along with the coal subsidy reform in France (10.2.2) are pointed out as good examples of research to identify the negatively impacted by desubsidization, and the importance of information campaigns about the benefits of reform, including cash transfers to the poor. The strong evidence base is seen as a key requirement of public acceptance and clarity of aims and transparency in reducing the heavy good vehicle subsidies in Europe (10.2.17). For the successful removal of company car subsidies in England (10.2.20), a strong evidence base was necessary to convince doubters that change was needed. Only when government departments and progressive companies had been persuaded was it possible to make real progress. In reforming the German biofuel subsidies (10.2.7), knowledge about the large budgetary implications of the tax exemptions secured political support for these reforms, despite domestic industry opposition.

Conversely, lacking information has shown to hamper reforms. The setbacks of the removal of the German eco-tax exemptions (10.2.6) illustrate the difficulty of defending the general concept of environmental tax reform to the public and stakeholders, when environmental effects interact. Missing information is a possible explanation to the lacking success of the water subsidy reform in Australia (10.2.24). Most individual consumers faced higher water prices. But the understanding of the benefits were diffuse and poorly understood by the public, as were the costs of inaction. There was also lack of consensus on some of the basic scientific questions.

Missing support may reflect uncertainty about, or a lack of understanding of, the severity and causes of an environmental problem, or the benefits of action. Typically, there is a lack of knowledge about the actual size of the support to energy production and consumption. The policy choice is more transparent if the targets for the budget spending are clearly identified.

Also, as any subsidy reform will have distributional consequences, it is likely that the evidence itself will be contested by stakeholders. This underlines the importance of scientifically objective, transparent and robust information, and that the information is communicated to the public. 


\section{Predictable and clear policy is also important}

In line with relevant information about the costs and benefits to different groups and the society as a whole, it seems important that the reforms are carried through in a clear and predictable manner. Designing and properly implementing an appropriate strategy will improve the chance of successful reform.

A successful example is the agricultural subsidy reform in New Zealand (10.2.26). There was a general consensus among the main political parties over the need for reform, and the reform was implemented to an agreed and transparent timetable - with farmers being given clear signals about the depth, breadth and pace of the reform.

As illustrated by Laan et al. (2010), countries without a comprehensive strategy, such as Indonesia (10.2.9) and Senegal (10.2.11), flounder in their efforts to eliminate fossil fuel subsidies. Any reform strategy should include effective mechanisms to prevent backsliding, such as independent regulation of fuel prices, automatic price-setting mechanisms, and education of decision-makers and the public about the problems with government intervention in externality pricing.

A coherent reform policy establishes a timeframe for implementation, and includes information on complementary policies to offset undesired secondary impacts. A broadest possible political support reduces the risk of political parties working against the reform in the implementation phase. International political consensus proves important particularly for reforms involving competitive export industries, such as aviation (cf. chapter 6.8) and to justify increasing costs of addressing global warming.

\section{Strong political will and stable political power strengthen reform}

Many examples show that strong leadership and a broad coalition are necessary factors to secure successful subsidy reforms. Appropriate and conductive institutional frameworks are key factors. Conversely, the absence of a constituency for reform can be a major factor undermining the successful adoption or implementation of environmental policy reforms.

As an example, the successful coal subsidy reform in England (10.2.1) is partly explained by privatization and strong political will following the Thatcher period, who managed to drive reform through. The heavy good vehicle subsidies in Europe $(10.2 .17,10.2 .18)$ point to the need for strong leadership, cross-party consensus to reach broad public acceptance and overcome opposition.

As another example, the use of economic instruments in the Dutch water pollution control policy was a great success, while similar reforms executed in Germany and Denmark were less successful due to manipulations of local authorities (Andersen 2001). 
Other examples of weak political foundation are many. Laan et al. (2010) refer to the example of Ghana (10.2.10) which demonstrates that a reform strategy will only be as robust as the political will to carry it through and uphold it. Due to lacking political acceptance, the change in policy regime opened for reversing the reform. Governments can always override the regulator's decisions and laws can be changed. The Senegalese government appears to have the will for reform of their fossil fuel subsidies, but could potentially benefit from a more systematic and comprehensive set of policies to support de-subsidization (10.2.11).

The commuter subsidies in Europe have been popular among a broad range of the population, and prove hard to remove (10.2.19). The same problem prevails for the company car subsidies (10.2.20-10.2.21). Lacking support may be due to the many opponents among commuters who benefit from the tax deductions, with only the pressing need to close large budget deficits providing sufficient political will to reduce the subsidy. As pointed out by IEEP et al. (2007), budgetary difficulties can be a motivating force for tax or subsidy reform.

The difficulties in removing the coal subsidies in Germany (10.2.3) are partly explained by the strong links between particular interests and political parties. Considering the attempt to eco-tax in Germany (10.2.6), it is seen likely that re-election gave momentum to reform plans that already existed earlier, and changing governments allowed for reconsiderations of the eco-tax exemptions. Also, the lack of VAT subsidy reforms in the UK (10.2.14) is explained by a lack of political will.

\section{Compensation is often necessary}

Compensatory measures have proven to be of crucial importance in many of the successful reforms around the world. Particularly, this is important in the low income countries, where the subsidies may constitute a significant portion of their income. For example, the Indonesian fossil fuel subsidy reform (10.2.9) highlights the importance of ensuring a suitable compensation strategy for poorer sections of the community, and at the same time reducing the impact on government expenditures. In Malaysia (10.2.12), several compensation packages were used to mitigate increased costs. The fossil fuel subsidy reform in Mexico (10.2.8) is an example of how to improve price signals and reduce the environmental costs, and at the same time compensate the social groups initially targeted. Lack of compensation is a possible reason why water subsidies are hard to remove in Spain (10.2.25).

Also in higher income countries, different kinds of compensations prove important to get the necessary political support, and to avoid significant social costs. In the successful agricultural subsidy reform in New Zealand (10.2.26), the subsidy reductions were part of a wider economic reform programme that included measures which reduced factor input prices, to mitigate the increasing costs. A key lesson from the UK coal 
subsidy reform (10.2.1) is that coupling the reform with measures to stimulate economic development, and therefore create new job opportunities in areas where industrial activities are to be scaled down or closed, can increase support to the reform and foster economic growth. In France (10.2.2), the expansion of nuclear-based electricity generating capacity and the generous provisions offered to the former miners helped making the closure of all the coal mines possible. Also, the Dutch tax increase on natural gas was followed with reduced personal income taxes (10.2.16). Consequently, gross wage levels rose, and the large majority of households saw an overall increase of net disposable income.

\section{Timing can be essential}

Changing economic conditions with high economic growth are good starting points for reforms. It is easier to implement a reform when the economic outlook is good. Also, environmental considerations increase with economic growth, and can play a major motivation role determining the success of reform. The political and economic change in 1989 from communism to a market economy allowed changes in the mining sector and the reform of government subsidies to the sector in Poland (10.2.4). While inflation was falling continuously from 586\% in 1990 to $7 \%$ in 1999, real disposable household income was increasing rapidly. These favourable circumstances also created room for reducing the VAT subsidies in Poland (10.2.13).

Another experience is the removal of fishery subsidies in Norway (10.2.28). This reform was helped by the sharp decline in oil prices in 1986 and the upturn in both catch and fishery prices in the years after 1990. However, economic growth or lack of budget constraints can also be used as arguments for keeping the subsidies high. The national wealth from offshore oil and gas deposits in Norway discovered in the late 1960s kept up the fishery support for many decades.

The removal of natural gas subsidies in the US (10.2.15) is also an example of a reform being pressed forward by the economic realities. The consumers accepted the inevitability of higher natural gas prices after dramatic price rises in the petroleum markets.

\section{Gradual approach?}

Several of the examples from the subsidy reforms point to the importance of gradual changes. This may be particularly important when significant compensation is needed to avoid transition to poverty when removing subsidies. For example, IEA et al. (2010b) judged it important to provide a stepped approach to the Indonesian fossil fuel reform (10.2.9), with some fuels being tackled later in the reform process, and to focus on changing household behaviour. Also, the Czech water reform 
(10.2.23) approached a gradual increase in cost in step with increasing incomes, limiting the impact.

A gradual approach may contrast some of the experiences mentioned above, since long time tables can be exposed to shifting governments and mobilization of pressure groups. A contrasting example is the agriculture reform in New Zealand (10.2.26). The reform was carried through rapidly, over just a few years, and was followed by the other important success criteria as mentioned above; clear information and alleviating measures. In contrast, the French coal subsidy reform (10.2.2) took a long-term, gradual approach to help the miners and the economy to adapt. Still Laan et al. (2010) conclude that the deregulation is not an example of best-practice, as it required over 40 years to complete and billions of Euros to implement. Also, in Spain (10.2.5), significant subsidies remain almost 20 years after reforms started. 


\section{Compensation}

\subsection{Justifications for compensation}

Removing environmentally harmful subsidies often takes time, and in many cases significant social support is taken away from needy groups in the population. Without compensation, social costs could be very high, and political protests and opposition would stop reform. In many countries competitiveness concerns and regional interests reforms may also halt reforms and require compensation for subsidy removal. There are no general rules for if and how to compensate subsidy removals. Countries must evaluate the social needs, the political situation, and the need for adjustment periods in each case.

However, systematic evaluation is important to avoid unnecessary public spending and continuation of harmful subsidies. In this chapter we systematise the justifications for compensation along theoretical lines and point to some examples of compensation schemes related to the different justifications for support.

The theoretical justification for compensation, i.e. public support, is principally the same as for subsidies, cf. chapter 4.1; to correct for income distribution inequity and to correct for market failures. When it comes to environmentally harmful subsidy reforms, compensation is first of all justified in income redistribution. Also, compensation can be justified to help the reform through political processes in a temporary period.

\subsection{Income distribution inequity}

As seen in the examples in chapter 6, when removing fossil fuel subsidies in low-income countries, there are obvious needs for compensation. The original cause for the subsidies to consumption of energy is usually to support poor households. Formulation of efficient support programs is then a core part of the reforms. For rich countries, however, the need for compensation is generally more questionable.

The general rule is that compensation should be given as directly to the targeted group as possible. Direct income support targeted at the low income groups is far more effective than support via low energy prices. Energy consumption increase with income, and energy subsidies primarily benefit those using most energy. 


\section{Possible compensation policies}

Broad based social support programs may be most relevant to use when removing general subsidies covering large income groups, such as to fuel oil consumption. Examples of relevant direct transfer to low income groups are:

- Cash transfers, given as lump sum financial support to low income families

- Food-based programs, such as supplementary feeding programs and food stamps, vouchers, and coupons

- Support to health care and education

Successful examples of such programs in combination with removal of environmentally harmful subsidies are the Bolsa Familia program in Brazil, the Oportunidades program in Mexico, cash transfer programs in Indonesia (see box 7.1) and in Ghana (chapter 10.2.10). These examples are consistent with other studies showing that developing countries can transform environmentally harmful subsidies to comprehensive social protection packages efficiently targeting the low income groups. Other examples are the severance packages and direct aid provided to Polish, UK and French miners leaving work in the restructuring of the coal sector $(6.1,10.2 .1,10.2 .2,10.2 .4)$.

The Bolsa Familia program in Brazil represents an example of instruments targeting the income distribution problems directly, and at a low cost. Launched in 2003, the program provides income support to poor families, subject to their fulfilling of certain human development requirements, such as education participation and health programs. Examples are child school attendance including participation in supplementary socio-educational activities, vaccinations, nutritional monitoring, prenatal and post natal tests (ILO 2009a). Victims saved from forced labour automatically receive unemployment benefits, and those who have children are enrolled in the conditional cash transfer programme.

Bolsa Familia is the largest conditional cash transfer programme in the world. By the end of 2008, it had reached a quarter of Brazil's population (around 46 million people) and around $75 \%$ of the estimated number of poor families, corresponding to an annual cost of $0.4 \%$ of the GDP (ILO 2009a). The program is considered to have contributed strongly to the improvement of income distribution and to poverty reduction, and to be more efficient compared to other cash transfer programmes because of its targeting features (ILO 2009a). The Gini coefficient is a measure of the inequality of a distribution, a value of 0 expressing total equality and a value of 1 maximal inequality. ${ }^{1}$ From 2001 to 2007, the Gini coefficient declined from 0.6 to 0.55 , which was the lowest rate in the country's recent history. The social security pension transfers represent a high share of overall family income and accordingly impact income distribution.

Box 7.1: Examples of broad based support programs in combination with reductions of subsides of fossil fuel consumption. 
The program has improved the job market and resulted in real gains on the minimum wage. Rural pensions have strengthened the role of the unions and political associations representing rural workers in the rainforest.

The Brazilian experience is consistent with several studies and simulations carried out by ILO (ILO 2009b) that show that developing countries can afford to build appropriate and relatively comprehensive, even if basic, social protection packages.

The Oportunidades program in Mexico is their main anti-poverty program (described in IEA et al. 2010a). It targets human capital, i.e. education, health and nutrition of children. The distribution mechanism is cash transfer and health clinic visits. Another program in Mexico stimulates employment in rural and small communities. When labour demand is low and opportunities are few, work is provided in projects typically related to infrastructure and environmental preservation. This program is used to compensate reduced energy subsidies in Mexico, see chapter 6.5.

The Cash transfer programs in Indonesia are successfully designed targeted cash transfers that were adopted simultaneously with the fuel price increases in 2005 (IEA et al. 2010a). The Unconditional Cash Transfers program covers 19.2 million households, or one third of the Indonesian population. The government budget savings from the reduced cost of fuel subsidies (6.4), was estimated to be about $\$ 10.1$ billion in 2005-2006. The program delivered benefits covering more than the increase in energy costs. This served to increase the level of assistance for the poor and those on the verge from falling into poverty, and to make fuel price increases acceptable. The government also used the savings to finance programs in education, rural development, and health. The poorest deciles received $21 \%$ of the benefits, while deciles 2, 3 and 4 captured 40\%. IEA et al. (2010a) conclude that the program proved largely successful in reaching the poor.

Box 7.1 (continued): Examples of broad based support programs in combination with reductions of subsides of fossil fuel consumption.

High income countries offer other types of examples of direct income support. The Nordic countries are characterized by high income and well-functioning income tax and social support systems and an extensive social security net. The elements in the Nordic system can be possible models for other countries with more common use of environmentally harmful subsidies. Core instruments are:

Diversified income taxation. This is a textbook example of a direct measure to prioritise low income groups. E.g. the Norwegian income taxation is progressive, with a marginal tax of $0 \%$ for low income and increasing to maximum 54\% (employers' contribution included). Differentiation of this tax is also used to stimulate regional employment. There are several examples of gradual shifts from taxation of labour to taxation of polluting activities, e.g. in Denmark and Finland (c.f. chapter 3). The German eco-tax reform (10.2.6) was accompanied by lowered payroll taxes. Another example of diversified income taxation to compensate tax 
expenses are increased basic tax allowances following increases in taxes, c.f. the increase in electricity and heating oil taxes in Norway, and general pollution taxes in Sweden (chapter 3).

Public health insurance, pensions and social security. Pensions and social security are seen as the core fundaments in the social security net, securing the fundamental support to persons who do not receive employment income. The schemes are corrected for income, private capital and family situation.

Unemployment benefits. The labor market is also dominated by institutions including strong labor unions and employer associations, significant elements of wage coordination securing minimum incomes.

These schemes offer support to the individuals in different life situations when they are not able to, or have lower ability to self-support.

Capital taxes, heritage taxes and property value taxes are also instruments to secure public revenues and to redistribute wealth.

\subsection{Market failures}

Beside income distribution, the willingness to prioritize externalities increases with higher income. For example, cultural, landscape and historical values are typical common goods providing welfare to the society, beyond what is profitable according to pure market behaviour. A larger share of the budgets to support the development in rural areas may express increasing valuation of such positive externalities not taken care of in the market. Continuation of support to e.g. regional settlement and development can be theoretically justified if there are positive external qualities related to regional settlement and activity. The existence of positive externalities (not accounted for in the market) related to competitiveness for certain industries is more questionable. Often it is a means to maintain long-term employment and regional settlement, to secure full employment or the trade balance.

Again, the general rule is that the positive externalities should be corrected as directly as possible. If rural settlement implies positive externalities, the support should ideally be given to general activities linked to the actual areas, and in particular; it should not be earmarked at specific industries or households. Likewise, if the subsidy reforms reduce production in some industries and hence increase social costs related to unemployment, the first-best instrument should be directed at stimulating new activity in general, not particular industries. ${ }^{9}$

${ }^{9}$ Also, supporting specific industries directly is generally incompatible with international trade agreements (cf. the EU/EøS regulations). 


\section{Possible compensation policies}

General support over governmental budgets. Lump-sum support can be distributed to the local municipalities for their own distribution according to their preferences. The income system for Norwegian municipalities serves as an example. This system is meant to even out the differences between the different regions. Municipalities with low incomes, high population growth, and high level of decentralization are particularly emphasised.

Based on own incomes and governmental support, local politicians can stimulate regional development by prioritizing local infrastructure to attract new industries over municipal budgets.

The government can also stimulate regional development over the governmental budgets by investing directly in infrastructure, culture, decentralization of governmental institutions, supporting health care and social support programs.

\subsection{Adjustment policies}

As shown in the many examples in chapter 6, removing environmentally harmful subsidies requires time and patience. Normally, it takes a long time before the problems are acknowledged until reform starts up, and there will normally be a long transitional period toward a more efficient policy mix. It is therefore important to accept stepwise progress through second best solutions (where one or more optimality condition cannot be satisfied).

For instance, compensation can be needed as means to reach political support for the reform. It can also be necessary to alleviate adjustment costs in the intermediate period to the after-subsidy regime. If the justification is temporary adjustment, it is important to use temporary instruments, followed by a clear time-table for phasing out the support. In particular, it should be avoided to substitute one harmful subsidy by a new inefficient policy that shows difficult to remove in the long run.

Stepwise progress could be carried through by partial removal of subsidies. Two-part tariffs and intermediate compensation schemes may be second best solutions to total removal of the subsidies. Two-part tariffs can be used to secure a subsidized minimum consumption at low price, while the remaining consumption is subject to market prices. Such tariffs may be formulated as a lump-sum fee as well as a per-unit charge. Many water utilities around the world apply two-part tariffs where a volumetric tariff is combined with a fixed charge. The latter may include a minimum consumption or not. Two-part tariffs have also been used in the energy market (cf. the Norwegian electricity market up to the 1980s), with a low energy price below a certain consumption level, and a higher rate below this level. 



\section{Recommendations}

The survey of reform experiences outlined in chapter 6 clearly shows that each case is different. How to manage the reforms from environmentally harmful subsides to more sound policy must be considered separately for each case. Particularly, there are great differences between low-income and high-income countries in several respects; the need for subsidizing low-income groups is higher in low-income countries, the budgetary burdens of the subsidies are higher, the effects of pollution and environmental degradation more severe, and the political systems less able to handle the needed changes effectively. Bearing these important differences in mind, we will summarise some core steps in the direction of optimal environmental policy.

The general recommendation is to get the prices right, at the same time as compensating the low-income groups the environmentally harmful subsidies were meant to support. A total reform of environmentally harmful subsidies in many cases involves a two-step policy procedure. First, direct subsidies should be removed. The costs of subsidies to energy consumption pose the heaviest burdens on low-income countries. For example, subsidies to fossil fuel consumption are in general granted to support households. Such subsidies stimulate the related emissions, instead of reducing them. When reducing subsidies, compensation to low-income households is usually necessary in low-income countries.

Second, environmental taxes must be added and other, indirect subsidies should be removed. While this is a long step for countries who should first remove the budgetary subsidies to fossil fuel consumption, it is a more nearby challenge for high-income economies. Importantly, by getting the prices right, the resources are effectively utilized. More correct prices will help growth in low-income and improve the possibilities to support the poor. Besides, subsidies in terms of low energy prices first of all support those using most energy, which proves to be higher income groups.

Hence, by getting the prices right, we mean to 1) reduce the inefficient subsidies, 2) implement taxes on environmental externalities and reduce tax exemptions for existing taxes and 3) implement redistribution of income as closely to the prioritized groups as possible to avoid disturbing other parts of the market. 


\subsection{Identify the environmentally harmful subsidies}

While many environmentally harmful subsidies are already identified (cf. examples in chapter 2.1), costly subsidies may survive due to lack of knowledge about their effects. Particularly this is true for indirect subsidies, where it is difficult to trace the interacting effects and the legitimate purposes are often unclear. Indirect subsidies are used in all economies, but indirect environmentally harmful subsidies may be relatively most important in high-income countries. Then general mappings with no predefined subsidies in mind are relevant. In the practical mapping of subsidies, guidelines are formulated in the on-going works by e.g. GSI (2010).

A strong information base and spread of information are also important both to formulate an efficient policy reform, and to attain the necessary public and political support, cf. chapter 6.11. Hence, an important step is to identify the inefficient subsidies and the environmental costs they cause. This should take the theoretical perspective as point of departure (cf. chapter 4.2 and Appendix 1) and implies a thorough revision of the complex subsidy policies, cf. the identification of subsidies outlined in chapter 5 . The identification procedure principally implies revealing three main categories of inefficient subsidies (cf. chapter 4.2):

A. The first category comprises the direct subsidies to factors expected to cause negative environmental externalities

B. The second category comprises the subsidy elements due to lack of, or exemptions from, environmental taxation. This implies a thorough revision of the environmental externalities in the economy and the associated environmental taxes and regulations

C. Finally, other inefficient subsidies stimulating negative environmental externalities can take form of e.g. income and price support, preferential market access, exemptions from governmental standards (see table 5.1)

Note that by inefficient subsidies, we mean subsidies other than those that efficiently correct for positive externalities or efficiently correct for distributional issues.

\subsection{Estimate the environmental and economic costs}

To estimate the costs of the environmentally harmful subsidies, principally each form of subsidy must be evaluated. The analyses should cover three main types of costs: Environmental costs, budget costs and economic costs (see chapter 2.2). Estimates of environmental and economic costs and benefits form a basis for which reforms to prioritize.

The increase in costs due to the subsidies should be measured relative to the theoretical ideal. Due to complex interaction between sectors, 
such cost estimates are not straightforward. Subsidies to one recipient imply protection from competition and costs to the discouraged sectors. The analytical tools may be poor in many of the countries with the largest problems concerning environmentally harmful subsidies. Bearing this in mind, the costs should ideally be estimated within computable general equilibrium model frameworks if available. This would offer an aggregated cost picture, including the economic effects of the alternative products or discouraged technologies, and the total emission effects following changed relative prices. If such analytical tools are not available at sufficient detailing levels, estimates may rely on partial analyses.

\subsection{Evaluate the need for compensation}

To evaluate the need for compensation, the groups losing from the subsidy removals must be identified. In some cases, losing groups are easy to identify, cf. the subsidies to fossil energy consumption, while the groups affected by indirect subsidies may may be harder to identify. To identify the groups that potentially should be compensated, one method could be to identify and assess what groups benefit from the subsidies. This helps to reveal what political goal, or which groups were originally meant to be supported, and whether the support is still valid. This is a natural part of estimating the effects of the environmentally harmful subsidies discussed above. Another method is to revise political documents and/or interview politicians to gain understanding of the original political goals of the subsidies.

If the original intention of the subsidy with respect to re-distribution of income still prevails, if the subsidy removal has adverse social impacts, or if the social benefits are not fairly distributed, it can be argued that compensatory measures should be part of the reform. Compensation can also be justified to mitigate transitional costs and to secure political support for improved market efficiency in the longer term.

\subsection{Formulate the reform}

The reform generally implies the following elements:

1. Reduction/removal of environmentally harmful subsidies

2. Compensating measures

3. Time plan

The main part of the reform, the removal or reduction of environmentally harmful subsidies (1), may target existing subsidy instruments, and/or imply introduction of new environmental taxes. The new policy 
instruments should be formulated as closely as practically possible to the economic guidelines for regulation of externalities.

Broad based social support programs may be most relevant compensation schemes (2) when removing general subsidies covering large income groups, such as subsidies to energy consumption. Lump sum cash transfers, food-based programs and support to health care and education are examples of relevant direct transfer to low income groups. Successful examples of comprehensive social protection packages efficiently targeting the low income groups in combination with removal of environmentally harmful subsidies are the Bolsa Familia program in Brazil, the Oportunidades program in Mexico, cash transfer programs in Indonesia (see box 7.1) and in Ghana (chapter 10.2.10). Other examples are the direct aid provided to miners leaving work in the restructuring of the coal sector in Europe. Unemployment benefits can be used as direct measures to counteract the negative social effects of closing down polluting industries.

Further, diversified income taxation is a textbook direct measure to prioritise low income groups, and this instrument could be used if the subsidy removal has negative effects on low income groups in higher income countries. Health care, pensions and social security secure the fundamental support to persons who do not receive employment income.

If regional compensation is justified, lump sum support could be given to general activities in the actual regions, for example as general support to the local municipalities or as investment in infrastructure, culture, or decentralization of governmental institutions.

Compensation to reduce income effects are generally of a more permanent character than support in transitional periods aiming to leave room for adjustment, develop new production and employment or to secure political support. Since compensation measures prove difficult to remove, it is important to give clear signals when the time period is meant to be temporary, to avoid new, long-lasting inefficient instruments subsidies.

A good time plan (3) is important to secure adaptation of the involved parties to the changing economic frameworks, and to reach understanding and political support to the reform.

\subsection{Communicate the reform}

As argued in chapter 6.11, good communication about the reforms is a general factor helping the reform processes. An important challenge is to increase the common understanding of the benefits relative to the costs from correct pricing of environmental damages. The costs to environment and public budgets resulting from the existing subsidies must be communicated, as well as the estimated benefits from a reform and the potential compensatory measures. 
It is likely that the evidence will be contested by groups losing benefits, and solid, scientific and transparent calculations should be communicated. Generally, tax reforms, such as removal of environmental tax exemptions, increase in the polluters' costs. Industries may have to shut down, and often interest groups mobilize and argue in favour of preserving work places, tax incomes and export interests. Evidence suggests that the more environmentally damaging industries not only receive greater trade protection than other industries, but also face laxer environmental controls (OECD 2005). This reinforces the tendency to lobby more intensively when faced with multiple regulations, and is consistent with empirical evidence (OECD 2005). Taxing energy externalities may also affect households negatively. Particularly, costs will increase if tax exemptions or subsidies were meant as to distribute income.

Politicians are generally hesitant to implement new tools with any losing parts, and all parties involved may try to influence the policy responses to their own benefit. The information about consequences are generally asymmetric, as pressure groups and other competing political parties advocate the negative effects, while the positive, yet unseen effects of e.g. environmental taxation is harder to argue for. Hence, the majority of the public opinion is not always in favour of correct pricing of the external costs. This is reflected in the political representation, and explains why policy does not follow economic advice.

Even if the necessary political consensus exists, the politicians may be reluctant to direct budget support, as money transfer to low income groups may stigmatize certain parts of the population or seem unfair to the less supported groups. Instead, indirect subsidies covered under alternative political goals blur the impression of what groups are preferred. For instance, the support to energy production may be communicated as climate policy while the politicians see it as regional industry support. Also, direct support to industries can be difficult due to international trade legislation. Instead, indirect support as tax exemptions and subsidies can be more politically attractive. Information about the benefits of removing the environmentally harmful subsidies and the rationale for possible compensation measures are crucial to help the politicians overcome such barriers.

Likewise, the effects of the compensation measures must be communicated. It is generally important to understand the rationale for the compensation, since these in general are normative equity considerations, cf. chapter 6.11 .

Finally, the time plan must be as clear and transparent as possible, allowing the economy to adjust. The need for long term adjustments must be weighed against the higher costs and political uncertainty associated compared to rapid completion of reforms. 


\subsection{Correct for negative side effects}

If the reforms provoke new negative environmental effects, these should be corrected for directly by implementing correct prices or regulations. Adverse effects are often used as arguments against reforms. For example, the attempts to remove the biofuel subsidies implicit in the tax exemptions in Norway were contested on the arguments that fossil fuel consumption would increase. Rather, the optimal policy will be to remove the biofuel subsidy and secure correct prices on emissions from fossil fuels.

\subsection{Avoid new types of inefficient subsidies}

Care should be taken to avoid the development of new environmentally harmful subsidies. Recent examples are subsidies to other energy sources than fossil fuels. Support to research and development is correct as long as there are positive externalities associated with the activity, cf. 4.1. Mature renewable technologies however, do not involve positive externalities and do hence not require subsidies. As all energy production imply some sort of environmental pressure, all subsidies to mature energy technologies bring along negative externalities. Rather than subsidizing the fossil fuels alternatives, carbon emissions should be efficiently managed by carbon prices and/or emission trading systems. Another goal related to renewable energy is employment. Rather, the labour market should be stimulated by direct measures. The IEA estimates that worldwide government support to renewable electricity and biofuels (subsidies for renewable heat technologies and low-carbon energy technologies such as CCS) amounted to $\$ 57$ billion in 2009 , increasing from $\$ 41$ billion in 2007.

When transitional consequences are large, alleviating support to industries, the labour market or specific groups may be needed, or compensatory measures are necessary to overcome political barriers to reform. It is important that the creation of such subsidies has credible "sunset clauses" that ensure they are phased out in the long term, preventing them from turning into new sources of market inefficiencies. 


\section{Concluding remarks}

Environmentally harmful subsidies obviously contribute to significant environmental costs and pose heavy burdens on public budgets around the world. The potential gains from reducing such subsidies seem to be highest in low-income countries. The existing estimates particularly concern subsidies to consumption of fossil fuels. However, the estimates do not at all cover the total environmentally harmful subsidies, including tax exemptions and reductions and indirect support to polluting activities. To get a full picture of the costs related to such subsidies, there is a need for further estimates of the subsidies inherent in general governmental policy around the world. For instance, there is little insight into these numbers also in the Nordic countries.

To form a good basis for future environmentally harmful subsidy reforms, the framework for what subsidies to include should be developed and be closely linked to the theoretical definition, taking the first-best solution as the reference. The mapping should be extended to include more of the tax exemptions/lack of externality taxes and other implicit subsidies, in addition to the fossil fuel subsidies already investigated.

The existing estimates and common knowledge of the policies indicate that the problem decreases by income. It is a question then, whether the economies with the most pressing subsidy problems can learn from high income economies such as the Nordic countries. The social security systems within the Nordic model offer several possible compensation alternatives. However, other factors may be as important. Transparent information and communication about the benefits from environmental harmful subsidy reforms are crucial to get political support and to be able to implement the reforms. Compensation is another factor, but not always necessary. Environmental regulations can also be successfully be accompanied by policies promoting industrial restructuring and creation of new economic activities, such as policies supporting education, $R \& D$ and cutting regulations of industries that hamper change and growth.

Also, the Nordic welfare state model is reflected in relatively high tax levels. The social security system highly relies on these incomes. Thus, the relevance of applying the model to other countries requires relatively high incomes. As the average income levels increase, it is likely that the environmental qualities become more valued in all economies. This creates room for combined environmental taxes and compensation in terms of increased direct spending to social groups. 



\section{References}

Abouleinein, E.-L. and Kheir-El-Din (2009): The impact of phasing out subsidies of petroleum energy products in Egypt, The Egyptian Center for Economic Studies.

Andersen, M. S. (2001): Economic instruments and clean water: why institutions and policy design matter, OECD, http://www.oecd.org/dataoecd/48/14/1910825.pdf

Andersen, T. M., B. Holmström, S. Honkapohja, S. Korkman, H. T. Söderström and J. Vartiainen (2007): The Nordic model. Embracing globalization and sharing risks, The Research Institute of the Finnish Economy (ETLA), Helsinki, ISBN 978-951628-468-5.

Braithwaite, D., S. Soelaiman, G. K. Wiroyudo, H. Trimurdadi, S. Soeleman, S. P. Utomo, P. A. Rakhmanto (2010): Fossil fuels - at what cost? Government support for upstream oil activities in Indonesia, The Global Subsidies Initiative (GSI) of the International Institute for Sustainable Development (IISD), Geneva, Switzerland.

Bruvoll, A. (2009a): Måling og feilmåling av miljøavgifter, Økonomiske analyser 3, 36-42.

Bruvoll, A. (2009b): On the measurement of environmental taxes, Discussion Paper 599, Statistics Norway.

Bruvoll, A. and H. M. Dalen (2008): Lag på lag i norsk klima- og energipolitikk, Økonomiske analyser 5, 29-37, Statistics Norway.

Bruvoll, A. and H. M. Dalen (2009): Pricing of CO emissions in Norway, Documents 16, Statistics Norway.

Bruvoll, A., Fæhn, T. and B. Strøm (2003): Quantifying central hypotheses on environmental Kuznets curves for a rich economy: a computable general equilibrium study. Scottish Journal of Political Economy, 50(2), 149-173.

Burniaux, J.-M., Chanteau, J., Dellink, R., Duval, R. and S. Jamet (2009): The economics of climate change mitigation: How to build the necessary global actionin a costeffective manner, Economics Department Working Papers No. 701.

Diamond, P. and J. Mirrlees (1971): Optimal Taxation and Public Production I: Production Efficiency. American Economic Review, Vol 61 8-27.

ECON (1997a): Miljø og sysseletting. ECON-report 38/1997, Oslo.

EIA (2010): International Energy Outlook 2010, U.S. Energy Information Agency, Washington DC.

Ekins, P. and R. Salmons (2009): Making reform happen in environmental policy, OECD JT03274406,

http://www.oecd.org/officialdocuments/displaydocumentpdf/? cote=ENV/EPOC/WPNEP(2009)4/FINAL\&doclanguage=en

Ellis, J. (2010): The effects of fossil-fuel subsidy reform: a review of modeling and empirical studies, The Global Subsidies Initiative; Untold billions: Fossil-fuel subsidies, their impacts and the path to reform, International Institute for Sustainable Development.

ESMAP (2004): Energy Policies and the Mexican Economy. Technical Paper 047, January 2004. Washington, DC: World Bank.

Europe Economics (2006): Evaluation of State aid for the Coal Industry, A report by Europe Economics and Fraunhofer ISI with BSR Sustainability and the Krakow Institute for Sustainable Energy for the European Commission DG for Energy and Transport, http://ec.europa.eu/energy/coal/studies/coal_en.htm 
Freund, C., and C. Wallich (1997): Public-Sector Price Reforms in Transition Economies: Who Gains? Who Loses? The Case of Household Energy Prices in Poland, Economic Development and Cultural Change 46 (1), 35-59.

Fæhn, T., J.-A. Jørgensen, T. Åvitsland and W. Drzwi (2001): Effektive satser for næringsstøtte 1998, beregninger som inkluderer skatteutgifter, Rapporter 18, Statistisk sentralbyrå.

G20 (2010): ANNEX G20 Initiative on Rationalizing and Phasing Out Inefficient Fossil Fuel Subsidies Implementation Strategies \& Timetables.

http://www.g20.org/Documents2010/expert/Annexes_of_Report_to_Leaders_G20_I nefficient_Fossil_Fuel_Subsidies.pdf

GSI (2010): A how-to guide: Measuring subsidies to fossil-fuel producers, The Global Subsidies Inistiative, POLICYBrief, July 2010, GSI/IISD.

Hamid, J. (2008): Malaysia PM faces bigger protest, dissent over fuel, 12 June, Reuters.

Hannesson, R. (2006): Subsidy reform in the Norwegian fisheries sector, in: OECD (2005): Environmentally harmful subsidies - Challenges for reform, OECD Paris.

Holtsmark, B. (2010): Virkningene på klimagassutslipp ved økt bruk av biodrivstoff en litteraturgjennomgang (Th e effects on greenhouse gas emissions from increased use of biofuels - a survey), Rapporter 44, Statistics Norway.

IEA (2009): Energy Policies of IEA Countries Spain 2009 Review, OECD/IEA, Paris.

IEA (2010): World Energy Outlook 2010, International Energy Agency, IEA/OECD.

IEA, OECD, The World Bank (2010a): The Scope of fossil fuel subsidies in 2009 and a roadmap for phasing out fossil-fuel subsidies, and IEA, OECD and World Bank Joint Report Prepared for the G-20 Summit, Seoul, November 2010.

IEA, OPEC, OECD, World Bank (2010b): Analysis of the scope of energy subsidies and suggestion for the G-20 initiative, Joint report prepared for submission to the G-20 Summit meeting Toronto, June 2010.

IEEP, Ecologic, FEEM and IVM (2007): Reforming environmentally harmful subsidies, final report to the European Commission's DG Environment, March 2007.

ILO (2009a): Bolsa Família in Brazil: Context, concepts and impacts, Social Security Department, International Labour Office, Geneva March 2009.

ILO (2009b): Social security for all. Investing in social justice and economic development, Social security policy briefings Paper 7, Global Campaign on Social Security and Coverage for All, Social Security Department, International Labour Office.

Joskow, P. \& N. L. Rose (1985): The effects of technological change, experience, and environmental regulation on the construction cost of coal-burning generating units. RAND Journal of Economics 16(1), 1-17.

Laan, T., C. Beaton and B. Presta (2010): Strageties for reforming fossil-fuel subsidies: Practical lessons from Ghana, France and Senegal, The Global Subsidies Initiative; Untold billions: Fossil-fuel subsidies, their impacts and the path to reform, International Institute for Sustainable Development.

Lang, K., P. Wooders and K. Kulovesi (2010): Increasing the momentum of fossil-fuel subsidy reform: A roadmap for international cooperation, International Institute of Sustainable Development.

Larsen, H. (2002): The Danish tax reforms in the 1990's, OECD Conference on environmental fiscal reform.

Manzoor, D., A. Shahmoradi and I. Haqiqi (2009): An analysis of Energy Price Reform: A CGE Approach, Imam Sadiq University and Ministry of Energy, Iran.

Morgan, T. (2007): Energy Subsidies: Their Magnitude, How they Affect Energy Investment and Greenhouse Gas Emissions, and Prospect for Reform. Menecon Consulting.

Mourougane, A. (2010): Phasing out energy subsidies in Indonesia. OECD Economic Department Working Paper No. 808.

OECD (2000): The price of water: trends in OECD countries, The OECD environment programme 1999-2000. 
OECD (2005): Environmentally harmful subsidies - Challenges for reform, OECD Paris.

OECD (2006a): Subsidy Reform and Sustainable Development: Economic, environmental and social aspects, OECD, Paris.

OECD (2006b): The political economy of environmentally related taxes, OECD, Paris.

OECD (2007): Subsidy Reform and Sustainable Development: Political economy aspects, OECD, Paris.

OECD (2009): Agricultural policies in OECD countries, Monitoring and evaluation, ISBN 978-92-64-061729.

OECD (2010a): Making reform happen. Lessons from OECD countries, OECD, Paris.

OECD (2010b): Economic survey of Indonesia 2010.

http://www.oecd.org/document/60/0,3746,en_2649_34113_46261052_1_1_1_1,00. html

Oktaviani, R., D. B. Hakim and S. Siregar (2007): Impact of a Lower Subsidy on Indonesian Macroeconomic Performance, Agricultural Sector and Poverty Incidences: A Recursive Dynamic Computable General Equilibrium Analysis. MPIA Working Paper 2007-2008.

Pieters, J. (1997): Subsidies and the environment: on how subsidies and tax incentives may affect production decisions and the environment. Paper for the UN Fourth Expert Group, Meeting on Financial Issues of Agenda 21, January 8-10, Santiago, Chile.

Ramsey, F. (1927): A Contribution to the Theory of Taxation, Economic Journal, March 47-61.

Sachs, J. (2006): Revisiting the Nordic Model - Evidence on Recent Macroeconomic Performance. Jeffrey D. Sachs, Columbia University October 15th 2006.

Sandmo, A. (1975): Optimal taxation in the presence of externalities, Swedish Journal of Economics, Vol. 77 pp. 86-98.

Sandmo, A. (2000): The Public Economics of the Environment. Oxford: Oxford University Press.

Sawyer, D. and S. Stiebert (2010): Fossil fuels - at what cost? Government support for upstream oil activities in three Canadian provinces: Alberta, Saskatchewan and Newfoundland and Labrador, The Global Subsidies Initiative (GSI) of the International Institute for Sustainable Development (IISD), Geneva, Switzerland.

Steenblik, R.P. and P. Coroyannakis (1995): Reform of coal policies in Western and Central Europe. Energy policy, vol. 23, no. 6, pp. 537-553.

Stern, D. I. (2004): The rise and fall of the Environmental Kuznets Curve. World Development, 32, 1419-1439.

Suwala (2010): Lessons Learned from the Restructuring of Poland's Coal-Mining Industry, Global Subsidies Initiative (GSI) of the International Institute for Sustainable Development (IISD), Geneva, Switzerland.

SWECO (2008): Kartlegging av statlige tilskuddsordninger (postene 70-89) medmiljøskadelige konsekvenser, Rapport nr. 142231-101-A01.

TemaNord (2006a): The Use of Economic Instruments in Environmental Policy in the Nordic and Baltic Countries 2001-2005. TemaNord Report 2006:525, Nordic Council of Ministers.

TemaNord (2008): Trafikafgivter og klimapåvirkning, Hvordan sænker vi bilernes C02-utlegning? Det Økologiske Råd, Naturvernforbundet og Naturskyddföreningen, TemaNord Report 2008:587. Norisk ministerråd.

TemaNord (2009): The Use of Economic Instruments in Nordic Environmental Policy 2006-2009. TemaNord Report 2009:578. Nordic Council of Ministers.

The Commission of the European Communities (2009): Feform of the Common fisheries policyGreen paper, COM(2009)163 final, Brussels.

Valsecchi, C., F. Oosterhuis, M. Lewis, P. ten Brink, S. Bassi and S. Withana (2009): Environmentally harmful subsidies (EHS): Identification and assessment, Final report for the European commission's DG Environment, November 2009. 
Victor, D. (2009): The politics of fossil-fuel subsidies, The Global Subsidies Initiative; Untold billions: Fossil-fuel subsidies, their impacts and the path to reform, International Institute for Sustainable Development.

Wagner, A. (2008): Data Needs for Designing Responses to Rising Oil Prices in the Transport Sector, GTZ Transport Policy Advisory Services.

Wibe, S. (2010): Etanolens koldioxideffekter, en översikt av forskningsläget (The CO2 effects of ethanol, a survey of the research), Report to Expertgruppen för miljöstudier 2010:1, The Swedish Ministry of Finance, Regeringskansliet.

World Nuclear Association (2011): Energy subsidies and external costs, http://www.world-nuclear.org/info/inf68.html

WTO (2011): WTO analytical index: Agreement on subsidies and countervailing measures http://www.wto.org/english/res_e/booksp_e/analytic_index_e/ subsidies_01_e.htm 


\section{Appendix}

\subsection{Appendix 1 \\ - Theoretical foundation to taxes and subsidies}

Insight into optimal pricing of environmental problems is essential, both to understand how the environmentally harmful subsidies influence the environment through the economic mechanisms, and to understand how the alternative policies can be most efficiently formulated. This appendix offers a short introduction into the broader range of causes for market corrections, and in particular negative and positive externalities, optimal regulation and hence the use of corresponding taxes and subsidies. Also, the appendix points to examples of inefficient subsidies, increasing the environmental damages.

\subsubsection{The optimal regulation of externalities}

As shown in table 4.1, subsidies and taxes should be used to correct positive and negative externalities, and to adjust for equity concerns.

Environmental (Pigouvian) taxes are used to internalize environmental externalities into markets (Pigou 1920; Sandmo 1975). In the general case, marginal damage costs $(M D C)$ increase with increasing emissions, while marginal abatement costs (MAC) increase with higher abatement, i.e. decreasing emissions, see figure 10.1. The optimal emission level, minimizing the total abatement costs, occurs when marginal damage costs equal marginal abatement costs. This is when the tax, $t$, is set optimal, $t^{*}=M D C=M A C$. If $M D C$ is constant, $t^{*}=M D C$. This is relevant when the relevant regulation is not likely to influence marginal damage costs, e.g. local actions against greenhouse gas emissions.

The efficiency loss equals the difference between marginal damage costs and marginal abatement costs. In figure 10.1 this corresponds to the entire shaded area if no emissions are abated. In other words; the shaded area equals the efficiency gain given optimal regulation. 


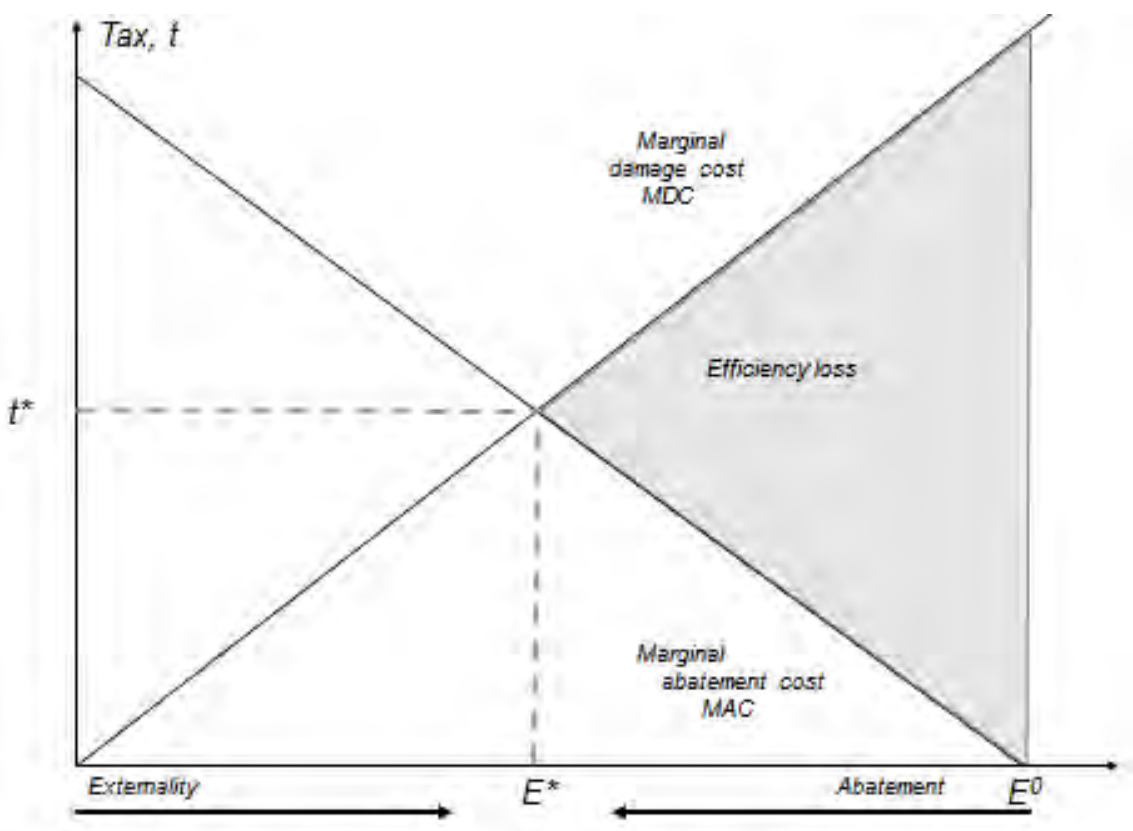

Figure 10.1. Optimal taxation of externalities.

Pigouvian taxes internalize the costs relating to environmentally harmful production and consumption. Typically, this is relevant for the fossil fuels, causing both greenhouse gas emissions and harmful emission with local health effects. A tax on emissions induces spill-over effects throughout the economy. The direct effects are increased costs and reductions in the production and consumption of polluting goods, such as fossil fuels. Nonpolluting technologies and R\&D in other technologies becomes more profitable. The relative consumption between energy and other goods is changed.

When the sources causing the externalities are hard to identify, or if the marginal damages would require infinitely high taxes, direct regulations can be more efficient than taxation. An infinitely high tax corresponds to a regulation with zero emissions, the externality would be zero in figure 10.1.

Cap and trade systems principally create the same efficient solutions as taxes. Then, the level $E$ is determined exogenously, leaving the market to find the equilibrium price equivalent to $t$ in figure 10.1. Ideally, the cap is set at the optimal emission level, $E^{*}$. The polluters trade emission permits. The polluters with the lowest abatement costs will reduce their emissions, while those with higher marginal abatement costs than the market price for emission permits will generate the remaining emissions.

\subsubsection{Taxing negative production externalities}

Figure 10.2 illustrates the market effect of an externality tax on the production of a polluting technology when a clean substitute exists. A typical example is carbon emissions in the electricity market, with coal 
based electricity production and non-carbon electricity production. Total supply faces increasing marginal costs comprising the polluting technology, $S^{b}$, and the non-polluting technology, $S g$. The willingness-to-pay (i.e. demand for electricity) is downward sloping, i.e., volumes increase with decreasing prices. In equilibrium, demand meets supply. The firstbest solution to an external problem is to obtain the right prices, i.e., by levying a tax on the polluting technology equal to the marginal external production cost. The tax shifts both the supply of the polluting technology and total supply inward to $S_{1}^{b}$ and $S_{1}$, respectively. In the new equilibrium, the purchaser price increases (from $p_{0}$ to $p_{1}{ }^{*}$ ) and total demand is reduced (from $x_{0}$ to $x_{1}{ }^{*}$ ). The polluting technology output price decreases from $p_{0}$ to $p_{1}{ }^{b}$, equal to the purchaser price, $p_{1}{ }^{*}$, minus the tax, $t$. The volume of the polluting technology reduces from $x_{0}^{b}$ to $x_{1}^{b}$. Since the clean technology is not taxed, it receives the total purchase price, $p_{1}{ }^{*}$, i.e., the price for the technology increases as does output (from $x_{0} g$ to $x_{1} g$ ).

Hence, taxing the polluting technology implies a support to the nonpolluting technology as profitability increases. The optimal solution internalizing total costs is at $p_{1}{ }^{*}, x_{1}{ }^{*}$. The efficiency gain relative to an unregulated market corresponds to the shaded area.

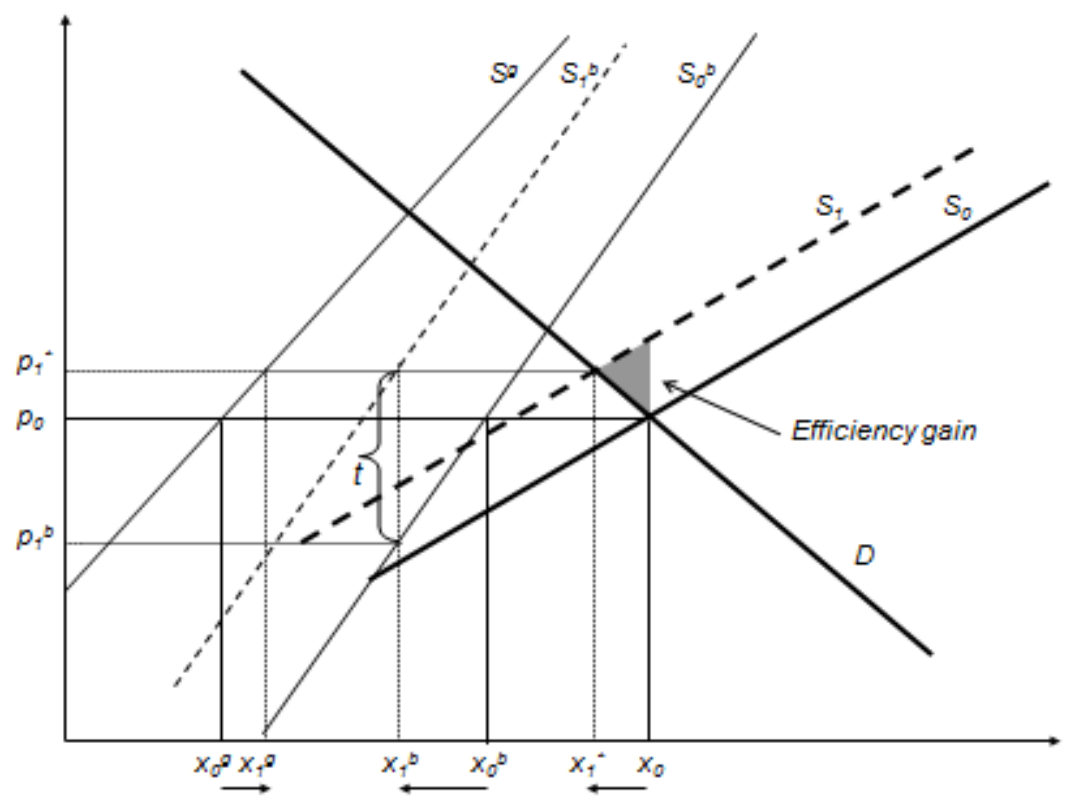

Figure 10.2. A tax on a production technology with a negative externality in a market with a substitutable good.

(Symbols: $\mathrm{S}=$ supply, $\mathrm{D}=$ demand, $\mathrm{g}=$ non-polluting technology, $\mathrm{b}=$ polluting technology, $\mathrm{x}=$ quantity, $\mathrm{p}=\mathrm{price}, \mathrm{t}=\operatorname{tax}$, $0=$ time before the tax, $1=$ time after tax, ${ }^{*}=$ optimal adjustment).

\subsubsection{Taxing negative consumption externalities}

Another case is negative externalities associated with consumption, such as locally harmful emissions from oil heaters. In that case, firewood and electricity are examples of alternative energy technologies. Then, the 
Pigouvian tax would be levied on the consumption side. As seen in figure 10.3 , the mechanisms would be the same as for the tax on the production side; the polluting energy production/consumption is reduced, alternative energy is stimulated, leaving the overall energy sales reduced. The efficiency gain relative to an unregulated market corresponds to the shaded area.

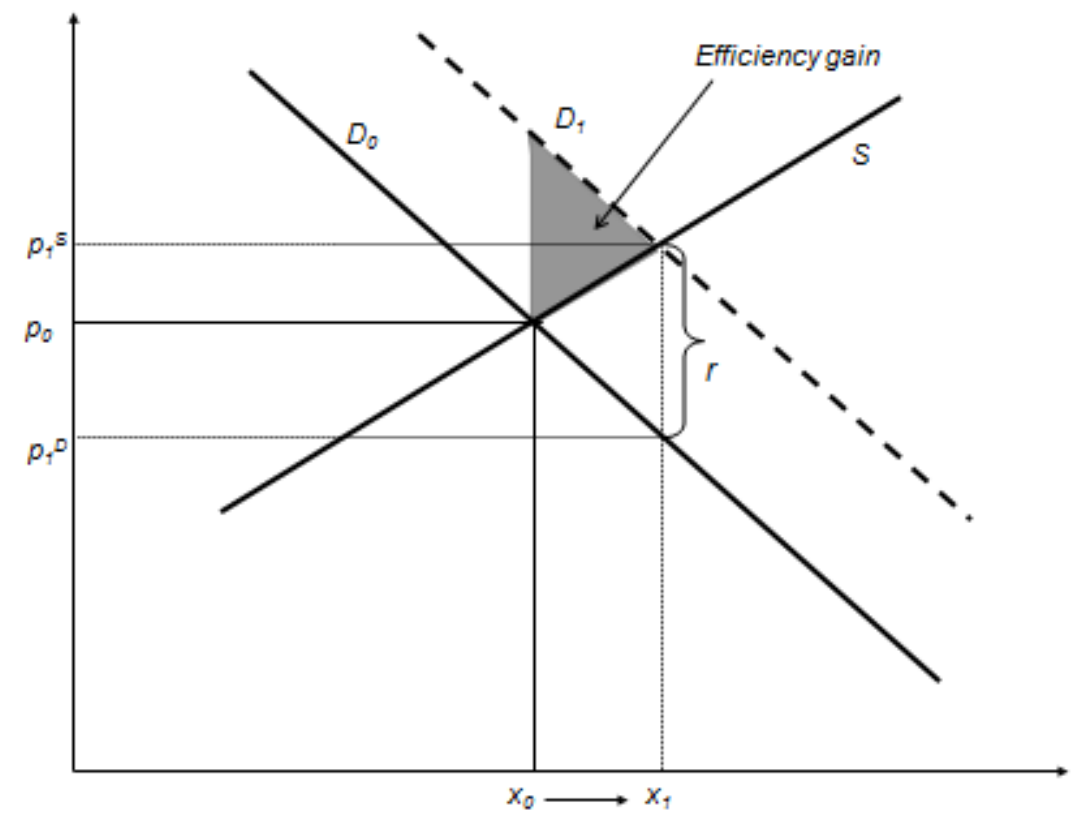

Figure 10.3. A tax on a consumption technology with a negative externality in a market with a substitutable good.

(symbols: $S=$ supply, $D=$ demand, $g=$ non-polluting technology, $b=$ polluting technology, $x=$ quantity, $p=$ price, $t=\operatorname{tax}$, $0=$ time before the tax, $1=$ time after tax ${ }^{*}=$ optimal adjustment).

\subsubsection{Subsidizing positive externalities}

In the presence of positive externalities, subsidies (negative Pigouvian taxes) serve the optimal solutions. The aim is to reward the agent causing the externality, and to create incentives to generate an optimal level of externality. This level is reached when production costs equal the marginal production costs including the externality values.

Typical examples of goods with positive external effects are research and development. Such activities normally generate knowledge over time that benefits other agents, or to new products that has a higher value than what is captured in the product price. Positive externalities are normally present at the research and development phase. This applies to research on new technologies through learning-by-doing (see, for instance, Joskow and Rose 1985).

Network externalities can arise at the implementation phase: the more agents use a network, the more useful for others using the same network. The use of a good that is interdependent in a network will increase the usefulness to others using the same technology. Network externalities often have tipping points. For example, electric cars are less 
attractive unless many utilize the technology to bring along enough charging stations for long distance transport. When passing a tipping point, it becomes profitable for to establish charging stations at less central locations. The market does not take this into account, and without regulation, lock-in effects may occur, i.e. the present tipping point may not be reached.

Other examples are education - one persons' knowledge level benefits the society beyond the private individual, and vaccination - which reduces the risk of non-vaccinated to get sick.

In the presence of positive externalities, prices should be corrected by a subsidy rate equal the value of the externality $r$, increasing the amount of supply to a level where marginal cost equals marginal benefit. When subsidising the supply of research, see figure 10.4, profitability increases as the suppliers receive the new market price plus the subsidy. Demand increases as the cost is reduced.

The same mechanisms work when subsidizing demand, see figure 10.5. A subsidy equal to the marginal benefit of e.g. network effects related to the use of charging stations would increase demand and reduce marginal costs related to supply of such energy. In both cases, supply and demand increase, marginal production cost increases but is compensated by the decrease in subsidy and consumer costs.

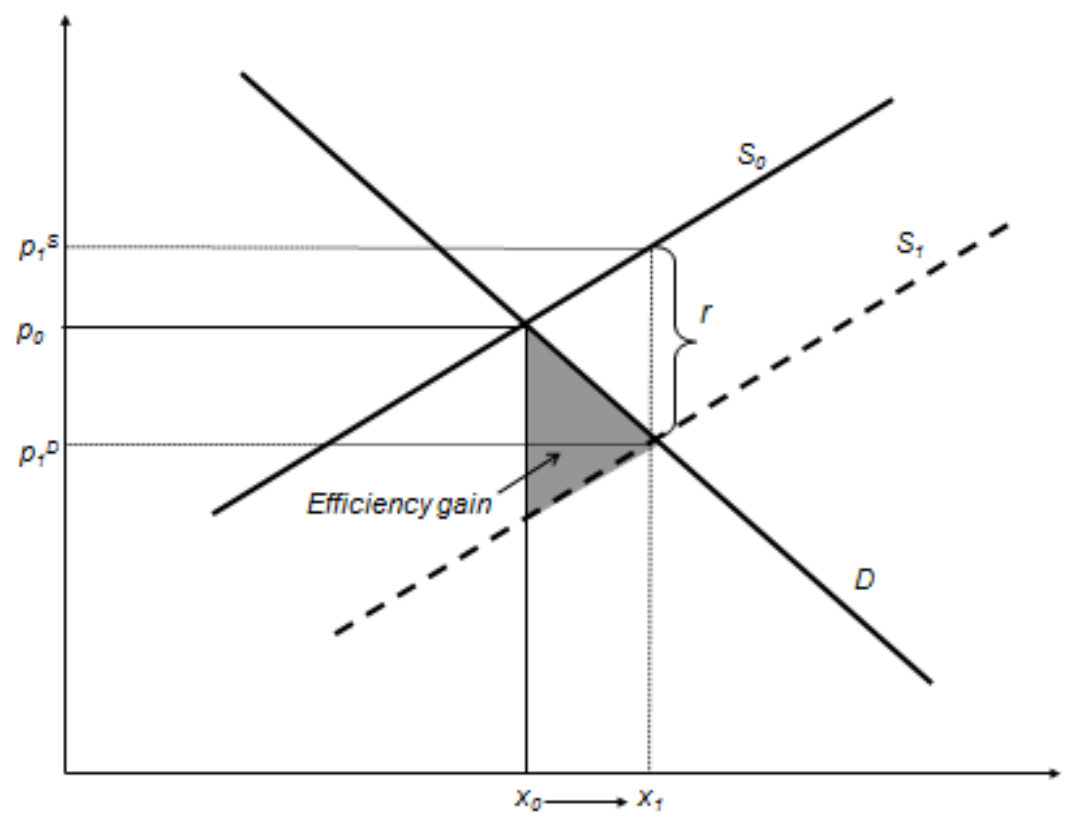

Figure 10.4. A subsidy on a production technology with a positive externality. (symbols: $S=$ supply, $D=$ demand, $x=$ quantity, $p=$ price, $r=$ subsidy, $0=$ time before the tax, $1=$ time after tax). 


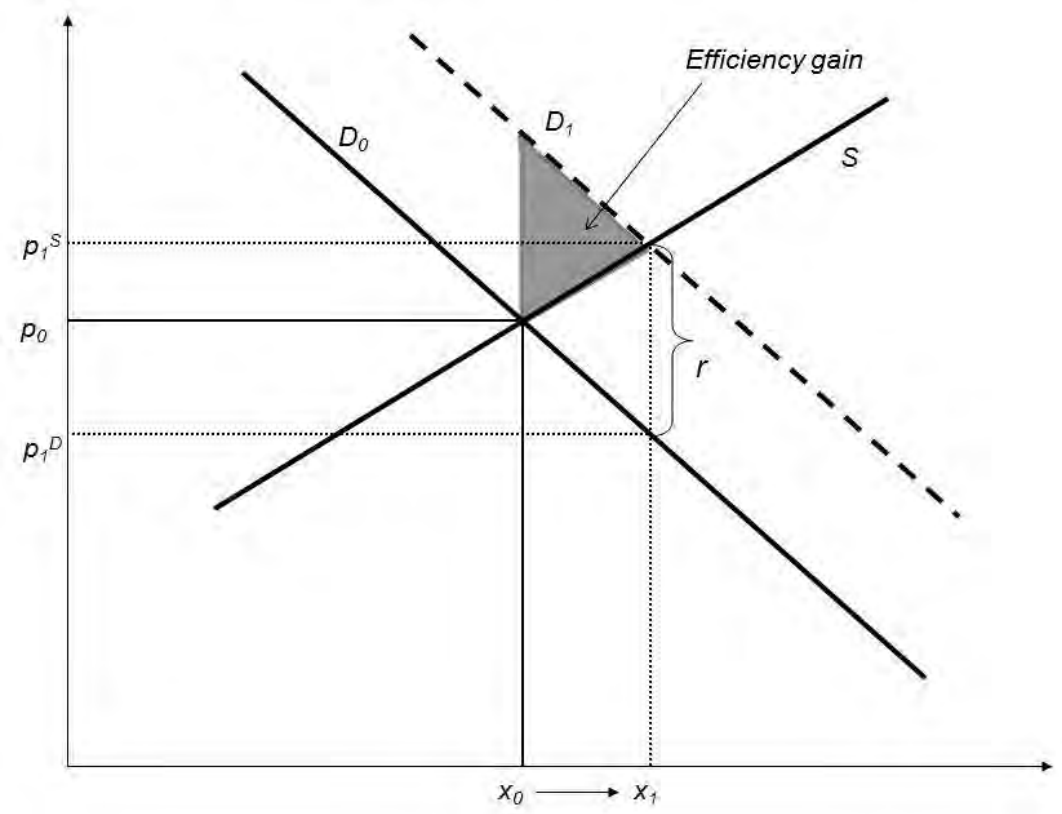

Figure 10.5. A subsidy on a consumption technology with a positive externality. (symbols: $S=$ supply, $D=$ demand, $x=$ quantity, $p=$ price, $r=$ subsidy, $0=$ time before the tax, $1=$ time after tax).

\subsubsection{Other market failures}

In addition to external effects, market imperfections are often associated with information failure, non-competitive markets or public goods. If a market failure exists, the outcome is not Pareto efficient. That means that improvements to at least one participant's well-being can be made without reducing any other participant's well-being. Such reallocations are typically best ensured by measures directly targeted at the market failure, both for environmental costs as described above, and for other market failures.

For example, to avoid lack of information, information campaigns, legislation to support a free press, banning of inside trade etc. are typical examples of regulations. To secure competitive markets, a necessary condition is the free entry of new suppliers and demanders. Such direct measures reduce the risk of creating unintended negative effects, such as environmental damages and over-exploitation of resources.

\subsubsection{Other reasons for policy intervention}

Then, interventions to correct for market imperfections are motivated in removal of failures that hinder maximum outcome in the economy. Another, principally different, form of intervention, is redistribution of wealth. Typical political goals are to avoid poverty, or to secure an even income distribution, to uphold regional settlement or certain industries. This is the main reasons for the use of inefficient subsidies not closely related to the groups in target, but at e.g. fossil fuel consumption or energy production industries. 
These interventions are political and normative, and economics has no role in determining which target group should be favoured. However, after the political goal is determined, economics can analyse how to reach the target at lowest possible cost.

Income distribution: Besides correcting for market failures, the main reason for public intervention is to influence the levels of wealth and income, to secure the living standards of low income groups in general and to reduce poverty in particular. In practice, this implies a transfer of resources from high to low income groups. The purpose of fiscal taxes is to raise revenue for public expenditure. To minimize any deadweight loss, fiscal taxes should be levied where they are least likely to distort economic activity (Ramsey 1927, Diamond and Mirrlees 1971). Note that this contrasts the purpose of the Pigouvian taxes, where the intention is to correct the market failure and influence market adjustment.

Regional development: Most countries consider some level of scattered habitation a good in itself. Regional policy is high on the agenda at least in the Nordic countries. Often, subsidies to particular industries are justified in regional concerns. E.g. coal subsidies in Europe were frequent particularly over the last half of the $20^{\text {th }}$ century, and, more recently, biofuel subsidies are partly motivated in support to agriculture and forestry, to uphold rural employment and habitation. If regional development is the political goal, the support would be most efficient if given as support to local communities and general industrial support, without being earmarked to specific industries or products. A development in the quality of public services, such as education and health services, is another type of policy stimulating a continuation of regional settlement.

Energy security? Energy security is frequently used as argument for subsidising energy production. The concerns for energy security are related to price levels and supply disruption ${ }^{10}$. First, politicians are concerned that users are able to access the energy services they require. This is principally a matter of prices - a well-functioning market will adjust market prices to balance demand and supply. The political concerns seem to deal with the level of the market price; relatively high market prices are politically unacceptable and taken as signals of lacking energy security. The second concerns relates to the ability of the energy system to cope with shocks and change, securing uninterrupted physical availability.

\subsubsection{Creating environmentally harmful subsidies}

Rather than using environmental taxes, subsidies of alternatives to negative externalities, such as less polluting energy sources, appear less politically controversial.

\footnotetext{
${ }^{10}$ See definitions from e.g. the IEA and the NewZealand Governments http://www.iea.org/subjectqueries/ keyresult.asp?KEYWORD_ID=4103. http://www.med.govt.nz/templates/MultipageDocumentPage__32084. aspx
} 
The effects of such subsidies are illustrated in figure 10.6, representing a "clean" technology, $S g$, in addition to the polluting technology, $S^{b}$. The supply curve $S^{*}$ represent the social cost curve, including both external costs and producers' costs. If these costs are not internalized, the market solution will be in $x_{0}, p_{0}$. Rather than taxing the negative externality, the government subsidizes the clean technology by a subsidy rate $r$. The supply of the clean technology then shift outwards $\left(S_{1} g\right)$ and total supply increases (from $S_{0}$ to $S_{1}$ ). The market equilibrium price decreases (from $p_{0}$ to $p_{1} b$ ). Consumers benefit while polluting producers lose from lower prices. The profitability of the alternative technology increases, as they receive the higher price $p_{1}^{b}+r$.

As the production based on alternative technologies increases and polluting production decreases, this seems to be a favourable regime. This resembles the effects as in the optimal situation, with a tax on the externality. The polluting technology would lose with an externality tax. Further, the profitability of the clean technology would increase. But these two solutions are principally very different. First, the potential efficiency gain from internalizing the externality is lost, cf. the dark shaded triangle in figure 10.6. Second, the efficiency loss is increased further by the subsi$\mathrm{dy}$, as the gap between the marginal production costs and marginal willingness to pay increases at any volume beyond $x^{*}$.

Naturally, the subsidy can be adjusted to attain the same pollution reductions in both alternatives. The difference is that a higher cost is imposed on the society, as the total consumption of energy increases (to $x_{1}$ ), rather than being reduced (to $x^{*}$ ) in the optimal alternative. The production of clean energy increases more than the reduction of the polluting technology. The lower purchaser prices and higher producer price reflect an increasing span between the marginal production costs and the marginal willingness to pay for energy.

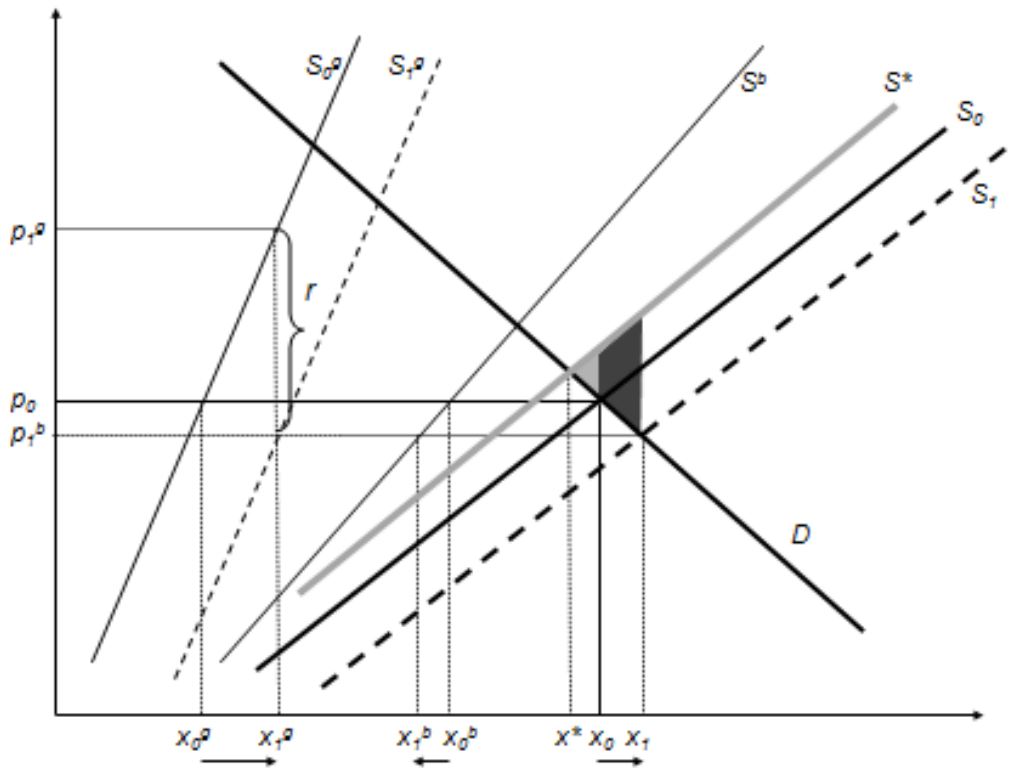

Figure 10.6. A subsidy on the supply side.

(symbols: $S=$ supply, $D=$ demand, $g=$ non-polluting technology, $b=$ polluting technology, $x=$ quantity, $p=$ price, $r=$ subsidy, $0=$ time before the subsidy, $1=$ time after subsidy, ${ }^{*}=$ optimal adjustment). 
Subsidies are also used to support particular parts of the demand side. Such subsidies are generally not theoretically well founded. The arguments are usually that the subsidies reduce negative externalities in other parts of the market. The same mechanisms would take place if the demand of the use of e.g. non-polluting energy was subsidized, rather than taxing the use of fossil fuels, see figure 10.7.

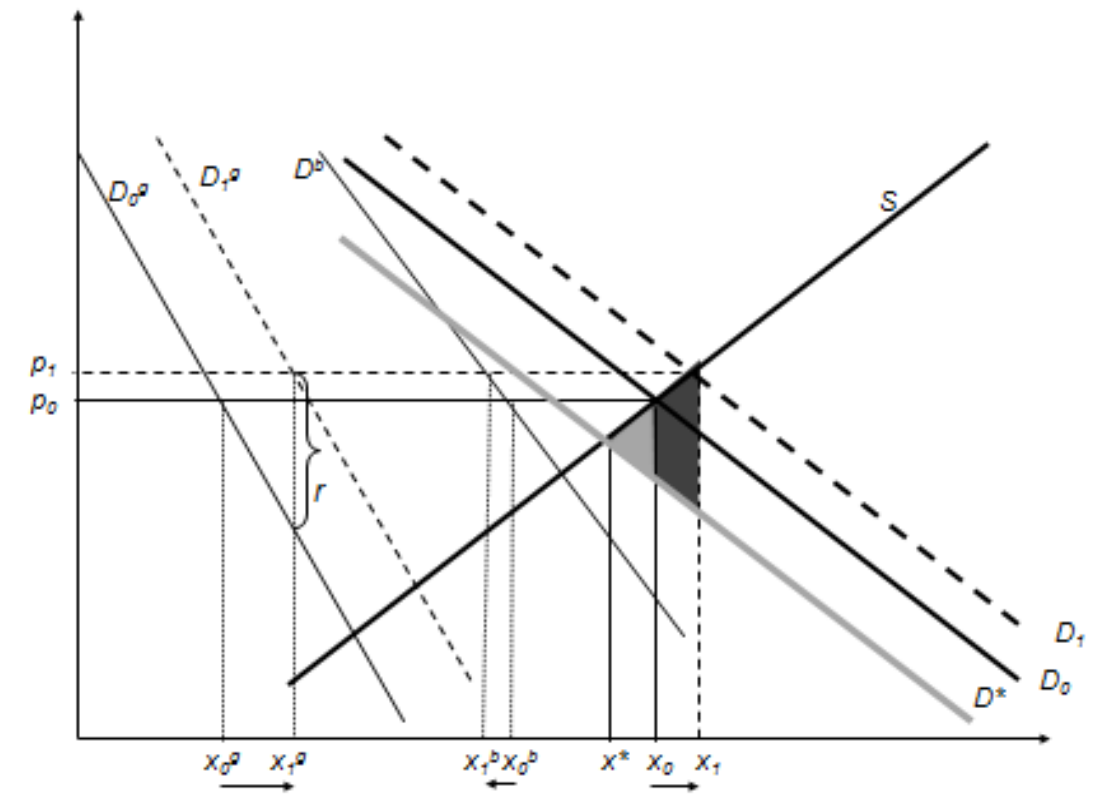

Figure 10.7. A subsidy on the demand side.

(symbols: $S=$ supply, $D=$ demand, $g=$ non-polluting technology, $b=$ polluting technology, $x=$ quantity, $p=$ price, $r=$ subsidy, $0=$ time before the subsidy, $1=$ time after subsidy, ${ }^{*}=$ optimal adjustment).

Compared to a tax on the demand causing the externality, the efficiency gain by adjusting to the optimal solution $x^{*}$ is lost. An additional efficiency loss accrue due to the subsidy, as marginal production costs are higher than marginal willingness to pay at any quantity beyond the starting point. 


\subsection{Appendix 2 \\ - Attempts to remove environmentally harmful subsidies}

\subsubsection{Coal subsidies in United Kingdom}

Sources: IEA et al. (2010b), IEEP et al. (2007).

\section{Background}

From 1957, British electricity generators were required to purchase a given quantity of British coal at set prices, but were allowed to pass the costs onto consumers (IEEP et al. 2007). Reforms had been attempted throughout the 1960s and 1970s. By the 1990s the British coal industry had become very inefficient by world standards.

\section{Policy change}

The privatisation of state-owned companies started in the late 1970s by the Thatcher government. Subsidies were removed in the mid-1980s, there were extensive mine closures, and in 1990 the UK government renegotiated the agreement to introduce a gradual decline over three years in guaranteed price and quantity purchased of British coal. The UK has since maintained a more or less competitive coal industry (IEEP et al. 2007). In 1999, however, the UK government imposed a moratorium on the construction of new gas-fired power stations in order to protect the domestic coal industry. This moratorium was replaced in 2000 with a direct subsidy to the coal industry of GBP 100 million per annum for the next two years, allowing the elements of the coal industry with a viable future without aid to ride out temporary market problems. In 2002, the government agreed to an investment aid package for the remaining coal mines in a bid to allow the British coal industry to compete in the reformed electricity market and to create or safeguard jobs within socially and economically disadvantaged areas (Europe Economics et al. 2006).

\section{Compensation}

Government aid to those entering unemployment from the coal-mining sector was focused on creating an enabling environment for the development of alternative economic activities in mining areas, rather than a severance package. This increased support to the reform and stimulated economic growth in otherwise disadvantaged areas (IEEP et al. 2007).

\section{Evaluation}

Privatization and strong political will following the Thatcher period were determining factors to drive the reform through. The UK underwent two recessions in 1980 and the early 1990s, particularly affecting the inefficient manufacturing sector (IEEP et al. 2007). The negative local and national economic situation was not a positive factor in the reforms. Coal-mining jobs in the coalfields of England and Wales ac- 
counted for about a quarter of all male jobs located in these areas. In 1981 there were 160000 unemployed, before the main pit closures began. The miner's strike of 1984-85 weakened the British trade union movement, as it was not effective at stopping the government plan to reform the sector (IEEP et al. 2007).

The UK experience shows that coupling the reform with measures to stimulate economic development, and therefore create new job opportunities in areas where industrial activities are to be scaled down or closed, can increase support to the reform and foster economic growth (IEEP et al. 2007). By 2004, some $60 \%$ of jobs lost from the coal industry in the early 1980s had been replaced by new non-coal jobs for men within the same area. The total unemployment rate was less than $1 \%$ above the national average in areas in which coal pits had been shut down between 1995 and 2005 (Europe Economics et al. 2006). Since then, the pace of non-coal male jobs continued to accelerate (IEEP et al. 2007).

\subsubsection{Coal subsidies in France}

Source: IEA et al. (2010b), Laan et al. (2010).

\section{Background}

After the World War II, coal was expected to play a key role in the reconstruction of the French economy. In the 1950s, the coal policy gradually changed, as the creation of a common market for coal and steel was formed, and the important mine areas Ruhr and Saar were re-unified with Germany. Coal production targets were reduced in the 1960s. At the same time, a special fund was created to promote investment in the mining regions, retrain workers and encourage entrepreneurship, and to support the establishment of new businesses, industrial zones and entities responsible for local economic development. In 1982, French coal prices was $60 \%$ higher than for imported coal.

\section{Policy change}

After a gradual reduction of coal production starting in the early 1960s, an agreement was reached in 1994 to close all remaining coal mines. Between 1971 and 2000, the state spent around $€ 35$ billion on restructuring the coal sector. In addition to European competition legislation, the major drivers of the reform were budgetary considerations and a reduced perceived need to secure energy independence via coal mining due to an expansion of nuclear energy capacity. In 2007, subsidies to the coal sector were largely stopped.

\section{Compensation}

Extensive measures were used to promote alternative economic activity in the affected regions and long-lasting measures to protect the interests of the former miners. Former miners were guaranteed employment until the age of 45 , when those with at least 25 years of service became eligi- 
ble for a leave, during which they would receive $80 \%$ of their final working salary until retirement (Laan et al. 2010).

\section{Effects}

While coal was still a crucial source of energy at the start of the reform, the last French coal mine was closed in 2004. However, after a reform lasting many decades social support is provided to over 200000 people. Its activities require state support of around $€ 700$ million a year, an amount that will decline over time (Laan et al. 2010).

\section{Evaluation}

The (costly) expansion of nuclear-based electricity generating capacity and the generous provisions offered to the former miners helped making the closure of all the coal mines possible. According to Laan et al. (2010), those likely to be negatively affected by the reform were identified early in the process, and a long-term, gradual approach was taken that enabled the miners and the economy to adapt. Still Laan et al. conclude that the deregulation is not an example of best-practice, as it required over 40 years to complete and billions of Euros from the French government to underwrite structural adjustment. Only wealthy countries like France can afford to pay such large subsidies over a long period to support the workforce of a single industry. However, the case study provides an illustration of good principles for reforming producer subsidies.

\subsubsection{Coal subsidies in Germany}

Sources: IEA et al. (2010b), IEEP et al. (2007).

\section{Background}

In Germany, hard coal mining has been subsidized for almost half a century. Subsidies are defended as a vehicle to maintain jobs and domestic energy supply. The original subsidies were provided by a surcharge on the price of electricity. This was considered unconstitutional and the subsidy was shifted to the budget in 1994. This shift of the source of subsidies from the energy consumer to the budget led to domestic budgetary and environmental considerations becoming the main drivers of subsidy reform. In 2007, the average mining job was subsidized by $€ 75,000$. Coal mining subsidies amounted to almost $30 \%$ of the direct subsidies granted by the government in 2003 .

\section{Reform}

The reform aims for a gradual reduction of the subsidies to a complete removal. Subsidies were reduced from €4.73 billion in 1998 to €2.38 billion in 2008, with a complete phase-out by 2018 . 


\section{Effects}

Production has fallen by $43 \%$ and number of employees by 50 percent from 1997 to 2005. The numbers of mines have fallen from 19 in 1997 to 8 in 2006, and the remaining number is expected to be 5 in 2012. The decline is however partly caused by other factors, causing a reduction in relative competition to other countries. The unemployment rates in the affected areas are somewhat higher than the national average.

\section{Evaluation}

The main argument against a subsidy reform seems to be energy security of supply and alternative domestic production. Strong links between particular interests and political parties makes it difficult to introduce reform. Public support for the sector has decreased over time, drive by tight budgets and decreasing reliance on coal, decreasing number of jobs and increased concern about the environment. At the same time there is a widespread public awareness that coal subsidies run counter to economic sense and about the financial and environmental effects of the subsidies (IEA et al. 2010b). Tight budgets, the decreasing reliance on coal, the decreasing number of jobs involved and a growing public concern about the environment and climate change has decreased public support for the sector over time. Also, shifts in political power have shown to open up new opportunities.

\subsubsection{Coal subsidies in Poland}

Sources: IEA et al. (2010b), IEEP et al. (2007).

\section{Background}

Prior to 1990, the coal mining sector in Poland was state owned and operated to provide high employment and cheap energy, rather than to generate profits. Local policies kept coal prices below international levels, with large economic and environmental consequences. This was achieved through low end-user prices, market barriers, and direct subsidies to the state-owned enterprises (IEEP et al. 2007, Suwala 2010). Political and economic change in 1989 from communism to a market economy allowed changes to the mining sector and the reform of government subsidies to the sector. A key objective of the government was to liberalise coal prices so that they could be determined by market forces.

\section{Reform}

1990-1993: Attempt to adapt to free market economy. 1993-1996: Restructuring provided for the closure of a number of unprofitable mines, adaptation of extraction levels to the falling domestic demand, a strong emphasis on environmental protection, and improved working efficiency. 1996-2002: Restructuring programmes, technical modernisation, debt forgiveness, export incentives, determined reduction of employ- 
ment, liquidation of consistently unprofitable mines, privatisation of those which turned a profit. 2002-present: Continued employment reductions, writing off some of the industry's massive debt, a freeze on remuneration until the programme's conclusion, privatisation of the more profitable mines and closure of the loss-making ones, introduction of a six-day working week.

\section{Compensation}

Relatively generous severance packages were provided to miners leaving work, based on individual arrangements. Miners who have accepted a one-off severance payment in return for an undertaking never again to seek employment in the mining sector have received an average payment of $€ 12,000$ to $€ 14,000$.

\section{Effects}

Extraction fell by almost 50\% from the mid 1980s to 2000 and employment levels were reduced significantly.

\section{Evaluation}

IEEP et al. (2007) conclude that the key components of the last programme period met with strong criticism from the trade unions in the mining industry. Still, in general, the reform was carried out without major social conflicts, despite the significant employment losses. It is easier to implement a reform when there is more confidence in the markets and from the public in new economic activities. IEEP et al. (2007) draws several conclusions from the Polish example: The rationale for the maintenance of inefficient subsidies and industries becomes weak when the economic outlook is bright. Reforming heavily subsidised sectors weighs heavily on state budgets, as generous severance packages are needed for buying support to the reform. Such costs are however experienced in the short to medium term, until completion of the reform, while subsidies would continue in the long term. Secondly, it is easier to implement a reform when the economic outlook is not grim, environmental considerations can play a major role in determining the success of reform: in particular, any efforts directed towards the reduction of GHGs emissions is now likely to be met with more tolerance by the public, given the high political priority that climate change is receiving. Third, reforms need to include analysis of the potential cascade impacts on the whole economy.

\section{Future}

Restructuring of the industry continues and public funding will be dedicated to restructuring of employment and reducing production capacities. The international price of hard coal has increased in recent years, improving the economic situation of some coal mines. This has raised questions about the rationale for maintenance of state support for profitable companies, and there is intense discussion on the efficiency of the 
sector. However, potential plans to withdraw financial support for selected mines face strong resistance from industry (IEA et al. 2010b).

\subsubsection{Coal subsidies in Spain}

Source: IEA et al. (2010b).

\section{Background}

In the 1980s the Spanish coal industry was heavily dependent on the energy supply industry and contracts it had made with governments. This enabled its expansion when the rest of the European coal industry was in decline (Europe Economics et al. 2006). Between 1994 and 2005 the EU authorised $€ 12.9$ billion in aid to Spain in order to provide operating aid to maintain access to coal reserves and support for reducing coal mining activity (Europe Economics et al. 2006). In 2004, the average cost per tonne of Spanish coal was up to 9 times higher than the imported coal cost (Europe Economics et al. 2006).

\section{Reform}

The energy market was liberalised in 1998 with the introduction of a long-term restructuring plan. Minimum quotas for Spanish coal continued, but power companies were allowed to contract directly with mining companies for the amount and price under their quota, leading to competition between the individual companies (Europe Economics et al. 2006). Power companies continue to have an obligation to purchase fixed quantities of domestic coal until the year 2012 as part of a subsidy agreement (IEA 2009).

\section{Effects}

Employment in the coal mining sector fell nationally from by nearly $70 \%$ over the period from 1995 to 2005 . Coal made up 34\% of the fuel mix for electricity generation in 2002 but and by $28 \%$ in 2005 (Europe Economics et al. 2006).

\section{Evaluation}

The Spanish hard coal sector is still dependent on subsidies to be competitive with imported coal, and significant subsidies still remain. Operating aid to coal mines is gradually declining from $€ 503$ million in 2005 to $€ 450$ million in 2007 , but these figures remain considerable for an industry with less than 7000 miners (IEA 2009).

\subsubsection{Eco-tax exemptions in Germany}

Source: IEA et al. (2010b), IEEP et al. (2007).

\section{Background}

The logic behind the German eco-tax, implemented in 1999, was to raise energy taxes to internalize the externalities of energy use. Eco-tax ex- 
emptions imply lack of taxes on the external costs from energy, and are principally equivalent to energy subsidies. A reform to reduce the ecotax exemptions was carried out in 2003. The drivers for this reform were both environmental and political. The European Commission was a main promoter of reform on competition grounds because eco-tax exemptions potentially distort competition. Arguments against the reform were concerns about competitiveness, the introduction of the emission trading system (ETS) and high energy prices.

\section{Reform}

In 2003, the eco-tax rates for businesses were increased from 20 to $60 \%$ of full rate. In 2006 however, new exemptions were introduced. The reform contained partial exemptions for enterprises in the manufacturing sector and in agriculture and forestry, allowing qualifying businesses to pay only $20 \%$ of the standard rate and guaranteeing enterprises in the manufacturing sector a refund of $95 \%$ of the remaining eco tax payments that exceed the relief on pension scheme contributions (IEEP et al. 2007). They are among the largest tax exemptions amounting to about 11 billion €per year in 2003-2006 (IEEP et al. 2007). The Commission allowed reduced industry eco-tax rates to be continued until 2012, but approved the tax cap only under the condition that the German industry meets its voluntary commitment targets. These targets were committed to by industry in order to obtain eco-tax exemptions and involve a mandatory reduction of $\mathrm{CO}_{2}$ emissions.

\section{Compensation}

The reform was designed as revenue-neutral with simultaneous increase in energy taxes and lowered payroll taxes.

\section{Effects}

The 2003 reform was carried out successfully but the reform faced a setback in 2006, with new exemptions having been created, including total exemptions of certain energy-intensive processes from energy taxation. In addition, the reduced eco-tax rates have applied to the entire energy tax rates for heating fuels, i.e. including the petroleum excise duty that already existed before 1999 . For electricity and for natural gas and liquefied gas, this continues to mean a reduction of $40 \%$; and for heating oil $27 \%$. A key outcome of the reform, however, was the chance of moving towards harmonised energy taxation with a harmonised reduction of subsidies.

\section{Evaluation}

The eco-tax is a step in the right direction for reducing subsidies related non-internalised external costs. The exemptions however represent a continuation of the pre-tax lack of correct incentives. The main reason seems to be concerns about competitiveness in the world markets. Increased energy prices contribute to the perception that there is already 
a heavy burden on industry. Worldwide differences in energy taxation provided the rationale for granting eco-tax exemptions to domestic industries and contribute to the difficulties in reforming the eco-tax (IEEP et al. 2007). IEEP et al. conclude that the reform relates to the question of setting incentives for industry to reduce its energy consumption without harming its competitiveness, and to find suitable ways to combine the economic instruments of energy taxation and emissions trading.

IEEP et al. (2007) conclude that strong leadership on its own it is not a sufficient condition for the reform to endure. A broad coalition supporting the reform is preferable to avoid setbacks. In this case, it is likely that re-election gave momentum to reform plans that already existed earlier. Changing governments allowed for re-considerations of the ecotax exemptions.

\subsubsection{Biofuel subsidies in Germany}

Source: Valsecci et al. (2009).

The EU biofuels Directive requires the members to ensure that a minimum proportion of biofuels and other renewable fuels are placed on their markets. A variety of measures were subsequently introduced, including preferential tax treatments. Removal of the tax exemption will increase the price of biofuels, thus reduce the incentive for production and therefore reduce impacts on the environment from the cultivation and processing of biofuels. Germany has a relatively long history of political support for biofuels and is currently the world's leading producer of biodiesel and Europe's leading producer of ethanol (Valsecci et al. 2009).

The value of the subsidy in 2004, measured in terms of total revenue forgone due to tax exemptions, was €618 million. The benefiters are biofuels producers (primarily large agro-industrial companies capable of producing large quantities of biofuels or petroleum companies using cheaper nondomestic production for their blends) and consumers of byproducts such as rapeseed cake sold as livestock feed. Losers are public budgets and to some extent consumers of other goods based on grain and oil seeds given price increases.

\section{Reform}

The 2004 tax exemption has undergone successive reforms despite industry opposition. In 2006, the German government established a system of gradually increasing taxes on biofuels. However, in 2007 a quota system was introduced, which sought to reduce the impact of the introduction of taxes on biofuels. The system is another form of subsidy, as it sets a minimum requirement of the biofuel content in relation to energy content. In the future, bio methane from biogas will also be considered in the total and the petrol quotas. 


\section{Evaluation}

The large budgetary implications of the tax exemption, secured political support for these reforms, despite domestic industry opposition. Instead, indirect subsidies were introduced through the quota system.

\subsubsection{Fossil fuel subsidies in Mexico}

Sources: G20 (2010), IEA et al. (2010a).

\section{Background}

Subsidized energy prices in Mexico have represented a serious economic strain on the government budget and contributed to increasing reliance on refined product imports. Subsidies for electricity, gasoline, diesel and liquefied petroleum gas were equivalent to more than one and a half $\%$ of GDP over the period 2005-2009.

\section{Reform}

Mexico is currently reforming its excise arrangements for refined products and the subsidies are expected to be eliminated by late 2012. Retail prices for gasoline, diesel and LPG are set by the government. Subsidies to gasoline and diesel are planned to be phased out by the end of 2010, and the gap of LPG prices is to close in 2012.

\section{Compensation}

The government has implemented a cash transfer intended to help very low-income households cover their energy needs, see box 7.1. This is better targeted at the poor and is formulated to avoid incentives for environmentally harmful increases in energy consumption.

\section{Effects}

Since 2009, retail prices of fossil fuels have been gradually increased. The prices of low-octane gasoline and diesel, high-octane gasoline and LPG increased by around $0.6-1.0 \%$ per month over a period, and prices on magna, premium, diesel and LPG increased by around $2.5-5.0 \%$ over six months.

\section{Future}

A census of fossil fuels consumers at the household level will allow welltargeted and focused support programs to compensate poor households for fossil fuel price increases. It is expected that the census will be finished in 2011. G20 (2010) expects that by continuing current policies and based on current market conditions, subsidies to gasoline, diesel and LPG are expected to disappear in the medium term.

\section{Evaluation}

This reform is an example of a reform achieving improved price signals and reducing the environmental costs, and at the same time compensating the social groups initially targeted. 


\subsubsection{Fossil fuel subsidies in Indonesia}

Sources: G20 (2010), IEA et al. $(2010 a, b)$.

\section{Background}

Indonesia has a long history of directly subsidizing energy as a means of supporting the incomes of poor households. In 2008, 19\% of government expenditure was devoted to energy-consumption subsidies. At the same time, a number of institutional reforms and policy changes are needed to meet Indonesia's targets for growth and poverty reduction and to move to an environmentally sustainable development path (OECD 2010a). Only a small amount of the subsidies to oil products reached the poor. In 1999 , only roughly $15 \%$ of the total kerosene subsidy reached the poorest $30 \%$ of the population.

\section{Reform}

In 2005 , the government started to gradually liberalize the fuel market with the aim of completely eliminating fuel subsidies. In 2010, Indonesia announced plans to eliminate energy subsidies by 2014. The government raised subsidized prices by an average of $125 \%$ in 2005 and 29\% in 2009. From 2010 the aim is to phase out fossil fuel subsidies, and there is a program to transform kerosene to LPG. The payment subsidy mechanism is changed from a cost and fee system to margin and a distribution cost system.

\section{Compensation}

A large part of the consumption basket of the poor is affected by higher fossil fuel prices. Alongside with the price increases in 2005 and 2009, the government undertook a cash transfer program to 16 million poor families, see box 7.1, the costs amounting to about $0.7 \%$ of GDP. In the continuation, the phasing out is implemented in a gradual manner in order to minimize the spill-over impact on the poor. Incentives are given to use cleaner and more efficient energy such as liquid gas, funding is given to develop the capacity to use renewable energy, income taxes are reduced, the rate of asset amortization is accelerated, and import duty exclusions for industries using renewable energies are used, fiscal disincentives, such as imposing sales tax and value added tax on fossil fuels, are performed. The distribution of subsidized fuel is contained to certain users, for example, by providing a subsidy for poor fisherman to buy fuel in fixed quantities. The price subsidies are transformed to a targeted subsidy through reinforcement of poverty alleviation programs.

\section{Effects}

The state budget for 2011 estimates that the share of government expenditure is reduced to $11 \%$ (19\% in 2008). The subsidies for diesel and fuel oil are completely eliminated. 40 million households shifted their consumption from kerosene to LPG in the period through 2009. 


\section{Future}

The phasing out strategy is to be sequenced through managing the demand side by adopting measures that will reduce fossil fuel energy consumption and then by gradually narrowing the gap between domestic and international prices.

\section{Evaluation}

The reform has significantly reduced the budget expenses to environmentally harmful subsidies. The Indonesian experience highlights the importance of ensuring a suitable compensation strategy for poorer sections of the community in implementing reform, and that this can be a reduced impact on government expenditures and as a proportion of GDP (Laan et al. 2010). At the same time, it was important to provide a stepped approach to the reform, with some fuels being tackled later in the reform process, and taking a comprehensive approach to the policy problem, for example, focussing on changing household behaviour with support to switch from kerosene to LPG (IEA et al. 2010b). Still, strong political opposition continues to hold back implementation of Indonesia's reform strategies (Laan et al. 2010).

\subsubsection{Fossil fuel subsidies in Ghana}

Source: Laan et al. (2010).

\section{Background}

In 2004, Ghana spent roughly 2.2\% of its GDP subsidizing fuel and 1\% on support to its national refinery company. A government commission found that Ghana's rich received the greatest benefits from subsidies and quantified how and to what extent the poor would be affected by future deregulation (Bacon and Kojima, 2006). This was an important foundation for communicating the necessity for reform and for designing policies to reduce impacts of higher fuel prices on the poor.

\section{Reform}

Ghana has made several attempts to liberalize their fuel prices. In the 2001 reform, ex-refinery petroleum prices increased by $91 \%$ and automatic price-setting mechanism were implemented. In the 2003 reform a new deregulation was carried through, and fuel prices rose by $90 \%$. In the 2005 reform, quarterly price adjustments were replaced by monthly price adjustments in 2006 to better link domestic with international prices. The reform included a communications campaign and mechanisms that were intended to reduce political interference in fuel prices.

\section{Compensation}

In the 2001 reform, the effect on the poor was cushioned by crosssubsidization fuels used typically for cooking and lighting (kerosene and LPG). The 2005 reform included policies to assist the poor. The govern- 
ment eliminated fees for state-run primary and secondary schools, increased the number of public-transport buses, put a price ceiling on public-transport fares, channelled extra funds into a health-care scheme for poor areas; raised the daily minimum wage by $22 \%$ and started programs to help spread electrification to rural areas and purchase essential equipment for workers. It also continued its previous policy of crosssubsidizing kerosene and LPG.

\section{Effects}

The poor were hardest hit, and the reform was suspended during 2003, citing fear of social and political instability in the run-up to elections. The gap between international and domestic prices increased. The policy was abandoned when oil prices soared in 2007 and 2008, and price ceilings were set in 2008 (Kojima, 2009). The government continued to subsidize fuel. After coming into position, the opposing party (NDC) fulfilled its promises from the election campaign and reduced fuel taxes in 2009. After that, fuel prices in Ghana were more than $45 \%$ below corresponding fuel prices in neighbouring countries, leading to a dramatic increase in fuel consumption and smuggling out of the country.

\section{Evaluation}

Laan et al. (2010) conclude that the policies employed to ease the removal of subsidies were only partially and temporarily successful. The price-setting regime proved to be only as robust as the political will behind it, demonstrating that governments will be tempted to intervene in fuel pricing for political reasons. Due to lacking political acceptance, the change in policy regime opened for reversing the reform. A completely independent pricing board is difficult to achieve. Governments can always override the regulator's decisions and laws can be changed. Automatic linking of domestic and international prices, without subsequent cross-subsidization, is necessary to prevent politicization of fuel prices. The 2005 reform included successful communication and compensation strategies that improved public acceptance of the price increases. Protests associated with the 2003 reform were not repeated in 2005.

\subsubsection{LPG subsidies in Senegal}

Source: Laan et al. (2010).

\section{Background}

In the 1970s, Senegal had a goal of reducing deforestation by substituting part of charcoal consumption with LPG. LPG was subsidized first through cooking equipment and from 1988 the government started to subsidize LPG fuel itself. The LPG subsidy program reduced household pollution and reduced pressure on forests. But the policy also led to an unsustainable fiscal burden, disproportionate benefits for the relatively rich and fuel smuggling. 


\section{Reform}

A phased reduction of the subsidy in annual increments of $20 \%$ was started in 1998. The plan was put on hold in 2002 due to increasing global LPG prices, exchange rate variations and inflation, resulting in continuing high subsidies.

\section{Effects}

In 2006, the cost of LPG subsidies amounted to $1.4 \%$ of GDP. In 2008, the IMF found that the 40 poorest $\%$ of the population gained only $19 \%$ of the total improvement in welfare from the LPG subsidy, while the richest $40 \%$ gained $61 \%$.

\section{Evaluation}

Laan et al. (2010) conclude that this is not the outcome of a successful policy. The government has attempted to reform the subsidy for over a decade and has made little headway. However, removal of the subsidy risks an increase in the use of charcoal and firewood by some households.

\section{Future}

According to Laan et al. (2010), Senegal could learn from the packages of measures used by Ghana and France (see chapter 10.2.2 and box 7.1): i.e., research to identify those most-likely to be negatively impacted by de-subsidization, information campaigns about the benefits of reform, cash transfers to the poor, and greater independence and transparency of fuel prices. Disincentives for the use of charcoal and wood, rather than fuel subsidies, would be a more direct way to address the goal of reducing deforestation. Earlier in the program to encourage LPG use, the government reduced charcoal production quotas and increased woodcutting licence fees (Sokona and Deme 2004). A program to promote the use of sustainably harvested wood fuel is reported to have helped to reduce the effect of LPG de-subsidization on deforestation (The World Bank, 2007). In addition, "green charcoal" made from agricultural waste is being tested in Senegal and offers a cheap alternative to charcoal from forests (All Africa, 2009). Disincentives for charcoal and LPG would make such more environmentally friendly technologies more profitable. Laan et al. (2010) claim research is required to identify the populations most likely to revert to charcoal use or to be otherwise disadvantaged by subsidy reform. The IMF has estimated that if conditional cash transfers were to target the poorest $10 \%$ of the population, 58 cents of each dollar spent would reach people in the poorest quintile of the population compared with only 22 cents from the excise tax exemption for kerosene and only 6 cents for the LPG gas subsidy (IMF 2008). 


\subsubsection{Electricity and petroleum subsidies in Malaysia}

Source: IEA et al. (2010b).

\section{Background}

Malaysia has had a cap on the price of electricity and petroleum products in place for some years. The difference between world market prices and the caps have been subsidised by the government. Rising oil prices in 2007 and 2008 substantially increased subsidies as the gap between world market prices and the price caps on electricity and petroleum products widened, putting pressure on the budget and prompting the Malaysian government to review their subsidy policies. Subsidies were reported to have cost the Malaysian government USD 14 billion in 2008, or about $4 \%$ of GDP.

\section{Policy change}

In 2008, the government introduced a broad package of reforms to their energy subsidies. The package included subsidy reductions and social support packages. In 2008 the price of natural gas for power generation was raised by $124 \%$, and the average electricity tariff for all sectors of the economy was increased by $24 \%$, petrol prices by $41 \%$ and diesel prices by $63 \%$ (Hamid 2008).

\section{Compensation}

To offset the increased prices, the Malaysian government offered cash rebates in the form of lower annual road taxes, cash rebates, windfall taxation on certain sectors and an expansion of the social safety net.

\section{Effects/evaluation}

The price rises were successfully implemented despite widespread protests (IEA et al. 2010b). Several compensation packages were used to mitigate increased costs.

\subsubsection{VAT subsidies on energy in Poland}

Source: IEA et al. (2010b), IEEP et al. (2007).

\section{Background}

The VAT rate for energy products $(7 \%)$ was less than one third of the basic national VAT rate (22\%) in Poland in the early 1990s. Freund and Wallich (1997) found that poor households in Poland benefited much less from energy subsidies than the richer ones. The main reason for the reform was budgetary, reinforced by external institutions such as the IMF and the World Bank. Both energy producers and consumers protested, as net sales prices decreased and consumer prices increased. 


\section{Policy change}

The reform proposed to gradually increase the VAT for energy products to bring it into line with the basic rate of VAT. This was planned to be carried out over three years from an initial base of $7 \%$ in 1995, to $12 \%$ in $1996,17 \%$ in 1997 , and finally up to $22 \%$ in 1998.

\section{Compensation}

Protests and strikes against higher energy prices and consumer price increases in general were widespread in Poland during the 1990s. Trade unions did not object to the raises in VAT, but sought compensation for energy price increases. The Polish government assured unions that excessive price hikes would not be allowed, and compensatory measures were taken for poor families and pensioners, including direct allowances and cheap credit to modernize heating sources. The amounts budgeted for direct compensation payments were generally modest and pertained only to $1 \%$ of all households.

\section{Effects}

The VAT increase from 1995 to 1998 was successful and took place as scheduled. However, a previous proposal that would have seen VAT on electricity increase to $22 \%$ in 1995 was dropped at the end of 1994 as part of a package of measures to curb inflation.

\section{Evaluation}

This case study shows that increasing VAT rates for energy products to basic VAT rates can be achieved relatively expediently with a limited need for compensatory payments, even in a country where, at the time, household income was much lower than in most EU Member States (IEA et al. 2010b). IEEP et al. (2007) conclude that the original rationale for the subsidy to help poor households was found not to be fully valid. Hence, change can be achieved in spite of a lack of public support if the need is strong enough. A favourable circumstance creating the policy space for the reform was that inflation in Poland was falling continuously from 586\% in 1990 to $7 \%$ in 1999, while real disposable household income was increasing rapidly. As a result, the share of expenditure on energy in household consumption was more or less unaltered over the 1990s despite the real energy price increases. IEA et al. (2010b) point to the fact that market fluctuations and the relaxation of price controls were more important determinants of consumer prices for energy than an increasing VAT rate in Poland during the 1990s. This is a key lesson for a number of other EC Member States which still have reduced VAT rates for energy products. 


\subsubsection{VAT subsidies on energy in UK}

Source: Valsecci et al. (2009).

The UK applies a reduced VAT rate on energy products (electricity, natural gas, heating oil and coal), thus providing a subsidy to the final consumers of these products and promoting greenhouse gas emissions, acidification and depletion of non-renewable energy resources. The subsidy value was $10 \%$ of product price in 2009 . The winners are the households and other eligible entities with the highest energy consumption.

\section{Policy change}

Attempt at reform in 1995 failed for political reasons. Sense of urgency seems to be lacking, as there are no signs of recent calls for reform.

\section{Future}

In contrast to the Polish VAT reform, the UK represents a less successful attempt. The original rationale to the subsidy, to support to low-income households, is no longer valid (Valsecci et al. 2009), but the political will to reform seems to be lacking. The share of energy costs in budget of households has decreased considerably, and other, less distortionary ways of providing support to the targeted households are available. The OECD Environment \& Taxation committee calls for reform, but there is no sense of urgency, as there seems to be no other signs of calls for reform.

\subsubsection{Natural gas subsidies in the United States}

Source: IEA et al. (2010b).

\section{Background}

Prices of natural gas transported across state lines were regulated in the United States from the mid-1950s through to 1978, resulting in a consumer subsidy for natural gas through price regulation. Prices were set to allow companies to charge prices high enough to cover the actual costs of producing natural gas, plus a "fair" profit. Regulating prices charged by the large number of different natural gas producers created extreme administrative burdens. Prices were kept artificially low in 20 years, fuelling a large increase in consumption. Producers had little incentive to explore for and develop new natural gas supplies at the regulated price. After the oil price shocks of the mid-1970s, natural gas became scarce, and electricity prices doubled or even trebled. In winters of 1976 and 1977, shortages of natural gas forced the closing of many schools and factories in the U.S. Midwest. In 1978, the government decided to end the subsidy through the de-regulation of federal government price controls on natural gas sold in interstate markets. 


\section{Reform}

The U.S. Congress started deregulation in 1978. In 1993, all remaining regulations applying to the well-head price of natural gas were eliminated, allowing the market to completely determine the price of natural gas at the wellhead.

\section{Effects}

The price deregulation spurred production, and encouraged a more rational use of natural gas. Whereas in the 1960s large industrial and power-plant facilities using natural gas burned it in rather simple steam generators, higher prices (combined with developments in technology) spurred the replacement of these inefficient technologies with combined-heat and power and combined-cycle gas turbines.

\section{Evaluation}

The effects of price regulation were foreseen by economists before the shortfalls in deliveries started to become acute, but it took a crisis to spur action. The process of deregulation took many years. Consumers accepted the inevitability of higher gas prices after petroleum prices had also risen dramatically in the mid-1970s. But once it was completed, new domestic supplies became available, in response to higher prices.

\subsubsection{Natural gas and electricity taxes in the Netherlands}

Source: OECD (2006b).

In 1996 the Netherlands introduced a regulatory energy tax on the use of natural gas and electricity. In later years, the rates were raised several times. As rates went up, the personal income tax was stepwise reduced, explicitly to redress in part the distributional impact of the energy tax. Gross wage levels rose continuously and benefit payments were regularly increased. As a consequence, although the isolated impact of the tax was slightly negative, the large majority of Dutch households saw an overall increase of net disposable income between 1995 and 2002.

\subsubsection{Heavy good vehicle subsidies in Europe}

Source: IEEP et al. (2007).

\section{Background}

There are considerable distributional issues related to transport taxes. In particular, it appears that there is a quite big discrepancy between levels of consumption and taxes paid by the business community and household. In the EU-15, households account for just over 50\% of energy taxes paid but their final energy consumption account for just above $26 \%$ of total energy consumption (IEEP et al. 2007). Heavy goods vehicles put significant stress on road infrastructure, increasing infrastruc- 
ture costs. To recover these costs, some countries have implemented charges to capture some of these costs, thereby reducing implicit subsidies to shipping by road. In Germany, the system collects net charges of $€ 2.5$ billion. In addition, the haulage load per vehicle has increased, the number of empty trips has decreased (by 6\%) and 6\% of road freight has shifted to rail. These changes have decreases associated emissions of carbon dioxide and other pollutants in Germany (CIT 2006).

\section{Reform}

Over the years 2001-2005, Austria, Germany and Switzerland implemented distance-based heavy goods vehicles charges to recover infrastructure costs.

\section{Results}

The main benefits have been economic, shifting infrastructure funding to more of a "user pays" model based on distance travelled and type of vehicle. In Switzerland, the policy has noticeably slowed growth in road freight, but has caused little modal shift. However, because the Swiss policy is based on vehicle weight and emissions, there has been a shift to lower emission vehicles (CIT, 2006).

\section{Evaluation}

IEEP et al. (2010) concluded that a strong external pressure on environment and economy (in this case, transit traffic) was a key driver of the countries leading on road pricing. IEEP et al. point to the need for strong leadership, cross-party consensus and broad public acceptance to overcome opposition. Also, a strong evidence base was a key requirement of public acceptance and clarity of aims and transparency in implementation are also important. According to IEEP et al., although not the most economically efficient solution, earmarking of revenues have improved public acceptance and less-than-ideal interim measures may be used.

\subsubsection{Diesel subsidies}

Source: Valsecci et al. (2009).

\section{Background}

Many EU Member States tax diesel fuel at lower rates than petrol, providing a subsidy for users of diesel fuel (households and firms). Diesel gives rise to $\mathrm{CO}_{2}, \mathrm{CO}$ and $\mathrm{NO}_{\mathrm{x}}$ emissions that cause climate change; it requires larger amount of oil for production and emits fine particles. Valsecci et al. (2009) examine non-commercial diesel subsidies in the UK (no subsidy; no difference between diesel and petrol excise duty), Austria (EU average subsidy; diesel is taxed $21 \%$ less than petrol, amounting to €128 million), and the Netherlands (EU high subsidy; diesel is taxed 
$40 \%$ less than petrol, amounting to $€ 570$ million). For commercial diesel, prices are lower in all three countries.

\section{Policy change}

UK has equalised its excise duty rates of non-commercial fuels. No evidence has been found of Austrian reform efforts. The Netherlands increased excise duty on diesel by 3 cents a litre in 2008 and an additional 1 cent per litre in 2009 , leaving petrol rates unchanged.

\section{Future}

Benefits of the subsidy accrue to owners of private diesel-fuelled vehicles, which tend to be wealthier than owners of petrol vehicles. The diesel subsidy disadvantages firms producing petrol and households owning petrol vehicles.

\subsubsection{Commuter subsidies in Europe}

Source: IEEP et al. (2007).

\section{Background}

Commuters' subsidies are often given in the form of deductions for travelling expenses from their income taxes and are in place in many countries. E.g. $€ 4,865$ billion were used in annual commuter-tax deductions in Germany, Austria, and Sweden (IEEP et al. 2007). Other countries that have this subsidy are Belgium, Denmark, Finland, Ireland, and the Netherlands.

In Germany, the original rationale for the subsidy was to increase access to job markets for people living in rural areas. The tax commuter subsidies were increased in order to offset the impacts of Eco-tax reform (see chapter 10.2.6).

In the Netherlands, all employees living more than $10 \mathrm{~km}$ from their work could deduct an amount of travel costs from their taxable income. This amount was related to the distance from home to work and it clearly was a subsidy on commuter traffic, including by car.

\section{Reform}

In Germany, the income tax deduction for automobiles was reformed to be independent of transport mode in 2000, also benefitting public transport users. At the same time, the per-kilometre rate was increased. In 2006, the subsidy was reduced further. After 2007, the subsidy was limited to travel exceeding 20 kilometres to work. In the Netherlands, the travel cost deduction since 2001 has been restricted to commuters travelling by public transport. 


\section{Results}

The 2004 German reform reduced the subsidy by $30 \%$ to $€ 4$ billion. The 2006 reform achieved further reductions. Since 2000, the subsidy has been cut almost in half from historical levels.

\section{Evaluation}

The reformers praised the German 2006 reduction in subsidies, but criticised the fact that by allowing the subsidy only for trips over $21 \mathrm{~km}$ per day, the end result was a subsidy even more heavily tilted to those living far away from their places of work (IEEP et al. 2007). Reform is made difficult by the trade-off between environmental and social considerations, with only the pressing need to close large budget deficits providing sufficient political will to reduce the subsidy. Main opponents were commuters who benefited from the tax deductions. As pointed out by IEEP et al. (2007), a gradual approach to reform can be effective and more easily accepted, and budgetary difficulties can be a motivating force for tax or subsidy reform.

\subsubsection{Company car subsidies in the UK}

Source: IEEP et al. (2007).

The system had three tax bands based on annual mileage, and a declining percentage tax rate applied to the band of drivers who drove the most. Tax breaks were available at the 2,500 and 18,000 annual mile thresholds, giving a strong incentive to drivers who were approaching these mileages to cover the additional miles to secure the tax benefits. In addition, once the vehicle was over four years old, the tax liability was reduced by $25 \%$. In 2005 in the UK there were 1.4 mill company cars, which represent $5 \%$ of the total numbers of registered cars. NGOs campaigned against the subsidy for many years, but were resisted by those benefiting from the system.

\section{Reform}

In 2002 , the system was fundamentally changed to be based on a combination of list price and $\mathrm{CO}_{2}$ emissions.

\section{Compensation}

The reform was intended to be revenue neutral.

\section{Effects}

The number of company cars in UK fell by 250,000 . The mileage-based approach has been eliminated. Average $\mathrm{CO}_{2}$ emissions from company cars were lower than for private cars in 2007. 


\section{Evaluation}

According to IEEP et al. (2007), it took a long time to achieve consensus, and a strong evidence base was necessary to convince doubters that change was needed. NGOs campaigned on this for many years, but only when several government departments and progressive companies had been persuaded was it possible to make real progress.

\subsubsection{Company car subsidies in other EU countries}

Source: Valsecci et al. (2009).

\section{Background}

Company cars are particularly important drivers of the whole fleet. The preferential fiscal treatment is common. The provision of company cars has in the EU become by far the most important category of fringe benefits (Valsecci et al. 2009). The subsidy reform in the UK, see chapter 10.2.20, is a good example of a successful reform. In another case, the Netherlands, there have been no attempts to remove the subsidy in the sense of increasing taxable income from company car possession to the "optimal" level. Rather, the company car taxation system encourages car use, as the marginal cost to the employee of driving a company car becomes often close to zero. The winners are employees with a company car (mainly male employees in the medium to high income brackets). Losers are the taxpayers in general.

\section{Future}

According to Valsecci et al. (2009), no reforms are conducted in the sense of increasing taxable income from company car possession to the "optimal" level. Only minor environmentally motivated differentiation reforms are done. Key challenges are strong vested interests and lobbies and the lack of awareness of implied welfare loss.

\subsubsection{Aviation subsidies in the $\mathrm{EU}$}

Source: IEEP et al. (2007).

\section{Background}

Since the 1940s, the aviation industry worldwide has enjoyed several benefits. Financial support to the aviation industry includes fuel tax exemption, VAT exemption on international tickets, and duty free sales on non-EU flights and on board. The main arguments for reform are to remove relative market distortions to other means of transport and to internalise external costs of aviation and to help meet $\mathrm{CO}_{2}$ reduction targets (IEEP et al. 2007). International aviation is not included in the Kyoto protocol in terms of emission reduction, but will be from the start of 2012. The intention is for the EU ETS to serve as a model for other countries considering similar national or regional schemes, and to link 
these to the EU scheme over time, and to form the basis for wider, global action.

\section{Reform}

From the start of 2012, emissions from all domestic and international flights on EU airports will be covered by the EU Emissions Trading System. ${ }^{11}$ Airlines will receive tradable allowances covering a certain level of $\mathrm{CO}_{2}$ emissions from their flights per year. After each year operators must surrender a number of allowances equal to their actual emissions in that year. Norway and Iceland have also decided to include emissions from air transport in the system. The Netherlands has been the first EU country to introduce a kerosene tax on domestic flights.

\section{Effects}

The introduction of the Dutch fuel tax allowed the reduction of the budget deficit, generating an estimated $€ 14$ million additional revenue.

\section{Evaluation}

From earlier attempts of removing the implicit subsidy to the aviation industry, IEEP et al. (2007) conclude that unilateral actions are unlikely to be successful. Consensus at the EU-wide level was necessary to ensure coordination and harmonisation of national strategies. As aviation is an international industry, competitiveness concerns are particularly acute. Despite EU wide harmonisation, it will still be necessary to ensure that other national carriers outside Europe do not enjoy unfair advantage: reaching an agreement at the global level will thus be necessary in the long term.

\subsubsection{Water subsidies in Czech Republic}

Source: IEEP et al. (2007).

\section{Background}

The pricing of water historically covered only a fraction of its cost. A low price for water, well below full cost recovery, was an actual subsidisation of water extraction, treatment and distribution and led to overexploitation of water resources.

\section{Reform}

After 1990, water pricing in the Czech Republic moved from covering only a fraction of the cost to full cost recovery. This hidden subsidy has been gradually removed, and in 2004 the cost of $1 \mathrm{~m}^{3}$ of water was 35 times higher than in 1990. In the Czech Republic, all houses have been provided with metering to measure drinking water consumption. The

11 http://ec.europa.eu/clima/policies/transport/aviation/index_en.htm 
reform also addressed the fees for withdrawal of both surface and ground water, and also the discharge of waste water.

\section{Effects}

The volume of water consumed in households decreased by about $40 \%$, from 1989 to 2002. In 2003, it was about 10\% below the EU average. Between 1990 and 1999 water withdrawals decreased by $88 \%$ in agriculture, by $47 \%$ in industry and by $34 \%$ in public water mains.

\section{Evaluation}

IEEP et al. (2007) conclude that this is a positive example of reform, with improved resource management. Affordability issues are in principle important where domestic consumers are concerned - however they were not directly addressed in this case. Gradual increase in cost, in step with increasing incomes, nonetheless helped to limit the impact. During the early 1990s, the former Czechoslovakia witnessed a major political change. The institution of the independent Czech Republic subsidies for operation costs decreased, lead to a gradual recognition of environmental values. The reform was hence part of the restructuring and shift to a market economy. Also, a gradual rise of water charges may have made the introduction of higher prices less problematic. The reform seems to have lacked social consideration, as lower charges were not designed for low income households.

\subsubsection{Water subsidies in Australia}

Source: Ekins and Salmons (2009).

\section{Background}

Prior to the 1980s, the emphasis of water policy was on engineering solutions and on increasing water supply to address shortages. The development of irrigation was linked to policies explicitly intended to promote rural settlement. Water was often over-allocated and was typically supplied below cost, providing little incentive for conservation. Furthermore, cross-subsidisation between sectors resulted in an inefficient allocation between competing uses. During the 1980s, increasing scarcity, rising supply costs and pressure on state budgets led to a number of state-level initiatives to improve the management of municipal water utilities and irrigation networks, including the first experiments with pricing reform and tradable water entitlements. While environmental and resource management considerations played their part, the main driver for reform in the water sector was a wider drive to improve the economic efficiency of infrastructure sectors and utilities, in order to improve competitiveness. This drive was underpinned by a belief in the benefits of introducing rational pricing for scarce resources and the development of competitive markets in these sectors. 


\section{Reform}

Among the objectives of the water reform in 1994 were to ensure that water prices reflected the full cost of resources and to eliminate crosssubsidies and make other subsidies transparent and increase efficiency. Most urban water authorities introduced consumption-based charges for households and firms. Cross-subsidies from industrial and commercial users to households were reduced or eliminated.

\section{Results}

This led to a decline in both individual water consumption and the unit supply cost of water in urban areas. However, progress was slow and uneven, both across water-use categories and between states, and new water reform initiative was launched in 2004.

\section{Evaluation}

Ekins and Salmons (2009) suggest several explanations to the slow progress. One is that the reform was very general, with no real consideration of detailed implementation issues. Further, the benefits - reduced environmental damage and improved economic efficiency of water allocation - were diffuse and poorly understood by the public, as were the costs of inaction. Rather, most individual consumers were worse off under the reform than they had been previously, in so far as they faced higher water prices. There was also lack of consensus on some of the basic scientific questions. Practical difficulties in measuring water use and in assessing the impact of water diversion on other users made implementation of reform principles exceptionally complex. Also, water entitlements were perceived as acquired rights, often under policies explicitly designed to encourage rural settlement and irrigation development. Consequently, there was considerable resistance to any reductions in volumetric entitlements. The reform did not address the potential social impacts of the reforms or the need for any transitional support.

\subsubsection{Water subsidies in Spain}

Source: Valsecci et al. (2009).

In Spain, water pricing is usually based on area size rather than on the actual volume of water used, and therefore does not provide incentives to farmers to improve water use efficiency, and has historically lead to a relatively high level of consumption. Traditionally irrigation has been used to increase productivity and enable people to settle in rural areas, and as an instrument for combating desertification. Valsecci et al. do not consider the rationale still valid, as low charges eventually translate into poorly maintained water infrastructures, which in turn reduce irrigators' competitiveness and capacity to pay, and influences the selection of crops leading to unsustainable patterns and low-value subsidised cultures. Furthermore, from a social perspective, subsidies benefit all farm- 
ers. Losers are reduced water availability to the society at large and farmers facing worsened environmental conditions, increased pollution and reduced water availability. The introduction of a price signal to make farmers aware of the scarcity of water resources has been recommended, and to induce them to adopt water-saving technologies without affecting crop distribution.

\section{Policy change}

Some successful attempts to remove subsidies have been made. In one region, a new water charging structure included both a fixed and variable charge linked to water use, with farmers paying significantly more than under the original area-based approach.

\section{Effects}

These changes resulted in a 30\% reduction in water consumption.

\section{Evaluation}

The reforms carried through had significant impact, but several regions still subsidize water consumption. Subsidy removal may significantly reduce farmers' income. Also, the issue of elasticity however has been stressed - i.e. under certain conditions price increases can have little effect on water consumption, and the impact on farmers' income can be significant. Valsecci et al. suggest compensation measures to low income farmers.

\subsubsection{Agricultural subsidies in New Zealand}

Source: Ekins and Salmons (2010).

\section{Background}

Over the 1960s and 1970s, there had been a gradual acceleration in grants and subsidies to the agricultural sector in New Zealand, including a range of production-related measures, fertilizer subsidies, loans to farmers at below-market rates, generous tax rebates and lucrative incentives for land development. Around 30 different forms of assistance were given to farmers. These subsidies caused severe distortions in the sector, with significant excess supply, inflated agricultural land prices and distorted production decisions (Ekins and Salmons 2010). In the early 1980s, New Zealand was suffering severe economic problems and substantive economic reforms were needed to increase growth. The agriculture sector was a primary target.

\section{Reform}

Starting in 1984, Government assistance to the agricultural sector was virtually eliminated over a short time period. Minimum price schemes for wool, beef, lamb and dairy products were abolished, tax concessions and free government services were withdrawn; land development loans, ferti- 
lizer and irrigation subsidies, subsidized credit, assistance for flood control, soil conservation and drainage schemes were phased out from 1987.

\section{Results}

The Effective Rate of Assistance (ERA) fell from 123\% in 1983 to around zero by the 1990s. The economic indicators for the agriculture sector have improved across the board since the subsidies were eliminated. The removal of fertilizer subsidies led to a reduction in phosphate leaching from hill country pasture catchments; the reduction in the national sheep flock yielded benefits for erosion control, water quality and methane emissions; the removal of land development subsidies led to a substantial decline in the felling of native forest. While these benefits were partly offset by the impacts of increases in other agricultural activities (e.g. dairy and deer sectors), the overall environmental impact was positive. The removal of subsidies was initially unpopular and culminated in the largest rural sector protest march in New Zealand's history in 1986. Rural incomes declined during the 1980s, many small rural firms went out of business. Still only around 1\% of farmers left the industry, while the overall rural population rose slightly between 1981 and 2001.

\section{Compensation}

Despite these social impacts, little use was made of transitional assistance measures. This was partly due to the speed of the reforms, and partly due to the state of the government finances. Some assistance was provided in the form of debt rescheduling in 1986-87 and with farm debt restructuring, while the government wrote off some farm debt and encouraged private lenders to do the same. Expert help was provided to help farmers with the development of business plans and credit mediation.

\section{Evaluation}

There was a general consensus among the main political parties over the need for reform - both in agriculture and the wider economy. The process was extended in 1990. The left-wing government did not have a significant constituency in rural communities and hence did not stand to lose much support. The reform was implemented to an agreed and transparent timetable - with farmers being given clear signals about the depth, breadth and pace of the reform. The reform of agricultural subsidies was part of a wider economic reform programme that included measures which reduced factor input prices. Thus, while the main farmers' organization was unhappy about the removal of subsidies, it strongly supported the wider reform process, which it considered would ease the pressure on farmers by lowering production costs. 


\subsubsection{Fishery subsidies in EU}

Source: Ekins and Salmons (2010).

EU fisheries subsidies were first introduced in 1970 with the objective of supporting and encouraging increased fish production. In particular, the subsidies were aimed at promoting capital investment in larger and more efficient fleets, and at adapting production and marketing conditions. As a result, there was a threefold increase in the engine power of the fishing fleets over the next seventeen years and the fishing industry became increasingly capital-intensive and technologically productive. The increased capacity of fishing fleets was a major factor in the depletion of fish stocks over the following decades. According to The Commission of the European communities (2009), 88\% of fish populations could increase and generate more economic output if they were left for only a few years under less fishing pressure. 30\% of these stocks may not be able to replenish. $93 \%$ of the cod in the North Sea are fished before they can breed. Most of Europe's fishing fleets are either running losses or returning low profits. Overall poor performance is due to chronic overcapacity of which overfishing is both a cause and a consequence.

In recognition of the role of subsidies in the build-up of overcapacity, and hence over-fishing, there has been a shift in focus towards balancing fleet sizes to available fish stocks.

\section{Reform}

The reforms did not reduce the magnitude of the support. The subsidies for the period 2000-2006 were double the contribution for the previous period. Rather, the subsidies shifted to provisions for environmental projects including provisions for the adjustment of fishing effort, reducing the excess capacity of the fishing fleet, development of marine protected areas, phasing-out of subsidies for vessel rebuilds, making available of extra funds for vessel scrapping. The reforms have aimed to balance between resources and fishing fleet capacity, strengthen the competitiveness of the sector, foster protection of the environment and natural resources and encourage the sustainable development in areas with activities in the fisheries sector.

\section{Compensation}

Early retirement schemes and individual compensatory payments for fishers made redundant as a result of vessel decommissioning.

\section{Results}

There has been a shift in focus towards balancing fleet sizes to available fish stocks. In particular, the most direct forms of capacity-enhancing subsidies have been phased out, with assistance being re-directed to provisions for vessel decommissioning, transitional support measures and environmental projects. 


\section{Evaluation}

The involvement of the environmental NGOs in the development of fisheries policy has played an important role in raising the public profile of fisheries subsidy issues and hence increasing the political pressure for reform. However, there were also a number of factors that have held back the reform process. The subsidy regime has been in place for over 35 years and has become an entrenched part of the fisheries management regime. When the financial periods have ended, there has been a presumption that subsidies would be renewed rather than removed, with no active reconsideration being given to the rationale for subsidies. New member states joining the EU in 2004 were poorer than the existing EU15 and had high expectations of support for their fishery sectors. Economic pressures resulting from rising oil prices and falling revenues as a result of the decline in fish stocks resulted in heavy lobbying by the fishing industry to maintain subsidies. This was successful in generating political desire to assist the industry and has impeded subsidy reform.

\subsubsection{Fishery subsidies in Norway}

Source: Hannesson (2006).

\section{Background}

The first years after the Second World War the fisheries in Norway were quite profitable. After some years, they started to lag behind other sectors, and subsidies were given to support incomes in the industry, see figure 11.1. This support was meant as extraordinary emergency. Instead, the subsidies continued to increase to a peak in 1981, amounting to about $70 \%$ of value added in the industry. According to Hannesson (2006), this was driven by the strong standing of the fishermen organization and the idea that fisheries were important to keep the fishing communities viable. In addition, the resource wealth in the form of offshore oil and gas deposits discovered in the late 1960s justified the support. Hence, the budget constraint was not pressing. Subsidies were given as price subsidies, to scrapping and selling of boats, to investment in boats and to interest payments. The effects on the fish stock are difficult to isolate, since stocks are subject to environmentally-driven fluctuations and exploitation by other countries. According to Hannesson, there are indications that the subsidies encouraged decline in the fish stock.

\section{Reform}

After the peak in 1981, the subsidies gradually came down.

\section{Results}

The removal of subsidies encouraged structural changes that have made a fundament for a self-sufficient industry. 


\section{Evaluation}

Hannesson concludes that the subsidy reform is easier when there is a perception of crisis, and if the pain is alleviated. The removal of fishery subsidies was helped by the sharp decline in oil prices in 1986 and the upturn in both catch and fishery prices in the years after 1990 .

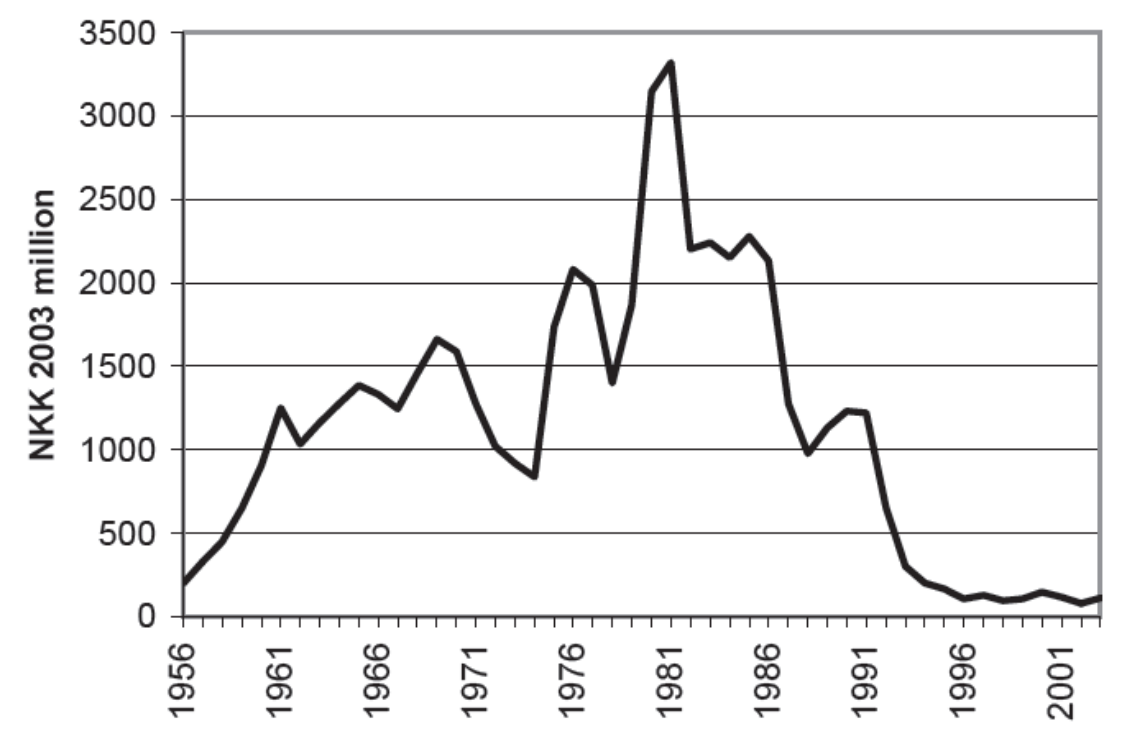

Figure 10.8. Government subsidies to Norwegian fisheries according to general agreement.

Source: Hannesson (2006). 


\subsection{Appendix 3 \\ - Planned reforms}

The potentials for future reforms are under investigation of several of the mentioned initiatives in chapter 1. IEA (2010) presents an updated overview over some announced reforms under planning, see table 12.1.

Table 12.1. Plans to reform energy subsidies in selected countries.

\begin{tabular}{|c|c|}
\hline China & $\begin{array}{l}\text { Oil product prices were indexed to a weighted basket of international crude prices } \\
\text { in } 2008 \text {. Natural gas prices rose by } 25 \% \text { in May } 2010 \text {. Plans exist to remove } \\
\text { preferential power tariffs for energyintensive industries and to extend tiered } \\
\text { pricing for households. }\end{array}$ \\
\hline Egypt & Plans to eliminate energy subsidies to all industries by the end of 2011. \\
\hline India & $\begin{array}{l}\text { Abolished gasoline price regulation in June } 2010 \text { and plans to do the same for } \\
\text { diesel. The price of natural gas paid to producers under the regulated price } \\
\text { regime was increased by } 230 \% \text { in May } 2010 \text {. }\end{array}$ \\
\hline Indonesia & $\begin{array}{l}\text { Set goal to reduce spending on energy subsidies } 40 \% \text { by } 2013 \text { and fully eliminate } \\
\text { fuel subsidies by } 2014 \text {. }\end{array}$ \\
\hline Iran & $\begin{array}{l}\text { Plans to replace subsidised energy pricing with targeted assistance to low-income } \\
\text { groups over the period } 2010-2015 \text {. Reforms call for the prices of oil products, } \\
\text { natural gas and electricity to rise to market-based levels. }\end{array}$ \\
\hline Malaysia & $\begin{array}{l}\text { Announced reductions in subsidies for petrol, diesel and LPG as the first step in a } \\
\text { gradual subsidyreform programme. }\end{array}$ \\
\hline Mexico & Intends to phase out subsidies to gasoline and diesel by the end of 2010 . \\
\hline Russia & $\begin{array}{l}\text { Natural gas prices for industrial users are to continue increasing toward interna- } \\
\text { tional levels through } 2014 \text { based on the balancing of revenues from domestic and } \\
\text { export sales. Pricing in the wholesale electricity market is scheduled to be fully } \\
\text { liberalised in } 2011 .\end{array}$ \\
\hline Saudi Arabia & $\begin{array}{l}\text { The Electricity and Co-Generation Regulatory Authority (ECRA) plans minor } \\
\text { electricity tariff increases for industrial and commercial users. }\end{array}$ \\
\hline South Africa & $\begin{array}{l}\text { Plans to increase electricity tariffs by approximately } 25 \% \text { per year over } 2010- \\
2013 .\end{array}$ \\
\hline
\end{tabular}

Source: IEA (2010). 
Ved Stranden 18

DK-1061 Copenhagen K

www.norden.org

\section{Reforming environmentally harmful subsidies}

How to counteract distributional impacts

The report discusses the theoretical principles for an efficient environmental and distribution policy and offers a comprehensive survey of experiences from policy reforms in different countries. The reform survey forms a background to recommendations for implementation of sustainable policy reforms, taking care of environmental, economic and distributional concerns. It particularly brings in the Nordic experiences, both to enlighten the problems with environmentally harmful subsidies in these countries, and to discuss what can be learned from the experiences in a broader international context.

The analysis has been carried out during the period October 2010 May 2011. The study was carried out by Vista Analyse AS and commissioned by the Nordic Council of Ministers for the Environment.

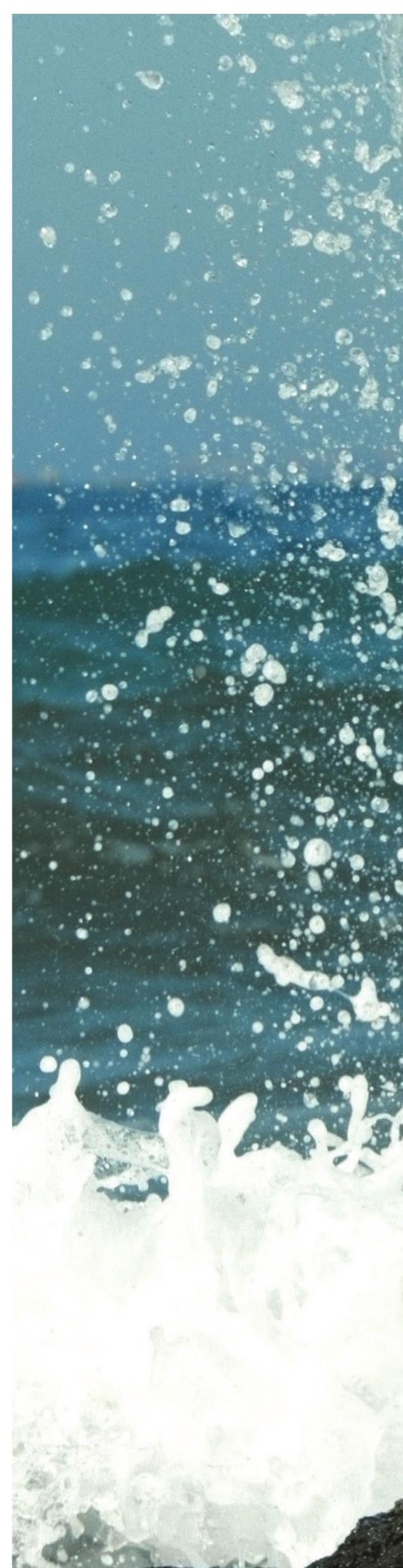

